UC-34c

Reporting Date: Dec. 1973 Issued: June 1974

\title{
EVXS: A Code to Generate Multigroup Cross Sections From the Los Alamos Master Data File
}

by

Margaret W. Asprey

Roger B. Lazarus

Robert E. Seamon 
This report was prepared as en sccount of work sponsored by the United States Government. Neither the United States nor the United States Atomic Energy Commission, nor eny of their employes, nor eny of their contrectors, subcontrectors, or their employes, makes eny werrenty, exprese or implied, or sesumes eny legal lisbility or responsibility for the sccurscy, completeness or usefulness of eny information, apperatus, product or procese dit. cloand, or represents that its use would not infeinge privately owned rights.

Printed in the United Slatem of America. Available Irom National Technical Inlormation Service

U.S. Depaxtmonl of Commerce S285 Port Royal Rood Springlield. Virginio 22151

Price: Printed. Copy S5.45 Microliche 51.45 
I. INTRODUCtION. . . . . . . . . . . . . . . . . . . . . 1

II. descalption of the los alahos master data file. . . . . . . . . .

A. LLbrary format. . . . . . . . . . . . . . . . . 3

1. General Remarks........................ 3

2. Croup Structures. . . . . . . . . . . . . . . . 4

3. Control and Crose-Section Records............. 5

4. ingular Diseribution Records. . . . . . . . . . . . 7

B. Heactions Avallable . . . . . . . . . . . . . . . . 7

c. Materials and Group struccures Avallable in the LAMP . . . . 10

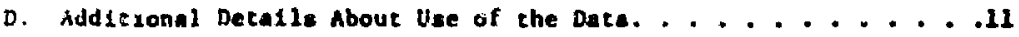

1. Log-Log Intetpolation Schemas . . . . . . . . . . . . . .1I

2. Secondary Energy Probab1l1ty D1atributions, . . . . . . . 12

3. Angular Olaterbution Reprenentactons. . . . . . . . . . .

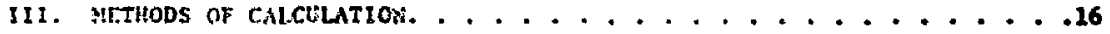

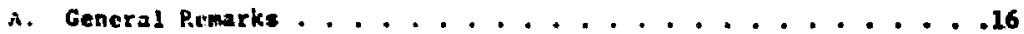

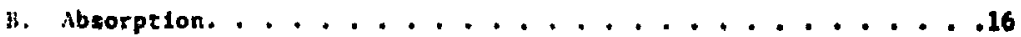

c. Scatcering Computed Using Angular Destrfbuctons.........17

1. Elabelc Scaccering. . . . . . . . . . . . . . . . . 21

?. Distege Intastic scatcering . . . . . . . . . . . . 22

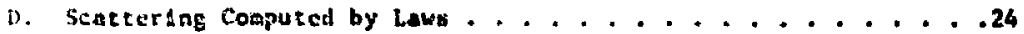

1. Nonclostic Scatering tiatrices. . . . . . . . . . . 24

2. Fistion theactions . . . . . . . . . . . . . . . . 27

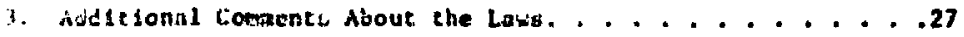

I'. Tramsport Appraxleactons and the Cross-Section Tables . . . . 31

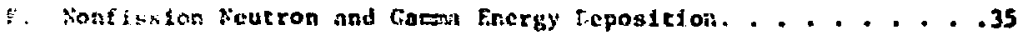

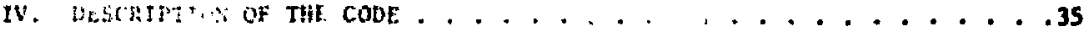

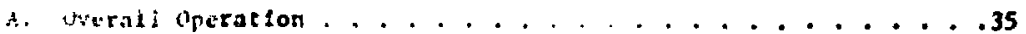

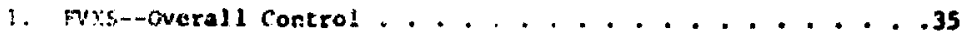

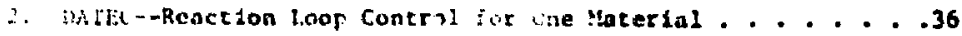

3. Cref-Compuzation Control fug ato Reaction. . . . . . . 37

4. Olhe: Raut Ines. . . . . . . . . . . . . . . 38

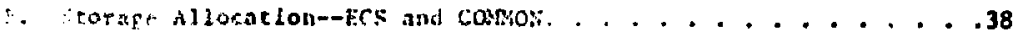

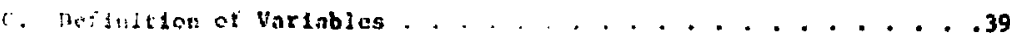

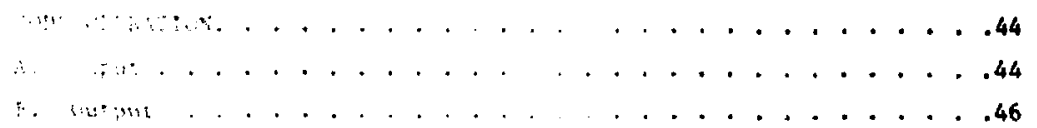

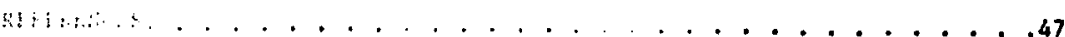

\section{HOTIC:}

thiv treath Mat pepoted th an sceount of wotk

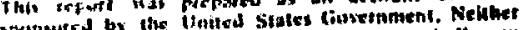

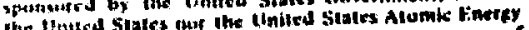

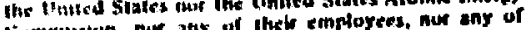

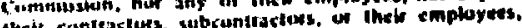

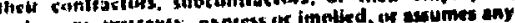

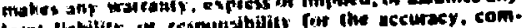

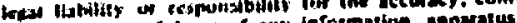

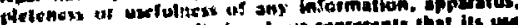

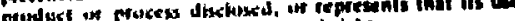

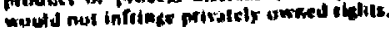




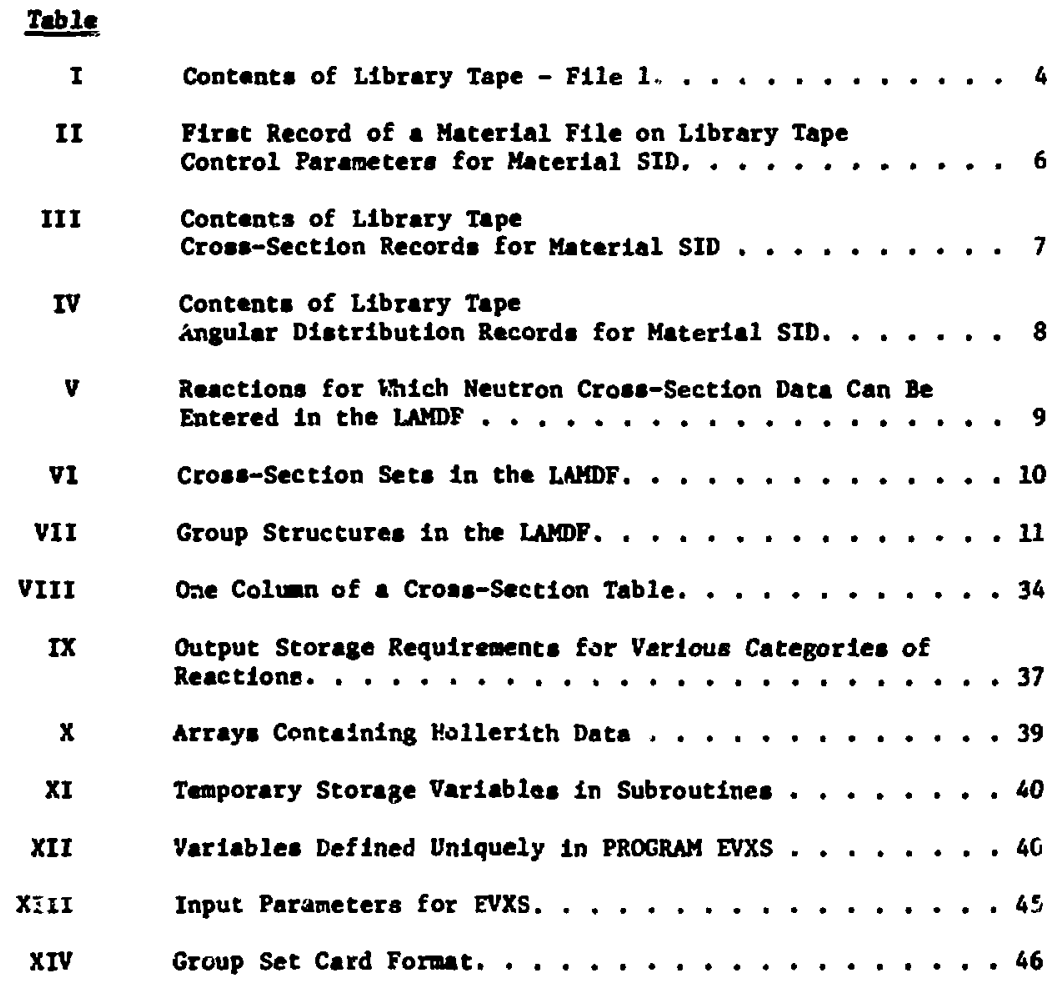

\section{FIGURES}

F1g. 1 Overall file structure of library tape .......... 3

F18. 2 Arrangement of the ESJ block ............ 13

F1g. 3 Arrangement: of principal subroutines......... 36

Fig. 4 Arrangement of dsta in extended core storage . . . . . 38

F1g. 5 Arrangement of data In large comon storage array MA . . 39 
EVXS: A CODE TO GENERATE MULTIGROUP CROSS SECTIONS

FROM THE LOS ALAMOS MASTER DATA FILE

by

Margaret W. Asprey, Roger B. Lazarus, and Robert E. Seamon

ABSTRACT

EVXS is a program for computing multigroup microscopic neutron cross sections from experimental data. It is a translation into FORTRAN-IV of a MADCAP code written by Roger Lazarus of LASL for the MANIAC computer. The sources of data contained in the library proceased by EvXS are varied, but the evaluations come primarily from AWRE, LLL, and LASL. The neutron cross sections, fluxes, and secondary energy and angular distributions are given in the library in tabular form with interpolation schemes such that the integrations over neutron energies may be performed exactly in arriving at the group-averaged cross sections. Higher order components of the mult1group cross-section matrices through $L=8$ have been generated using EvXs. The sode is written in standard ASA FORTRAN and is designed to be comititer independent. In addition to the printed resulta, the output can, at the user's option, Include punched cards or magnetic tape autable for Input to neutronics and burn codes.

\section{INTRODUCTJON}

For sone time the Los Alamos Scientific Laboratory (LASL) has mintalined a nuclear data library, referred to here as the Los Alamos Master Data File (LADF), coneleting of a collection of seta of evaluated dato prepared prianily at the Atoulc Weapone Regearch Establishent (AWRE), Lawrence Livernore Laboratory (LLL), and LASL. The enintenance of the LADF and the generation of multigroup crose sectione and tranafer atrices frow this library have been curried out at LASL uelng codes written by Roger Lazarus in the MADCAP language for the MANIC computer. To anke the LADF and the processing codse wore easily avallable to a wider group of ueers and to avold dependence on the MAIIC, the 11brary has been transferred to the CDC-6600 conputing machine, and the data handling and processins codes heve been rawritten into roxtruil-IV. Such codes aro used elther for the preparation and alinteanace of the pointules data on the librery or for the processing of the pointwiec date on the library into conplete cross-section sets sultable for Input to neutrontce or burn codes. The EVXS progran described In this report is of the letter type; it is a translation by Hargaret Asprey from MADCAP Into FORTRAN-IV of the original data processor for the LADP.

The balc function of any witigroup averaging code like EVXS is to calculate the everage crose section

$$
\sigma=\frac{\int d E \sigma(E) \omega(E)}{\int d E \omega(E)}
$$

Where Integration extende over the appropriate ener8y Intarva1. " The quantity $\sigma(F)$ is the erose anction beins averaged and $\omega(E)$ 10 aow appropriate weightIns function. In $\mathrm{Eq}$. (I) and throuthout this report ( "Wl1 energies throuthout are given and used in willon electron volts; crose sections are in barns. 
we follow the convention that a quantity with argument $E$ represents the magnitude of that quantity at a particular energy $E$, whereas the quantity without an argument denotes an averaged value. One unique feature of the LAMOF is the inclusion not only of the pointwlse neutron cross-section data, denoted generfcally as $\sigma(E)$ in Eq. (1), but also of the energ; group structure Information. The boundaries of the energy regions over which the averaging is to be performed are given and an appropriate neutron flux is tabulated at certain energy points within each of the energy groups. The filux distributions $\emptyset(\mathrm{E})$, which are normalized within each of the $G$ energy groups, are used as the weighting functions in Eq. (1). Ienoting one of the G energy groups by $g$ and the upper and lower energy boundaries of the gth group as $E_{g}^{+}$and $E_{g}^{-}$, the statement on normalization imlies that

$$
\int_{g} \operatorname{CE}(E)=1
$$

where $\int_{8} d F$ implies $\int_{E_{g}^{-}}^{E_{g}^{+}} d E$

Thus, Eq. (1) can be written

$$
\sigma_{8}=\int_{8} \mathrm{dE} \sigma(E) \sigma(E)
$$

Group-averaged cross aections must be calculated for each of the $R$ reactions for which pointwise cross sectiona are tabulated for a given material. Denoiting one of the $R$ reactions by $r$, we can write, starting from Eq. (3),

$$
\sigma_{r, 8}=\int_{8} d E \sigma_{r}(E) \phi(E)
$$

In the case of reactions for which angular probability diatributiona are tabulated, the nth Legendre component of the scattering crose section for the rth reaction is defined at

$$
\sigma_{r, n, 8}=\int_{g} d E \sigma_{r}(E) \emptyset(E) \int_{-1}^{+1} d \nu T(\mu, E) P_{n}\left(\mu_{L}\right)
$$

where $P_{n}$ is the Legendre polynomial of order $n, H_{L}$ Is the cosine of the scattering angle in the laboratory system, $T(\mu, E)$ is the normalized angular probability distribution, and $\mu$ is the scattering angle cosine in whichever system $T(\mu, E)$ is specified. If $\mu$ is in the center-of-mass system, then $\mu_{L}$ is computed as a function of $\mu$ as explained in Sec. III.

Contributions to the nth Legendre component of the multigroup transfer matrices from elastic, discrete inelastic, and nonelastic scattering are calculated from certain scattering integrals which define the number of neutrons in group $g$ that are downscattered in energy to group $g^{\prime}$. For elastic scattering ( $r=1$ in the LAMDF),

$\sigma_{1, \Omega, g, g^{-}}=\int_{g} \mathrm{~d} E \sigma_{1}(E) \emptyset(E) \int_{\Delta \mu\left(E, 8^{-}\right)} \operatorname{d\mu T}(\mu, E) P_{L}\left(\mu_{L}\right)$,

where $\Delta \mu\left(E, g^{\prime}\right)$ is the range of scattering cosine $\mu$ for which tine scattered neutron has energy $E^{-}$within the boundaries of energy group $g^{\prime}$. Note that

$$
\sigma_{1, n, 8}=\sum_{g^{-}=1}^{g} \sigma_{1, n, 8, g^{-}}
$$

For discrete inelastic scattering $\sigma_{r, n, 8, g}$ is calculated as shown in Eq. (6) except that $T(\mu, E)$ in the center-of-mass system is assumed to be 0.5 . For nonelasilc reactions, except fission, the contribution to the scattering matrix is defined as

$$
\begin{aligned}
\sigma_{r, n, 8,8^{-}} & =\int_{8} d E \sigma_{r}(E) \partial(E) N_{r, g^{-}}(E) \\
& \times \int_{-1}^{+1} d \mu_{L} T_{r}\left(\mu_{L}, E\right) P_{n}\left(\mu_{L}\right)
\end{aligned}
$$

It is explicitly indicated in Eq. (8) thet for nonelastic reuctione $T_{r}\left(H_{L}, E\right)$ is alwaye given in the

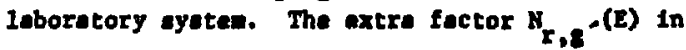


Eq. (8), compared with Eq. (5), is the fractional number of neutrons entering group $g^{-}$from reaction $r$ Induced by a neutron of energy $E$. The factor is obtained by incegrating the secondary encrgy probability distribution $P_{I}\left(E+E^{\prime}\right)$ over the $g^{\prime}=1$, ..., g energy groups; viz.,

$$
N_{r, 8^{-}}(E)=\int_{8^{-}} d E^{-} P_{r^{-}}\left(E \rightarrow E^{\prime}\right)
$$

There are several representations, or "laws," for the secondary energy probability distributions; the same parametrization of these laws is used in the LAMDF as is used in the UKAEA Nuclear Data Library. 1

For fission reactions, the fission spectrum $x$, the average number of neutrons per fission $\bar{v}$, and the total fission cross section are calculated. For example:

$$
\left(V \sigma_{f}\right)_{g}=\int_{g} d E \bar{v}(E) \sigma_{f}(E) \emptyset(E)
$$

where $\bar{v}(E)$ is the average ninber of neutrons per fission produced at energy $E$.

The formats and conventions used for deacribing the pointwise neutron cross-section data in the LAMDF are similar to those of the UKAEA Nuclear Data Library. ${ }^{1}$ There are, however, enough significant differences to warrant a complete description of the LALIDF in Sec. II. The types of neutron crosssection data stored and the way they are used in calculation ure also discussed in Sec. II, and detalls of the format for the library are presented there, along with 2 description of the materials in the library at this writing. The methods of calculation are described in detall in Sec. III, and in Sec. IV the EVXS PROGRAY is described. A user's mariual for EVXs is given in Sec. $v$.

\section{rI. DESCRIPTION OF THE LOS ALAMOS MASTER DATA FILE} A. Library Formet

1. General Renarke. The library tape that is used as Input to PROGRAM EVXS conteins energy group structure information and many sets of eveluated crose rections. The division of the binary 1itrary tape Into NS files* Is shown schematically in F1g. 1. The first file containe the energy. group structure informetion and the reanining NS-1 files; contain the neutron crcss-section data for NS-1 materials, one material per file. The firet record of File 1 has descriptive inforation to identify the edition of the LAMDF and the total number of files, NS, on the library tape. The remeining $N G$ records in File 1 contain the energy boundaries and neutron fluxes for each of the NG group struc-. tures. As indicated in Fig. 1, the general structure of all remaining files, one for each material, is the same. The first record contains the material Identification number and other control paraseters; the next $R$ records contaln cross sectlons for the $R$ reactions appropriace for this material, as well as information about the energy distribution of secondary neutrons; the final ND records contain the angular distribution information.

\begin{tabular}{|c|c|}
\hline IILE 1 \\
RECOND 1 \\
RECOND 2 \\
$\vdots$ \\
$\begin{array}{c}\text { RECOND NG + } \\
\text { RND-OF-FILE }\end{array}$
\end{tabular}

FIL:

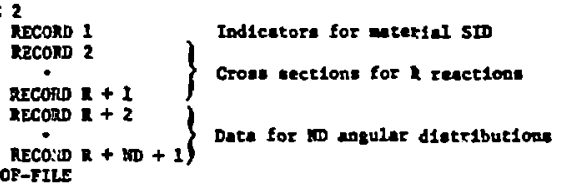
$\left\{\begin{array}{l}\text { Data for } \\ \text { firot } \\ \text { inteinel } \\ \text { 1uthe } \\ \text { Ifbrars }\end{array}\right.$

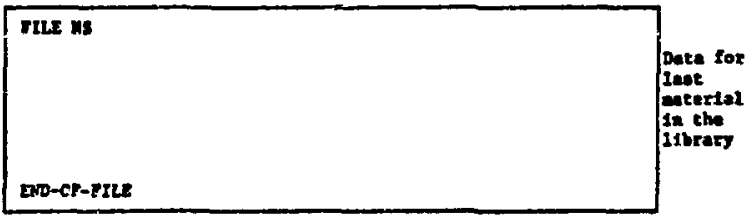

ETD-OF-TAPS

Fig. 1. Overall file structure of library tape.

\footnotetext{
Our use of the word file conforma with the genaral practice of the computer industry; the NS files on the library tape are well defined binary files separated by END-OF-FILE anke which can be detected using "IF (EOF)" teata. NS, NG, ND, KG, etc., are ingle integers in the FORTRA sense.
} 
2. Croup Structures. A detalled description of the first file of the binary Itbrary tape $1 \mathrm{~s}$ given in Table $I$. The Integer variables can take on values no larger than those Indicated in parentheses following the varlable name; the size of the descriptive arrays TAD and GDES as provided in PROGRAM EVXS is given in the parentheses following those varfable names. For each of the NG group structures in the library there is one long record containing a unique Identification number, alphanumeric descriptive Information, the group boundarles $E_{g}$, the flux distributions $\emptyset(E)$, and appropriate control information. There may be as many as 80 energy groups for which a total of up to 500 values of the flux distribution can be tabulated, allowing miny values within each group. The $2 \mathrm{KG}$ words at the end of the record contain $K G$ paits of values of the flux $\emptyset(E)$ and energy
E. These values are alternately read Into arrays $\mathrm{PH}_{k}$ and $\mathrm{EK}_{k}$ with subscript $k$ running from 1 to $\mathrm{KG}$. The first energy $\mathrm{EK}_{1}$ corresponds to the low energy boundary of the first group $g=1$; the highest energy $\mathrm{EK}_{\mathrm{XG}}$ corresponds to the upper boundary of the Gth energy group. The function $D(E)$ represented by the values of $\mathrm{PH}_{k}$ is assumed to vary smoothly enough to be regarded as continuous (see Sec. II.D.1) everywhere except at the group boundaries $\mathrm{E}_{\mathrm{g}^{*}}$ This discontinulty is a result of the required within-group normalization, namely:

$$
\int_{E_{g}^{-}}^{E_{g}^{+}} d E \phi(E)=1
$$

TABLE I

CONTENTS OF LIBRARY TAPE - FILE 1

\section{Variable Name}

\section{Record 1:}

TAD (100)

NS $(\leqslant 500)$

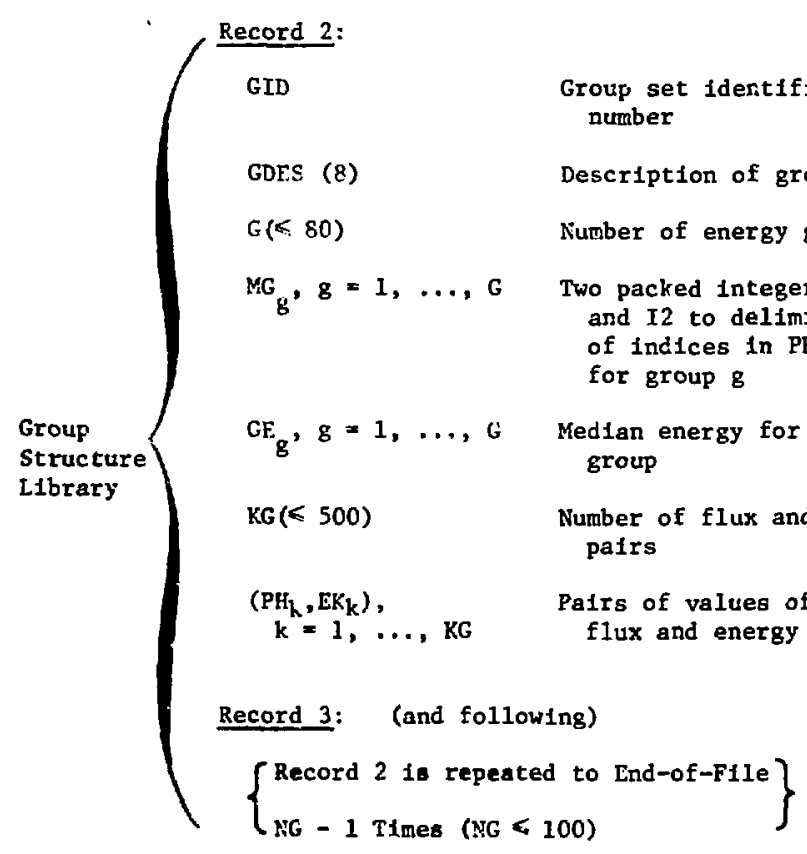

\section{Description
Tape description}

Total number of files number roup set roups

II range and $E K$ ach ergents

(a)

\section{Format \\ Display (A10) \\ Integer}

Integer

Display (A10)

Integer

Detal

(n)

Floating

Integer

Floating
Positive

Comments

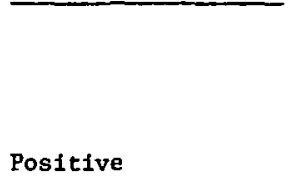

Positive

Positive

$I 1=\operatorname{MG}(\mathrm{g}) / 2^{24}$

$I 2=M G(g)-I 1 * 2^{24}$

Positive

Energy in $\mathrm{MeV}$ 
where the lower and upper energy bounds of the gth group are designated $\mathrm{E}_{\mathrm{g}}^{-}$and $\mathrm{E}_{\mathrm{g}}^{+}$, respectively. Thu for every value of $g$ except $g * G$, there wfll be some value of $k$ such that $E K_{k}=E K_{k+1}=E_{g}^{\dagger}$ wintch also equals the lower bound $\vec{E}_{g+1}^{-}$for the next higher energy group. The array MG contains for each of the $G$ groups two values of $k$, packed into one word, which indicate the lower and upper energy bounds of each group in the EK table. Each 60-bit word in MG is divided into two parts--the first 36 bits for an integer $I 1$ ard the remaining 24 for integer $I 2$. The range of values for $k$ corresponding to one energy group is then delimited by $I 1$ and $I 2$. From the discussion of the discontinuities in the tabulation of $D(E)$, It can be seen that I1 for group $g+1$ is one more than $I 2$ for group 8 . The $G E$ array consists of weighted mean energles for each of the $G$ groups in the group structure; these are used only in spectal calculations described in Sec. III.F.

\section{Control and Cross-Section Records. As} shown in Fig. 1, all remalning files on the library tape have the same structure; each file is assoclated with some material and is tagged with a unique identification number. Within each material file there are three different types of records. The contents of the first record are sumarized in Table II. The first word in the record is the integer Identification number SID. When reference is made to a particular SID in the LAMDF, it is understood that one is referring to a particular set of evaluated cross sections for some materfal; there can be, and often are, several different evaluations for the same material. The second word of the record gives the number of sets of angular distributlons stored (for this SID) on the libraxy tape; the following ND integers are identification numbers for these sets of which there can be no more than 25 . The next 8 words contain the cross-section set description (SDES)--80 optional alphanumeric characters to Identify the SID more completely as to material described and source of data. The total number of reactions for which cross sections are tabulated in succeeding records 18 given by the Integer R. By "Ieaction" we mean elastic scattering, discrete Inelastic scattering, nonelastic scattering, fission, and absorption as will be discussed In connection with Table $v$. The TIDR array consists of $R$ integers to Indicate which of the ND sets of angular distributions is appropriate for each reaction. The first set of angular distributions is always used for elastic scattering. The nonexistence of an appropriate angular distribution set among the ND sets avallable is indicated by a negative number in the TIDR array. Ixceptions and extensions to these rules are discussed in Sec. III.

The cross sections for the $R$ reactions are tabulated on a conmon energy mesh. The total number of energies NES must be less than 3000; this control parameter is followed by NES values of the energies. The IDR array contains integers to Identify the type of cross section represented by each of the $R$ reactions. These numbers are larger by 1000 than the standard reaction identification numbers summarized in Table $v$. The cross sections for each reaction may not be given at all of the NES energies, but only in the energy rauge over which they are avallable. For example, cross sections for a reaction with a threshold energy are not tabulated at energles below the threshold. The array ME contains $R$ octal numbers with two packed integers, $\mathrm{Jl}$ and $\mathrm{J} 2$, one pair for each reaction. They are packed in the same manner as described in Sec. II.A.2 for the MG array. Integers $\mathrm{J} 1$ and $\mathrm{J} 2$ are Indices for entries in the ES array corresponding to the initial and final energles for which the reaction cross section is tabulated. The $R$ entries in the IRS array give the number of entries in the ESJ array for each of the $R$ reactions; the ESJ block contains Information usea to describe the energy distribution of secondary neutrons. The reaction energy $Q$ values for each of the $R$ reactions are stored in the $Q R$ array. The last three Integers in Record 1 of a material file are the proton number $z$ for the material, a flag to Indicate whether the material is a single isotope or a mixture of more than one, and a final control flag $K 2$ to describe the energy distributions of outcoming neutrons. The last flag, R2, is not used in PROGRAM EVXS. With the exception of the energies ES, reaction energies $Q$, and deecriptive display information SUES, all items in the firat record of a material file are control paraneters in integer format used to govern the reading of aucceeding records in the material file. 
FIRST RECORD OF A MATERTAL FILE ON LIFRARY TAPE

CONTROL PARAMETERS FOR MATERIAL SIU

Comments

Varicble ilame

Description

Format

Record 1:
SID

$\mathrm{ND}(\leqslant 25)$

$\operatorname{TIDS}_{n}, \mathrm{n}=1, \ldots, \mathrm{ND}$

SDES (8)

$R(\leqslant 50)$

$\operatorname{TIDR}_{r}, r=1, \ldots, \mathrm{R}$

NES ( $\%$ 3OCO)

$E S_{1}, 1=1, \ldots, N E S$

$\mathrm{IDR}_{r}, \mathrm{r}=1, \ldots, \mathrm{R}$

$\mathrm{ME}_{\mathbf{r}}, \mathrm{r}=1, \ldots, \mathrm{R}$

$\mathrm{QR}_{\mathrm{r}}, \mathrm{r}=1, \ldots, \mathrm{R}$

NZ

MIX

$\mathrm{K} 2$

IRS $_{r}, r=1, \ldots R$

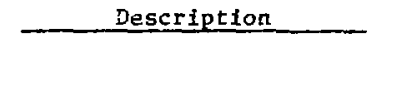

Crass-section set identification number

Number of sets of angular Integer distriutions

Identification numbers Integer

sets in order as stored

on library tape

Description of cross-
section set

Number of reactions

Identification of angular distribution to be used with rth reaction

Number of energies in FS block

Energies at which cross sections are tabulated
Reaction identification numbers

Two packed integers, J1 and $\mathrm{J} 2$, to Indicate range of entries in ES for which reaction $r$ cross sectlons are tabulated

Number of words in ESJ for the rth reaction
Energy released by rth reaction

$Z$ number for material

Nonzero for isotope mixture

Number of data to describe energy distribution of outcoming neutrons
Integer

\author{
Integer \\ Integer
}

Integer

Floating

Inceger

Octal

\section{Positive}

Positive

Positive

If negative, no angular distrdbution

Positive

Positive

$\mathrm{J} 1=\mathrm{ME}(\mathrm{r}) / 2^{24}$

$J 2=M E(r)-J I * 2^{24}$

Positlve numbers greater by 1000 than the Identification numbers In Table $V$

Floating

Integer

Positive

Positive

Positive; not used in EVXS 
The contents of the $R$ records following the first record are summarized in Table III. For each reaction there is one record consisting of the cross sections SIG and the secondary energy parameters ESJ. The number of cross-section values for the rth reaction is calculated from the two packed integers $\mathrm{J} 1$ and $\mathrm{J} 2$ In $\mathrm{ME}_{\mathrm{r}}$; the number of ESJ values for reaction I Is given by IRS ${ }_{Y}$. Data will be given in the ESJ block for all reaction types that produce secondary neutrons unless the secondary energy distributions can be implicitly determined from the angular distribution information. Thus, for elastic scattering ( $r=I$ fin the LAMDF) and discrete inelastic scatterIng, the ESJ block is omfted. There should be entrles in ESJ for all reactions $r$ such that $15<$ $\mathrm{IDR}_{r} \leqslant 31$, which are the nonelastic reactions including Inelastic scattering to the continuum, fission, $(n, 2 \pi)$, and $(n, 3 n)$.

4. Angular Distribution Records. The contents of the last ND records of a material file for a particular SID are summarized in Table IV. As shown In Fig. I and indicated in the table, the first of these records in the material file is numberer? $R+2$. The first word of each of the ND records is the number TID used to Identify the set of angular distributions; this word is followed by eight words of alphanumeric descriptive information TDES.

The set of angular distributions consists of NED normalized probability distributions $T\left(\mu, E_{1}\right)$ at NED energies $E_{1}$. The integer SYS indicates whether the probabilities are given in the center-of-mass or

TABLE TTK

COKTEMSS OF LIBRARY TAPE CROSS-SECTION RECOEDS FOR MATERLAL SID

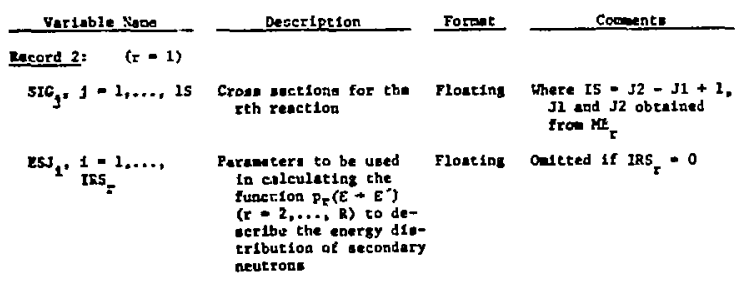

Becord 3: $\{x=2\}$

Sue forwe as Recard 2

lecord $2+1: \quad(r-x)$

Sace forme as Record 2 laboratory system; the atomic mass $A$ of the material Is measured in units such that for the ground state of $c^{12}$, A is exactly 12. The specifications for the probability distributions $T\left(\mu, E_{1}\right)$ are given in the TK block which has a total of KT eatries, where KT must be no larger than 3000 . For each of the NED energles, there is a group of entries in the TK array; the MD array contains NED octal numbers consisting of two Integers $K 1$ and $K 2$ packed as described for the MG block in Sec. II.A.2. These specify the first and last entries in the TR array for each of the NBD energies. The number of entries In TK for the ith energy is $K=K 2-K 1+1$. The probability functions are given either in tabular forn or in terms of Legendre expansion coeffictents. Integer flag LEGN specifies the number of energies for which probability distributions are given in terms of Legendre coefficients. If LEGN $=0$, the probabilities are tabulated for all energles and the TK block contains $K / 2$ pairs of values for $\mu$ and $T\left(\mu, E_{f}\right)$ for each of the energies with the palrs in order of Increasing $\mu$, with $\mu=-1$ and $\mu=+1$ alway. present. If LEGN $>0$, then for all energies $E_{1}$ such that $1<L E G N$, the TK block contains Legendre expansion coefficients $F_{n}$. The number of coefficlents is spectfied by NF, the first word of the TR block for this energy; this is followed imediately by the NF values of $F_{n}$. It $<s$ evident that NF $=R-1$. When LEGN $>0$ and $1>$ LEGN, the TK block contains $\left(\mu, T\left(\mu, E_{1}\right)\right)$ pairs as described for LEGN - 0 . The integer NINC specifies the number of Intervals to be used In the numerical integration with respect to $\mu$ over the range $-1<\mu<+1$.

Angular distributions for elastic scattering a:e given in the center-of-mass system; for discrete fnejastic reactions, lsotroplc scattering in the center-of-mass system is assumed; for nonelastic reactions the laboratory system is used. $I_{1}$ any case where this convention is not followed, PROGRAM EVXS proceeds as if it were, but a warning measage is printed.

B. Reactions Ava1 lable

Within the file for each materlal SID, cross sections are glven for many different reactions. A summary of all the reactions for which reaction cross-section data can be entered in the LAMDF is listed in Table $v$. The various reactions are 
TABLE IV

CONTENTS OF LIBRARY TAPE

ANGULAR DISTRIBUTION RECORDS FOR MATERIAL SID

Variable Name

Record R+2: $\quad(n=1)$

TID

TDES ( 8 )

$\operatorname{NED}(\leqslant 400)$

$E_{i}, i=1, \ldots, N E D$

SYS

A

LEGN $(<$ NED $)$

$\mathrm{KT}(\leqslant 3000)$

$\mathrm{TK}_{\mathrm{k}}, k=1, \ldots, \mathrm{KT}$

$\mathrm{MD}_{i}, i=1, \ldots, \mathrm{NED}$

NINC

Same format as Record 2

•

$\frac{\text { Record } R+N D+1:}{(n=N D)}$

Same format as Record 2

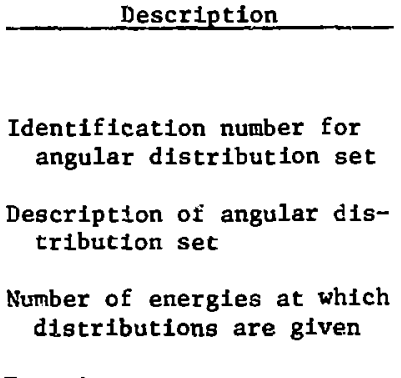

Energies

1 or 2 - Center-of-mass or laboratory system

Atomic mass of material

Number of energies w1th Legendre coefficients

Number of words in TK

Specifications for the probability distribution $\mathrm{T}(\mu, E)$

Two packed integers $\mathrm{Kl}$ and $\mathrm{K} 2$ to indicate range of entries in $T K$ for the ith energy

Number of intervals to be used in integrating with respect to $\mu$

Format
Integer
Display (A10)
Integer
Floating
Integer

Floating

Integer

Integer

Floating

Octal

Integer
$\mathrm{KI}=\mathrm{MD}(1) / 2^{24}$

$\mathrm{K} 2=\mathrm{MD}(\mathrm{i})-\mathrm{K} 1 * 2^{24}$

Positive

Comments

Positive

Positive

Positive

Always 1 for elastic Always 2 for nonelast Ic

Mass of $\mathrm{c}^{12}$ (ground)

$=12$ units

At present, if LEGN $\neq 0$, LEGN $=$ INED

Positive identified by number in accordance with the classification scheme prescribed for the LK Library, the only difference being that reactions numbered 1,3 , and 4 are onfted from the LAMDF. The reactions can be grouped into broader categories: elastic, discrete inelastic, nonelastic, and absorption. For all materials, the first reaction $(r \propto 1)$ is elastic scattering with ID $=2$.

Inelastic scattering to the discrete levels is represented by reactions with identification numbers ID such that $5 \leqslant$ ID $\leqslant 14$ and $51 \leqslant$ ID $\leqslant 80$; IV numbers 81 through 100 have been reserved for future needs in describing discrete irelastic reactions. For discrete inelastic reactionis the notation $\left(n, n^{-} j\right)$ is used to represent inelastic scattering such that the target nucleus is loft in its $\mathrm{fth}$ excited state. Inelastic scattering in which sufficient energy is transferred from the incident neutron to the target to leave it with energy 
TABLE $\mathbf{P}$

REACTIONS FOR WHICH NEUTRON CROSS-SECTION DATA CAN BE EMTERED IN THE LAMF

\begin{tabular}{|c|c|c|c|}
\hline & Type & Reaction & Reaction Description \\
\hline 2 & 1 & $(n, n)$ & $\begin{array}{l}\text { Elastic (note that reactions numbered } 1,3 \text {, and } 4 \text { are } \\
\text { onittad from the LAMDF) }\end{array}$ \\
\hline $\begin{array}{r}5 \\
6 \\
7 \\
8 \\
9 \\
10 \\
11 \\
12 \\
13 \\
14 \\
\end{array}$ & $\begin{array}{l}1 \\
1 \\
1 \\
1 \\
1 \\
1 \\
1 \\
1 \\
1 \\
1\end{array}$ & $\begin{array}{l}\left(n, n^{-} 1\right) \\
\left(n, n^{-} 2\right) \\
\left(n, n^{-} 3\right) \\
\left(n, n^{-} 4\right) \\
\left(n, n^{-} 5\right) \\
\left(n, n^{-6)}\right. \\
\left(n, n^{-} 7\right) \\
\left(n, n^{-} 8\right) \\
\left(n, n^{-} 9\right) \\
\left(n, n^{-10}\right)\end{array}$ & Discrete Inelastic \\
\hline $\begin{array}{l}15 \\
16 \\
17 \\
19 \\
19 \\
20 \\
21 \\
22 \\
23 \\
24 \\
25 \\
26 \\
27 \\
28 \\
29 \\
30 \\
31\end{array}$ & $\begin{array}{l}1 \\
2 \\
3 \\
0 \\
0 \\
1 \\
2 \\
1 \\
1 \\
2 \\
3 \\
2 \\
1 \\
1 \\
1 \\
1 \\
1\end{array}$ & 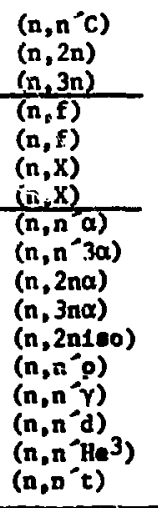 & 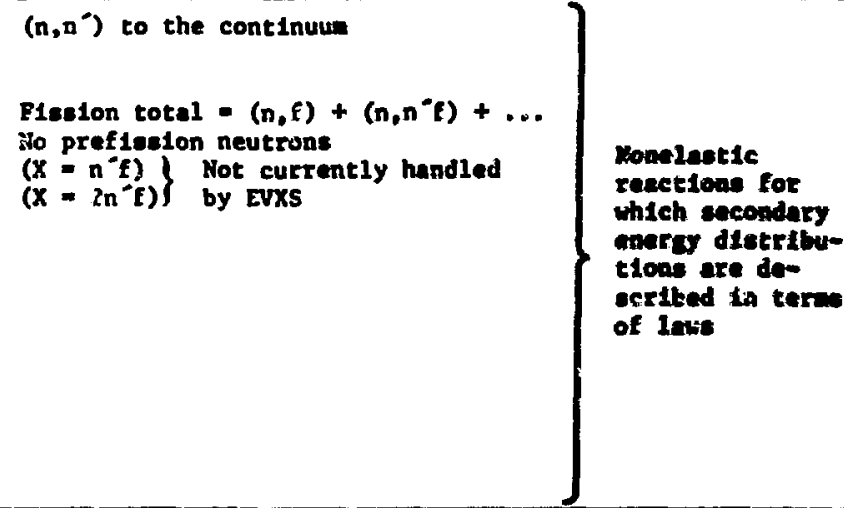 \\
\hline $32-50$ & 0 & $(N, X)$ & Undefined (allowed for ocher nonalastic rasctions) \\
\hline $\begin{array}{r}51 \\
52 \\
53 \\
54 \\
55 \\
. \\
\dot{78} \\
79 \\
80\end{array}$ & $\begin{array}{l}1 \\
1 \\
1 \\
1 \\
1 \\
: \\
\dot{1} \\
1 \\
1 \\
1\end{array}$ & $\begin{array}{c}\left(n, n^{-11}\right) \\
\left(n, n^{-12}\right) \\
\left(n, n^{-13}\right) \\
\left(n, n^{-14}\right) \\
\left(n, n^{-15}\right) \\
\vdots \\
\vdots \\
\left(n, n^{-} 38\right) \\
\left(n, n^{-} 39\right) \\
\left(n, n^{-40)}\right.\end{array}$ & Discrete Inelastis (continued) \\
\hline $81-100$ & 0 & $(n, x)$ & Undefined (allowed for ocher discrete inelaste resctions) \\
\hline $\begin{array}{l}101 \\
102 \\
103 \\
104 \\
105 \\
106 \\
107 \\
108\end{array}$ & $\begin{array}{l}0 \\
0 \\
0 \\
0 \\
0 \\
0 \\
0 \\
0\end{array}$ & $\begin{array}{l}(n, p a r \quad a) \\
(n, y) \\
(n, p) \\
(n, d) \\
(n, t) \\
\left(n, H e^{3}\right) \\
(n, a) \\
(n, 2 a)\end{array}$ & Parasitic absotption \\
\hline $109-150$ & 0 & $(\mathbf{n}, \mathbf{x})$ & Undefined (allowed for other abeorption resetiono) \\
\hline
\end{tabular}

The convention used for reaction 1dentification nubber 10 the san so thrt preseribed for the UK L1brary. 1

The number of outconing neutrons from the given reactions 1 s given by TrRE. 
correspording to the continum of lavils it ropresenced by $\left(n, n^{*} \mathrm{C}\right)$. I0 -49 .

tranelagte reacrion: wich is it 11 art chose for wich secondary nutrons are produced whost energy discributichs ear be daseribed in cern:

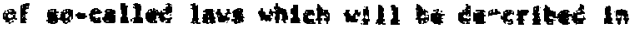

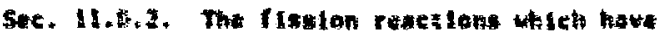

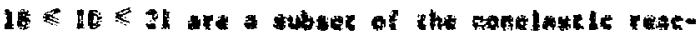
tons.

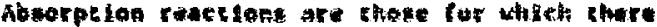

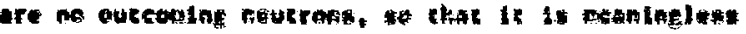

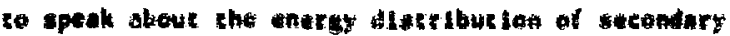

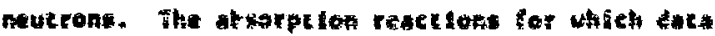

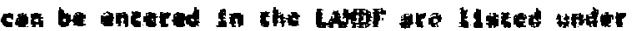

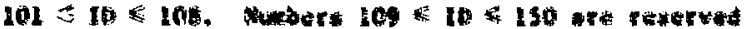
for ochar absurpetan sacklone.

The Integers llacet under Tre desterdbe the

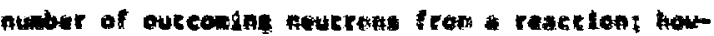

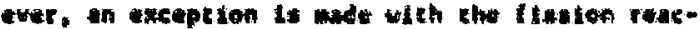

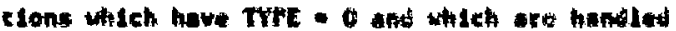

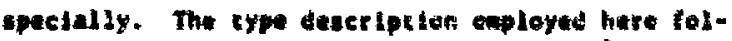
lowe the sonwation und in cte the former.

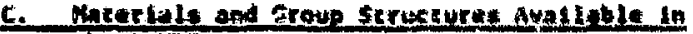 Alic Lilis}

Alehough the purpose of this repert is co bi" scrtbe mulcteroup averegtat codt and the format of the Ibrary on whth the prostesor operakes. It do upproprlate co cosentar the currane ednetrit. of the LMpf as a means of beccar underarandins the cype of Inforeation centaime thereln. The wose recthe ediclon (January 1972) contahs cross sections tor

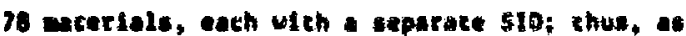

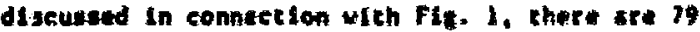
thles on the libraty cope. Thls nuber It considerably lese than 500 , which is the muterim quber of the allowed. In Table v1 there is 11 tot of all the cross-sestion sece currenty in the library. wht the crosesection set Identitieacion number sip and the set descripeton. The line of afphunumerte

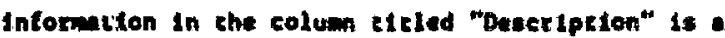
reproducten of the 80 eharactert of dara coneatned In the SDES array for each 510. The InEeger nd for each SID Is lisked in ahe chand colum under the tiele "Muber of sete of Angular Aretribuelons." In thie odition of the library the largeter value of $\mathrm{kb}$ 45 3, weh lees then the alloved naximu of 25. The nusber of reactions $R$ Is Insed th the fourth colum; the larteet value is 27 (maklime allowed is 50)
Fint 1

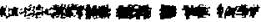

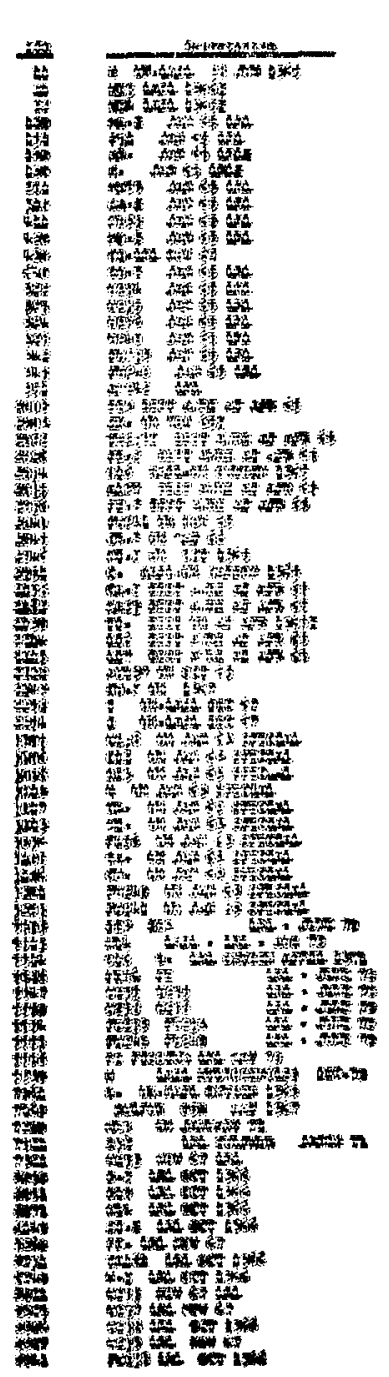

Which oecure in the oxyeen rwalution (SID - 2034) prepared in 1965 at the knolls aconte Powe Laboracory (kapt). The number of enarefes was in the ES block for each SID is listed to the lase colun of Table V1. By fat the lorgest auber of enargy pothk (WEs - 1919) It requited for the U-238 evaluntion, 5ID-3003. Such a large puber is not unreasonable because many poinke are requitred to deceribe edequately the resenance bahavior of the urantu crost section. Howaver, thts aumar is wuch lower than the maxiocon of 3000 tndlested in Toble II. 
The 34 group ecructures stored in File 1 of the wot recent edicion of the WNDF are listed in Table vit. For each separate eroup etructure there I* a sroup set Identiffeation nuber GID followed by the dascription of the sec as contalned in the cots arzay. The number of sroups $G$ and the number of flux, enercy parte KG are listed in the third and fourth colums of the table. The largest nuber of groups in any set 1968 and the larteet nuber of antay polnte for whtch valus of the flux are tabulaced is 169. These nubers are well under the manlims valuas of 60 and 500 allowed In Table I for variables $G$ and KC. respectively.

Addichoal cross-saction sets and proup struccures can be addad to the library tape at any tine. The rominat code XswoD has bean uricten at LASL by Narche Noyt to parform these functions. It ahouid be emphasied, howver, that when using any adition of the LuDF, one lo not Inited to the reup etrueeures coatained thercin but can Insteed use any arbleraxy valghting etructura usint cards as input.

\section{Addiclonal Deta12s About lee of the Date}

1. Lot-Lot Incerpoletioa Schene. Enereydependent quancteles aboue which Informetion is atven In the IAbr-quantities like the flux distribuelons $(E)$. resecion crose sections $\sigma_{r}(E)$, and the averace number of neutrone per fiaston $v(E)$--are assumed to vary swoothly enough wich energy that the

Tw15 ur:

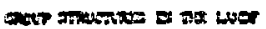

\begin{tabular}{|c|c|c|}
\hline Gextom & stope of & now of \\
\hline 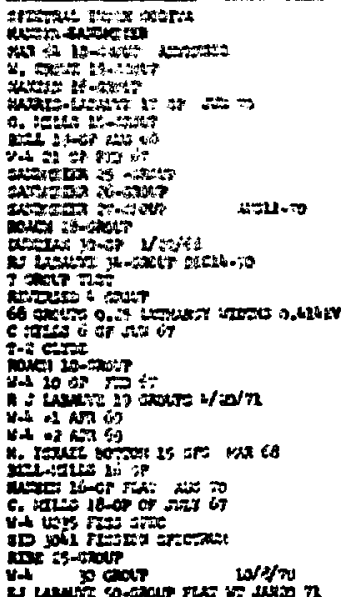 & 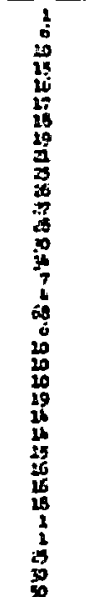 & 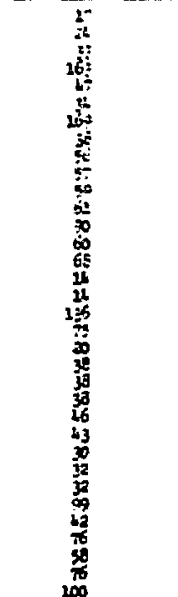 \\
\hline
\end{tabular}

functional dependence can be repreaented by the coordinates of and poists of IInear segente teken from en $X$ ve $\ln E$ plote, $X$ repreanting $1, \sigma_{r}$, or $v$. In the "log-log" representation the quantity $X(E)$ for $E_{k}<E<E_{k+1}$ is interpolated between the tebulated pairs of values $\left(E_{k}, x_{k}\right)$ and $\left(E_{k+1}, x_{k+1}\right)$ using the formula

$\ln \left[\frac{X(E)}{X_{k}}\right]-\ln \left[\frac{X_{k+1}}{X_{k}}\right] \ln \left[\frac{E}{E_{k}}\right] / \ln \left[\frac{E_{k+1}}{E_{k}}\right]$

with $E_{k}<E<E_{k+1}$.

Equation (12) can be rewritten

$$
\ln \left[\frac{X(E)}{X_{k}}\right]-Y \ln \left[\frac{E}{E_{k}}\right] \text {, }
$$

where

$$
Y=\ln \left[\frac{X_{1+1}}{X_{k}}\right] / \ln \left[\frac{E_{k+1}}{E_{k}}\right] \text {. }
$$

Furthermore, if we define

$$
s=\ln x_{k}-y \ln E_{k}
$$

chen the interpolated value $X(E)$ can be expressed

$$
X(E)=e^{S} E^{Y}
$$

This form is extremely convenient since the integrals, such as those in Eq. (4), can then be written In the form

$$
\int_{E_{8}^{-}}^{E_{g}^{+}} d E x_{1}(E) x_{2}(E) \ldots \ldots x_{n}(E)
$$

where

$$
x_{n}(E)=e^{s_{n}} E^{Y_{n}}
$$

and

$$
E_{k}<E_{g}^{-} \text {and } \quad E_{g}^{+}<E_{k+1} \text {, }
$$


which can be integrated exactly. Hence the integral can be further simplified to

$$
e^{S_{1}} \cdot e^{S_{2}} \ldots e^{S_{n}} \int_{E_{B}^{-}}^{E_{g}^{+}} d E \cdot E^{Y_{1}} \cdot E^{Y_{2}} \ldots z^{Y_{n}}
$$

or

$$
e^{S_{1}+S_{2}+\cdots+s_{n}} \int_{E_{8}^{-}}^{E_{8}^{+}} d E \cdot E^{Y_{1}+Y_{2}+\cdots+Y_{n}}
$$

The lower and upper energy bounds of the gth group are desigaated $E_{8}^{-}$and $E_{8}^{+}$, as described previously. Also note that because of the logarithic interpola$t$ Ion, It 18 Impossible to use values of 0.0 for elther $x_{k}$ or $E_{k}$. Instesd, In all cases $10^{-20}$ is used to approximate 0.0 .

\section{Secondary Energy Probability D1stributions.}

For a reaction with identification number ID such that $15<$ ID $<31$, the entry in the IRS array will be nonzero and, as mentioned in connection with Table III, the cross-section record will contain values of ESJ as well as the cross sections thewselves. The secondary energy probability distributions $p\left(E \rightarrow E^{\prime}\right)$--the probability that neutrons of energy $E^{-}$will be produced by an incident neutron of energy E-are calculated from eniries in ESJ.

For each reaction, $P\left(E \rightarrow E^{-}\right)$is normalized such that

$$
\int_{0}^{E^{\prime} \max } P\left(E \rightarrow E^{-}\right) d E^{-}=\text {TYPE, }
$$

where $E^{\prime}{ }_{\max }$ is the maximum possible secondary neutron energy. Each probability distribution can be broken down Into partial distributions $F_{k}\left(E+E^{\prime}\right)$ such that

$$
p\left(E \rightarrow E^{\prime}\right)=\sum_{k=1}^{10} w_{k} F_{k}\left(E \rightarrow E^{\prime}\right),
$$

where $w_{k}$ is the fractional probability that the distribution $F_{k}\left(E+E^{\prime}\right)$ is to be used to describe the outgoing neutrons. Equation (22) is obtaleed by requiring that

$$
\sum_{k=1}^{10} w_{k}=\operatorname{TYPE}
$$

where TYPE is the number of econdery neutrons produced in the reaction. Ench $F_{k}\left(E \rightarrow E^{\prime}\right)$ is defined by a different analytic representation called a law; we say that $w_{k}$ is the weight for this kth 1aw. As Indicated In Eq. (23), provision has been ande for ss wany as 10 lawe, although only 8 ara now beins used in the LAWF. The dietributione $E_{k}\left(Z+E^{\prime}\right)$ are snalytic in secondary onergy $E^{\prime}$ only; separate tabulatione of the paraneters and/or date for the varlous lawa wust be given for any valuse of the incldent neutron enerey $E$. Thus, the ESJ block is broken Into sublists, one for each of several Inc1dent neutron energies $E_{1}$; each of the sublists can be broken into no wore than afgt sub-sublists, one for each of the eight allowable lawe. All nubers in the ESJ block are in floating point form. Various combinaticns of negative numbra serve as flage to separate the subliste and sub-subliste within the ESJ block. All data other than thene flage w11l be $>0.0$. A detalled dewcription of the organization of the ESJ block is given in F1g. 2.

The length of the block for the $r$ th reaction as given in the rth entry of the IRS array is deterained by the particular reaction, the number of incident neutron energies $E_{1}$ at which the probability diatributions are to be calculated, and the number of laws required to apecify each distribution. Two thinge are always the game: (a) The first word in the block is the Identification number for the reaction in floatini; point. (b) The laat word of the ESJ block will be -1.0 . As shown in Fig. 2, the win part of the blosk is broken up into several sublists ending with two negative numbers $-5.0,-2.0$. The first word of eash sublist is an incident neutron energy $E_{1}$ followed by up to eight sub-sublists which correspond to the elght lawe currently provided for. Each sub-sublist begins with a pair of numbers $w_{k}$ and $L_{k}$, where $L_{k}=1.0,2.0, \ldots, 7.0$, or 10.0 and $w_{k}$ Is the weight to be soctated with the kth law; the sub-eublist 1s etided with the number -4.0 . Thus there are really three negative numbers at the end 
3

$$
\begin{aligned}
& \text { 1. } 1 \\
& \text { Pareaters subnilust to }
\end{aligned}
$$

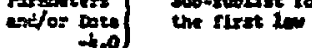

$$
\begin{aligned}
& \mathrm{u}_{2}, \mathrm{~km}
\end{aligned}
$$

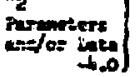

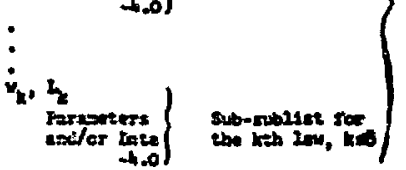

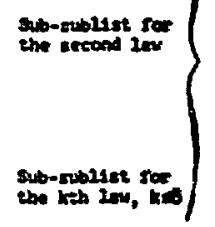$$
-5.0,-2.0
$$

Sublest toe toellent

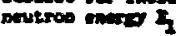

suslent sor lnellent neviroll mertit 5

$$
\begin{aligned}
& i_{k}, 4 \\
& \text { parasertir: } \\
& -3.0,-2.0,-2.0 \\
& \boldsymbol{D}_{\mathrm{P}} \\
& E_{2}, u_{1}, \Sigma_{2}, u_{2}, \ldots E_{0}, u_{n} \\
& -2.0
\end{aligned}
$$

Fig. 2. Arrangenent of the ESJ block.

of exch sublist: the nuber -4.0 signifies the end of the sub-sublist for the last law and the patr $-5.0,-2.0$ arks the and of the subliat for aone enercy. The sublista are arranged so that the energies $E_{1}$ appear In order of ascending agnitude, Each probebility distribution $p\left(E^{-}+E^{\prime}\right)$ is assuned to be Independent of $\mathrm{E}$ over energy ranges whose boundaries are delinated by the $E_{1}$; the probability distributions are not interpolated between the energies for which the subliste are given. Instead, one ascunes

$$
p\left(E+E^{\prime}\right)=p\left(E_{1} \rightarrow E^{\prime}\right)
$$

for $E_{1}<E<E_{1+1}$. At energies above $E_{f}$, the energy 0 i the final sublist,

$$
p\left(E+E^{\prime}\right)-p\left(E_{E}+E^{\prime}\right)
$$

The eublists are repeated unt1l the final energy oublist which ends with four negative numbera $-4.0,-5.0,-2.0$, and -1.0 . Thie combinction of negetive numbers arks the end of the ESJ block except in the case of the fiasion reactions with
ID $=18,19,20$, or 21 . For fleuton renctions the Eat of four nubers is folloued by apecial block contalning dete on the enersy depepdence of $v_{1}$ the average number of aeutrons per fiastan. The firat word of the spectal block is an Identiffention nuber $I D+4000$ In flontins point; $4, a$, fot I0 - 18 the first word of the special block would be 4018.0. Then followe a sequence of palre of values of enarsy and $v$ i thle apectal block is tetranated with the negative numer $=1,0$.

To understend fully the eSJ array, the functional form of the probablitty distributlone antet be deseribed and the arrapgenont of the parsmeters thereof as reed frod the sub-subilste wat be defined. The atght law curraptly provided for in Evxs are sintlat to those prescribed for the It Library. ${ }^{1}$ The detalls of the lawe as prescrtbed for the LarDr are stuen here.

Ly 1. In this representatfon the accondary neutrons are enited with flxed discrote energine $E_{1}^{*}$ so that

$$
g_{1}\left(E+E^{\prime}\right)-\sum_{1=1}^{I} f_{1} \delta\left(E^{-}-E_{1}^{\prime}\right)
$$

where $f_{i}$ ts the frection of the secondary neutrons calted with energy $E_{1}^{\prime}$ and $\delta\left(E^{-}-E_{1}^{-}\right)$is the Dirac delta-function diatribution used to rapresent the discrete nature of energy $E_{f}^{-}$. It is required that

$$
\left|\sum_{i=1}^{I} f_{i}-1.0\right|<0.005 .
$$

The entriee in the oub-sublist for thie law are $w_{1}$ * $L=1.0, E_{1}^{-}, f_{1}, \ldots, E_{I}^{\prime}, f_{I},-4.0$.

Ley 2. Thin law is used to repreant secondary neutrons with discrete energiee $E_{1}^{\prime}$ wich are direct1y related to the incident nautron energy. $Z$. The diatribution $F_{2}\left(E+E^{-}\right)$1e expreseed

$$
z_{2}\left(E+E^{-}\right)=\sum_{1=1}^{I} f_{1} \delta\left(E^{-}-E_{1}^{\prime}\right)
$$


bụt hẹre

$$
E_{i}^{*}=A_{1}\left(E-D_{1}\right)
$$

where $E$ is the Incident neutron thergy, $D_{1}$ is sowe discrete energy decrement, and $A_{1}$ is the reduction facter. As for law 1 , the $f_{f}$ an to unity. The entries in the aub-subliet for this law are $w_{2}$. $L=2,0, D_{1}, A_{1}, f_{1}, \ldots, D_{I}, A_{I}, f_{I},-4,0$.

Ley 3. The distribution furction for this lew is a continuous norallized spectrua $f\left(E^{\prime}\right)$ indefendent of the Incident energy $E_{\text {. The, }}$

$$
E_{3}\left(E^{+}+E^{+}\right)=f\left(E^{-}\right)
$$

the function $f\left(E^{-}\right)$is given in tabular form so that the entrias in the aub-eublist for this law are $w_{3}$, $L=3.0, E_{1}^{-}, f\left(E_{1}^{*}\right), \ldots, E_{I}^{\prime}, f\left(E_{I}^{*}\right),-4.0$.

Ly 4. Reuirons with secondary energy $E^{\prime}$ are represented by the noralized distribution function $F_{4}\left(E \rightarrow E^{\prime}\right)$ which is tabulated so a function of $E^{\prime}$ for several values of $E$. The sub-sublist for this Law looks just like that for Law 3 , because the dependence on $E$ is introduced solely through the use of several aublists. Specifically, the sub-sublist for some energy $E$ has the form $w_{4}, L=4.0, E_{1}^{*}$, $f\left(E \rightarrow E_{1}^{*}\right), \ldots, E_{I}, f\left(E \rightarrow E_{I}^{*}\right),-4.0$.

Law 5. The distribution funciton for this law 1e witten

$$
F_{S}\left(E \rightarrow E^{*}\right)=g\left(E, E^{-} / E^{q}\right)
$$

where $q=1 / 2$. The function $g\left(E, E^{-} / E^{q}\right)=g(E, x)$, where $x=E^{-} / E^{q}$, is tabulated as a function of $x$ so that the aub-sublist for this law for a particular energy has the form $w_{5}, L=5.0, x_{1}, g\left(E, x_{1}\right), \ldots$, $x_{I}, g\left(E, x_{I}\right),-4.0$.

Law 6. The diatribution function for this law has the sare form as that for Law 5 except that $q$ - 1. It should be noted that laws 4,5 , and 6 have the same form except that $q=0,1 / 2$, and 1 , respectively.

Law 7. A detalled representation of the generalized fission spectrum is given by the distribution for this law. The probabllicy distribution is writcen

$$
\begin{gathered}
F_{7}\left(E+E^{\circ}\right)=a \frac{E^{-}}{T^{2}} e^{-\frac{E^{\prime}}{T}}+(1-a) \frac{2}{\sqrt{\pi} B^{3 / 2}} \\
\therefore \cdot E^{-\frac{E^{-}}{B}}
\end{gathered}
$$

where

$$
\begin{aligned}
& B=a+b(\bar{i}+1)^{1 / 2} \\
& T=c\left(E-E_{f}\right) /\left(14-E_{f}\right) \text { (energies in HeV), (35) } \\
& E_{f}=\begin{array}{l}
\text { threshold energy for the }\left(n, n^{-} f\right) \\
\text { reaction }
\end{array}
\end{aligned}
$$

and

$$
a=\frac{\sigma_{n, n-f}+\sigma_{n, 2 n-f}}{\bar{v}\left(\sigma_{n, f}+\sigma_{n, n-f}+\sigma_{n, 2 n-f)}\right.}
$$

Quantities $a, b, c$, and $E_{f}$ are input through the ESJ array; the remaining quantities (the $E, \bar{v}$ pafrs) muat be obtalned from the speciel section at the end of the ESJ array. The dependence of $F_{7}\left(E+E^{\prime}\right)$ on the Incident neutron enersy $E$ is stated explicitIy in the expression for $T$, but it is Implicit in the quantities $\bar{v}$, the average number of neutrons per flasion, and the various fission reaction crose sections used in calculating $B$ and $a$. The aimple Maxwellien flasion distribution

$$
f_{7}\left(E+E^{\prime}\right)=\frac{2}{\sqrt{\pi^{\prime}}} \frac{1}{\mathrm{~B}^{3 / 2}} \sqrt{E^{-}} e^{-\frac{E^{\prime}}{B}}
$$

Is a special case with $a=b=0.0$.

This distribution is normalized so that

$$
\int_{0}^{\infty} E_{7}\left(E+E^{-}\right) d E^{-}=1.0
$$

At present EVXS is programed to handle only the cases with $a=b=0.0$. Herein lies the ortgla of the comment in Table $v$ concerning resctions with 
ID - 20 and 21, the $\left(n, n^{-} f\right)$ and $\left(n, 2 n^{-1} f\right)$ reactions not currently handled by Evis. However, proviston hes been ande in the oub-sublist for this in to Include all four Input paranetera; ite suneral fore 1. $w_{7}, \mathrm{l}=7.0, \mathrm{a}, \mathrm{b}, \mathrm{c}, \mathrm{E}_{\mathrm{f}},-4.0$.

Lew 10. An evaporation epectru is represented by Lat 10; viz.,

$$
F_{10}\left(E+E^{\prime}\right)=\frac{E^{-}}{T^{2}} e^{-E^{\prime} / T}
$$

where

$$
r=\sqrt{e} / a
$$

Dependence on energy $E$ is introduced through energy dependance of paraneter $a$. For a given $E$ the subeubliat for La 10 is eimly written $w_{10}, L=10.0$, $a,-4.0$. This lav is really ont special lintt $(\alpha=1)$ of Law 7 .

For the tabulation in Lara 3, 4, 5, and 6, it 1. assumed that linear Interpolation betwan tabulated points is adequate to deacribe the functions wo thet the crapezoldal rule ang be used in the nuarical integrations carried out with respect to the secondary energy $\mathrm{E}^{*}$.

3. Anvular Dietribution Repreaentations. The contents of the engular distribution records were outlined in the diecussion centered around Table IV. It was pointed out that the apecifications for the probability dietributione $T\left(\mu, E_{1}\right)$, elther in tabular form or in terms of Legendre coefficiente, are contalned in the TR array. The number of words XT contained therein cannot be explicitly defined; it tepende on whether Legendre coefficlente or tabulated data are given, and on the degree of anisotrony of the angular diatributions. Obviously, fewer date points are required to specify an isotropic distribution than one which is highly aniwotropic. There are oufficlent data to specify NED normalized probabllity dietributione $T\left(\mu, E_{1}\right)$ corremponding to the NED incident neutron energiee $E_{1}$. The $M D$ array contains octal numbers (packed a described in Sec. II.A.2) to specify which entries in the TK array are intended for each of the NED energiea. The normalization requirement inulies thet

$$
\int_{-1}^{+1} T\left(\mu, z_{1}\right) d \mu=1.0
$$

It 1s understood that the angular distributione at Internediete energies are to be obtalned by linene interpolation betwen those st margles $z_{1}$ and $z_{1+1}$, regardlese of whether $T\left(\mu, I_{1}\right)$ is tepulated directly. or obteined fro Lagendre coefficients. Thus,

$$
T(\mu, E)=T\left(\mu_{0} I_{1}\right)+\left(I-E_{1}\right)
$$

$$
\times \frac{T\left(\mu, E_{1+1}\right)-T\left(\mu, E_{1}\right)}{E_{1+1}-E_{1}}
$$

whare $E_{1}<E<E_{1+1}$. The norwalization is thereby preserved at the interindiate onergy $E$. It romins to define explicitiy how the information in the $T$ block for each enarey is to be Introduced into the calculation.

Where the paraneter IEGA is sreater than zero, the probability distributions for the first IntI energtee are spectfled in term of Legendre coefficlente. In auch cases the first word of thy ubblock In $T$ contains an Integer $W$ to epecify the number of Legendre coeffj.clente that imediately follow; opecificaliy, the words are $\mathrm{KF}, \mathrm{F}_{1}, \mathrm{~F}_{2} \ldots$, $F_{\mathrm{MF}}$. From these the probability distribution to calculated

$$
T\left(\mu, E_{1}\right)=\frac{1}{2}\left\{1+\sum_{n=1}^{N}(2 n+1) F_{n} P_{n}(\mu)\right\} \text {, }
$$

where $P_{n}(\mu)$ is the nth order legendre polynomial and $N<$ NF. The upper limit $N$ of the sumation deserves explanation.

Angular distribution date in the LAME way be given in teras of legendre cuefficiente for nonelastic reactions only; furtherwore, whether specifled In tems of Legendre coefficlente or tubulated functions, the probability functions $T\left(\mu_{L}, E\right)$ are in the laboratory system (SYS = 2) for thene reactions. The expression in Eq. (8) for calculeting nth order legendre components of cross sections for such reactons containa an integral of the form 


$$
\int_{-1}^{+1} T\left(\mu_{L}, E\right) P_{n}\left(\mu_{L}\right) d \mu_{L}
$$

where $n=0, \ldots, \max$ and $\sin$ is the anxioun order of anisotropy desired. Using the expression for $T\left(\mu_{L}, E\right)$ as found in Eq. (44) we can write Eq. (45) as

$$
\begin{gathered}
\frac{1}{2} \int_{-1}^{+1}\left\{1+\sum_{m=1}^{N}(2 m+1) F_{m} P_{m}\left(\mu_{L}\right)\right\}_{n}\left(\mu_{L}\right) d \mu_{L} \\
=\delta_{0, n}+\sum_{m=1}^{N} F_{m} \delta_{m, n}
\end{gathered}
$$

where $\delta_{1, j} 13$ the celebrated Kroenecker delta. We have taken advantage of the orthogonality of the legendre polynomials over the range $-1<\mu_{L}<+1$ in arriving at Eq. (46). Since $n$ will be no greater than wax, there id no contribution to the summation in Eq. (46) for $m>$ nux. Thus it is clear that $N=\operatorname{MuX}$ or NF, whichever 18 smaller, and that the IntegraI In Eq. (45) can be expressed as a sum of the Legendre coefficlents for the expansions of the angular distribution data.

In a set of angular distributions there are NED energies for which probability distributions $T(\mu, E)$ are given. The first LEGN thereof are specifled in terms of Legendre coefficlents; the remainIng NED-LEGN distributions are tabulated so that each sub-block for these distributions consists of $(\mu, T(\mu, E))$ pairs starting with $\mu=-1.0$ and ending wth $\mu=+1.0$.

\section{II1. METHODS OF CALCULATION}

\section{A. General Remarks}

For any single material for which cross sections are tabulated in the LAMDF, group-averaged sross sections are calculated by PROGRAM EVXS, reaction by reaction. The various reactions (summarized in Table $V$ ) can be grouped into two broad categories depending on whether or not secondary neutrons are produced.

Absorption reactions are those for which there are no outcoming neutrons so that it is meaningless to speak about calculating a contribution to the scattering matrix. As Indicated in Table $V$, these reactions with ID -101 and TYPE $=0$ absorb neutrons and, therefore, one can calculate only a total cross section for neutron disappearance due to each such reaction.

The other category of reactions--those for which secondary neutrons are produced--1s more difficult to calculate because one must average these cross sections over both the incoming and outgoing energy groups. This second category can be subdivided into two classes: (1) Those reactions for which there is a direct kinematical relationship between the outgoing energy and the scattering angle so that the width of the outgoing energy group $B^{\prime}$ can be related to a range of the scattering cosine $\mu$. (2) Those reactions for which the secondary energy distributions are not directly related to the scattering angle, but are described Instead in terms of the fractional probability that a neutron of Incident energy $E$ w1ll produce secondary neutrons of energy $E^{\prime}$. Legendre components of the scattering matrix are calculated for all reactions in the second category.

For absorption reactions, only the total cross section is calculated. For elastic, discrete inelastic, and nonelastic reactions, the total and scattering cross sections are computed. For fission reactions, the total cross section, the flssion fraction $X_{g}{ }^{-}$, and the average number of neutrons per fission $\bar{v}$ are calculated. After the multigroup, microscopic neutron cross sections have been calculated for all reactions, the total cross sections and scattering matrices are combined into DTF format suitable for input to neutron transport calculations. In Sec. III we present in detail the procedure for group-averaging the data in the LAMDF described in Sec. II.

\section{B. Absorption}

For each reaction $r$ such that $101<$ ID $<108$ and TYPE $=0$, a total cross section is calculated for each of the $G$ neutron energy groups; $v i z .$,

$\sigma_{Y, g}=\int_{E_{B}^{-}}^{E_{g}^{+}} d E \emptyset(E) \sigma_{r}(E) \quad(8=1,2, \ldots, G)$ 
where $\sigma_{r}(E)$ is the absorption cross section and $\emptyset$ (E) is the normalized welghting function. The upper and lower energy bounds of the gth group are $\mathrm{E}_{\mathrm{g}}^{+}$and $\mathrm{E}_{\mathrm{g}}^{-}$. Note that $\mathrm{E}_{\mathrm{g}}^{+}$is the same as $\mathrm{E}_{\mathrm{g}+1}^{-}$.

Both $\sigma(E)$ and $\sigma_{r}(E)$ are tabulated as linear segments on $\log -10 \mathrm{~g}$ plots so that the integral in Eq. (47) can be performed exactly. The energy range $E_{g}^{-}$to $E_{g}^{+}$is divided into $I$ smaller intervals determined by the values of $E_{j}$ and $E_{k}$ at which the cross sections and fluxes, respectively, are tabulated. Equation (47) can then be written

$$
\sigma_{r, 8}=\sum_{i=1}^{I} \int_{E 1_{1}}^{E 2} d E_{1} \sigma\left(E_{1}\right) \sigma_{r}\left(E_{1}\right)
$$

where the low energy boundary $\mathrm{E} 1_{1}$ of the first interval is $\mathrm{E}_{\mathrm{g}}^{-}$and the $\mathrm{h}$ igh energy boundary $\mathrm{E}_{\mathrm{I}}$ of the Ith group is $\mathrm{E}_{\mathrm{g}^{+}}^{+}$As shown in Sec. II, the expression for the fiux in any one of the Intervals such that $E_{k}<E_{i}<E_{k+1}$ can be written

$$
\phi\left(E_{1}\right)=e^{P_{1}} E_{1}^{x_{1}} \text {, }
$$

where

$$
x_{1}=\frac{\ln \left(\theta_{k+1} / \theta_{k}\right)}{\ln \left(E_{k+1} / E_{k}\right)}
$$

and

$$
P_{i}=\ln \left(\phi_{k}\right)-x_{i} \ln \left(E_{k}\right)
$$

SImilarly, for $\sigma_{r}\left(E_{i}\right)$ in the range $E_{j}<E_{i} \leqslant E_{j+1}$,

$$
\sigma_{r}\left(E_{1}\right)=e^{S_{1}} E_{1}^{Y_{1}}
$$

where

$$
Y_{1}=\frac{\ln \left(\sigma_{j+1} / \sigma_{j}\right)}{\ln \left(E_{j+1} / E_{j}\right)}
$$

and

$$
S_{1}=\ln \left(\sigma_{j}\right)-Y_{1} \ln \left(E_{j}\right)
$$

Note that $P_{1}, S_{1}, X_{1}$, and $Y_{1}$ are constante. Thus,

$$
\begin{aligned}
\mathrm{INT} \equiv & \int_{E 1_{1}}^{\mathrm{E} 2} d E_{1} \theta\left(E_{1}\right) \sigma_{r}\left(E_{1}\right)=\int_{E 1_{1}}^{E 2} d E_{1} e^{P_{1}} \\
& \times E_{1}^{X_{1}} e^{S} E_{1}^{Y_{1}}=e^{P_{1}+E_{1}} \int_{E 1_{1}}^{E 2} d E_{1} E_{1}^{X_{1}+I_{1}}
\end{aligned}
$$

In the case $x_{1}+y_{1}+1=0$,

$$
I N T=\left.e^{P_{1}+S_{1}}\left[\ln \left(E_{1}\right)\right]\right|_{E 1_{1}} ^{E 2}
$$

When $x_{1}+y_{1}+1 \neq 0$.

$$
I N T=\left.e^{P_{1}+S_{1}} \frac{E_{1}^{X_{1}+Y_{1}}}{x_{1}+Y_{1}+1}\right|_{E 1_{1}} ^{E 2}
$$

The total integral is the sum of the integrals over the I smaller Intervals. As we have seen, the integrals for $\sigma_{r, g}$ are performed exactly; no numerical approximations have been made. of course, the groupaveraged total cross section is no more accurate than the representation of the experimental data as found in the LAMDF.

\section{Scattering Computed Using Angular Distributions}

The cross sections for scattering reactions must be averaged over both incoming and outgoing energfes. For elastic $(I D=2)$ and discrete inelastIc $(5 \leqslant I D \leqslant 14$ and $51<I D \leqslant 80)$ reactions, there 1s one outgoing neutron for every incident natron, and a definite relationship exists between the cosine of the scattering angle and the energy of the outgoing neutron. For these reactions we calculate Legendre components of the cross section for scattering neutrons from Incident energy group 8 to scattered group $\mathrm{g}^{\circ}$, where $\mathrm{g}^{-}<\mathrm{g}$. Upacattering in energy of the neutrons is not allowed, although It would be relatively simple to add to the code if it were needed. 
The Integral expression to be evaluated is

$$
\begin{gathered}
\sigma_{r, \mathrm{n}, 8,8^{-}}=\int_{\mathrm{g}} d E \sigma(E) \sigma_{\mathrm{r}}(E) \int_{\Delta \mu\left(E, g^{-}\right)} d \mu \\
\times T(\mu, E) P_{n}\left(\mu_{L}\right)
\end{gathered}
$$

whine $\Delta \mu\left(E, B^{-}\right)$is the angular range allowed for sce.tered neutrons having energies within the bounds of the $g^{\text {th }}$ group. Here, as before, $\theta(E)$ and $\sigma_{r}$ (E) are the weighting $f 1 u x$ and the cross section, $\mu_{L}$ is the siattering cosine in the laboratory system, $P_{n}\left(\mu_{L}\right)$ is the Legendre polynomial of order $n, T(\mu, E)$ is the angilar diatribution, and $\mu$ is the scattering cosine in whichever system $T(\mu, E)$ is specified. The abbreviation

$$
\int_{8} \int_{8}^{E_{8}^{+}}
$$

has been used in Eq. (58) and will be used throughout. It is claar that for the lowest energy group $\left(g^{-}=i\right), \mu_{m i n}=-1.0$, and $\mu_{\max }$ cannot exceed +1.0 in the highest secondary energy group $g^{\prime}=g$.

The total cross section $\sigma_{r, n, g}$ for reaction $r$ and group 8 is the sum of the cross sections for scattering into group $g$ and all lower energy groups:

$$
\sigma_{r, n, 8}=\sum_{g^{\prime}=1}^{g} \sigma_{r, n, g, g^{\prime}},
$$

which can be written

$$
\begin{aligned}
& \sigma_{r, n, 8}=\sum_{g^{\prime}=1}^{g} \int_{g} d E \phi(E) \sigma_{r}(E) \int_{\mu_{m 1 n}\left(E, g^{\prime}\right)}^{j \max \left(E, g^{\prime}\right)} \\
& \times d \mu T(\mu, E) P_{n}\left(\mu_{L}\right)
\end{aligned}
$$

The fractional number of neutron's of energy $E$ scattered Into secondary energy group $g^{-}$is given by the angular distribution integral

$$
N(E)=\int_{\mu_{\min }\left(E, 8^{\prime}\right)}^{\mu} d \mu T(\mu, E) P_{n}\left(\mu_{L}\right)
$$

In Eqs. (58), (60), and (61) the determination of the 1 imfts on $\mu$ depends on whether the scattering is elastic or discrete inelastic, and these cases must be considered separately. F1rst let us consider some additional general detalls about the evaluation of the integral in Eq. (58).

The integral in energy over the $g$ th group in Eq. (58) is computed in a fashion similar to that for the absorption reactions. The energy range $\mathrm{E}_{g}^{-}$ to $\mathrm{E}_{g}^{+}$is divided into smaller intervals determined by the energies at which the fluxes, cross sections, and angular distributions are tabulated. As in Eq. (48) and those following, let the flux (E) be expressed in the range $E_{k}<\mathrm{E} 1<\mathrm{E}<\mathrm{E} 2<\mathrm{E}_{\mathrm{k}+1}$ is

$$
D(E)=e^{P} E^{X},
$$

let the cross section $\sigma_{r}(E)$ be expressed in the range $E_{\mathrm{J}} \leqslant \mathrm{E} 1<\mathrm{E} \leqslant \mathrm{E} 2<\mathrm{E}_{\mathrm{j}+1}$ as

$$
\sigma_{\mathbf{r}}(E)=e^{S} E^{Y}
$$

and let the angular distributions $T(\mu, E)$ be given at energies $E_{a}$ and $E_{b}$ such that $E_{a}<E 1 \leqslant E<E 2$ $<E_{b}$. Upon substitution of the above expressions, that portion of the integral in Eq. (58) over the energy interval $\mathrm{E} 1 \leqslant \mathrm{E} \leqslant \mathrm{E} 2$ can be written

$$
\begin{aligned}
I N T & =\int_{E 1}^{E 2} d E e^{P} E^{X} e^{S} E^{Y} N(E) \\
& =e^{P+S} \int_{E 1}^{E 2} d E E^{X} E^{Y} N(E) \\
& =e^{P+S} \int_{E 1}^{E 2} d E E^{X} E^{Y} \frac{B(E)}{E}
\end{aligned}
$$

where the angular integral $N(E)$ is defined in Eq. (61). Recall that $P, S, X$, and $Y$ are constants. 
Equation (62c) serves to define B(E). From Eqs.

(61) and (62c) we fur ther define

$B_{0} \equiv B\left(E_{a}\right)=E_{a} \int_{\Delta \mu\left(E_{a}, g^{\prime}\right)} d t T\left(\mu, E_{a}\right) P_{n}\left(\mu_{L}\right)$

and

$B_{1} \equiv B\left(E_{b}\right)=E_{b} \int_{L \mu\left(E_{b}, g^{\prime}\right)} d \mu T\left(\mu, E_{b}\right) P_{n}\left(\mu_{L}\right)$. (64)

The angular integrations are performed only for those energies at which the angular distributions are specified. An approximation is made in assuming that the quantity $B(E)$ at intermediate energy $E$ may be obtained by linear interpolation between the quantities $B_{0}$ and $B_{1}$ at energles $E_{a}$ and $E_{b}$. The following explicit form for $B(E)$ is used:

$E(E)=\frac{B_{0}\left(E_{b}-E\right)-B_{1}\left(E_{a}-E\right)}{E_{b}-E_{a}}$

$$
\left(E_{a} \leqslant E \leqslant E_{b}\right)
$$

Substituting into Eq. (62c) we find that

$I N T=e^{P+S} \int_{E 1}^{E 2} d E \frac{E^{X+Y}}{E} \frac{B_{0}\left(E_{b}-E\right)-B_{1}\left(E_{a}-E\right)}{E_{b}-E_{a}},(66)$

which can be written

$\begin{aligned} \text { INT } & =\left[B_{1}-B_{0}\right]\left\{\frac{e^{P+S}}{E_{b}-E_{a}} \int_{E 1}^{E 2} d E E^{X+Y}\right\} \\ + & {\left[E_{a} * E_{b}\left(\frac{B_{0}}{E_{a}}-\frac{B_{1}}{E_{b}}\right)\right]\left\{\frac{e^{P+S}}{E_{b}-E_{a}} \int_{E 1}^{E 2} d E E^{X+Y-I}\right\} . }\end{aligned}$

The terms in the square and curly braces are combined in SUBROUTINE COEF; the expressions Inside the curly braces are actually evaluated in SUBROUTINE SSUM. Using the notation which is essentially that of the FORTRAN programing, we let

$$
\begin{aligned}
& P S=P+S \\
& X Y=X+Y \\
& E E=E_{b}-E_{a} \\
& A A=B_{1}-B_{0} \\
& B B=E_{a} * E_{b}\left(\frac{B_{0}}{E_{a}}-\frac{B_{1}}{E_{b}}\right)
\end{aligned}
$$

$$
\begin{aligned}
& \text { ASUM }=\frac{e^{P S}}{E E} \int_{E 1}^{E 2} d E E^{X Y} \\
& B S U M=\frac{e^{P S}}{E E} \int_{E 1}^{E 2} d E E^{X Y-1} .
\end{aligned}
$$

Then

$$
\mathrm{INT}=\mathrm{AA} * \mathrm{ASUM}+\mathrm{BB} \text { * BSUM }
$$

Generally,

$$
A S U M=\frac{e^{P S}}{E E} \frac{E 2^{X Y+1}-E 1^{X Y+1}}{X Y+1}
$$

and

$$
B S U M=\frac{e^{P S}}{E E} \frac{E 2^{X Y}-E 1^{X Y}}{X Y}
$$

If $|X Y|<0.001$, then the following approxinations are used:

$$
\text { ASUM }=\frac{e^{P S}}{E E}(E 2-E 1)
$$

and

$$
\mathrm{BSUM}=\frac{\mathrm{e}^{\mathrm{PS}}}{\mathrm{EE}} \ln \left(\frac{\mathrm{E2}}{\mathrm{E} 1}\right)
$$

Furthermore, if $|X Y+1|<0.001$, special attention is given to the evaluation of ASUM, which is rewritten as

$$
A S U M=\frac{e^{P S}}{E E} \int_{E 1}^{E 2} d E \frac{E^{X Y+1}}{E}
$$

The numerator of the Integrand is expanded; 


$$
E^{X Y+1} \approx 1+(X Y+1) \ln (E)+\ldots \ldots
$$

where the first two terms of the expansion are assumed suffictent because $X Y+1 \approx 0$. Hence, ASUM is approximated as

$$
\begin{aligned}
\text { ASUM } & =\frac{e^{P S}}{E E} \int_{E 1}^{E 2} d E[1+(X Y+1) \ln (E)] \frac{1}{E} \\
& =\frac{e^{P S}}{E E} * \ln \left(\frac{E 2}{E 1}\right)\left[1+\frac{X Y+1}{2} \ln (E 1 * E 2)\right]
\end{aligned}
$$

From each small energy interval E1 $<$ E < E2 in the Integral over the gth group, there will be a contribution to the $g^{-}$th group, where $g^{+}=1, \ldots, g$. Therefore, even though it is not explicitly indicated In the notation, quantity $\mathrm{B}(\mathrm{E})$ defined in $\mathrm{Eq}$. (62c) and the constants $B_{0}$ and $B_{1}$ in Eqs. (63) and (64) are depondent on the outgoing group $\mathrm{g}^{\circ}$. In PROGRAM EVXS, $B_{0}$ and $B_{1}$ are arrays $B O$ and $B 1$ Into wh1ch are stored $g$ values of $B\left(E_{a}\right)$ and $B\left(E_{b}\right)$ for each of the $g^{-}$groups. As the range of the incident neutron energy $E$ increases to the point that $E 1=E_{b}$, the values in the $B O$ array are replaced by those in the $B 1$ array, and new values for the $B 1$ array are calculated at some new, higher energy $E_{b}$. If $E$ should exceed $E_{\text {MED }}$, the highest energg for which an angular distribution is given, we continue with the same values of $B_{0}$ and $E_{1}$, letting the interpolation become an extrapolation.

The angular distribution integral in Eq. (61) over the range $\Delta \mu\left(E, G^{\prime}\right)$ is obtained by taking the difference between the two integrals from -1 to $\mu_{\max }$ and $\mu_{\min } ; v 1 z$. ,

$$
\begin{aligned}
N(E) & =\int_{-1}^{\mu} \max ^{\left(E, g^{\prime}\right)} d \mu T(\mu, E) P_{n}\left(\mu_{L}\right) \\
& -\int_{-1}^{\mu_{\min }\left(E, g^{\prime}\right)} \operatorname{d\mu T}(\mu, E) P_{n}\left(\mu_{L}\right) .
\end{aligned}
$$

'The Integrals are not evaluated for these limits explicitly, however. Instead, we calculate a set of Integrals

$$
f_{1}(E)=\int_{-1}^{\mu_{1}} d \mu T(\mu, E) P_{n}\left(\mu_{L}\right)
$$

where $1=0, \ldots$, NINC

and

$$
\mu_{1}=-1+\frac{21}{\text { NINC }}
$$

The integer NINC is the number of intervals into which the scattering cosine range -1 to +1 1s divided, and it is read from the angular distribution record. For $\mu_{1} \leqslant \mu<\mu_{1+1}$

$$
\begin{gathered}
\int_{-1}^{\mu} d \mu T(\mu, E) P_{n}\left(\mu_{I}\right)=E_{1}(E)+\left(\mu-\mu_{1}\right) \\
\times\left[\frac{f_{1+1}(E)-f_{1}(E)}{\mu_{1+1}-\mu_{1}}\right] .
\end{gathered}
$$

Th1s interpolation is carried out in SUBROUTINE FF. There are NIMP $=$ NINC +1 values for both $f_{1}\left(E_{a}\right)$ and $f_{f}\left(E_{b}\right)$ stored in arrays DUTL and DUTP, respectively. The integral over the scattering cosine in Eq. (77) is carried out in SUBROUTINE INTG using Simpson's rule for numerical integration. Simpson's rule is witten

$$
\int_{a}^{b} F(x) d x \approx \frac{b-a}{3 \cdot 2 \cdot m}\left[F\left(x_{0}\right)+4 F\left(x_{1}\right)+2 F\left(x_{2}\right)+4 F\left(x_{3}\right)+\ldots+4 F\left(x_{2 m-1}\right)+F\left(x_{2 m}\right)\right],
$$


where the interval in $x$ from a to $b$ has been divided

Into 2m Intervals, m being an approprlate Integer.

In our case $F(\mu)=T(\mu, E) P_{n}\left(\mu_{L}\right)$. We write

$$
\begin{aligned}
\operatorname{DUTP}_{1} & =f_{1}(E)=\int_{\mu_{0}=-1}^{\mu_{1}} F(\mu) d \mu=\left(\frac{\mu_{1}-\mu_{0}}{3 \cdot 2 \cdot 1}\right) \\
& \times\left[F\left(\mu_{0}\right)+4 F\left(\frac{\mu_{0}+\mu_{1}}{2}\right)+2 F\left(\mu_{1}\right)+\ldots+2 F\left(\mu_{1-1}\right)+4 F\left(\frac{\mu_{1-1}+\mu_{1}}{2}\right)+F\left(\mu_{1}\right)\right]
\end{aligned}
$$

The coefficiont in round braces can be expressed

$$
\frac{\mu_{1}-\mu_{0}}{61}=\frac{-1+\frac{21}{\operatorname{NINC}}-(-1)}{61}=\frac{\operatorname{vinc}}{3} \text {, }
$$

where VINC $=1 /$ NINC. The calculation is arranged in the following way:

$$
\begin{aligned}
\operatorname{DUTP}_{0} & =0.0 \\
\operatorname{DUTP}_{1} & =\frac{\operatorname{VINC}}{3}\left[F\left(\mu_{0}\right)+4 F\left(\frac{\mu_{0}+\mu_{1}}{2}\right)+F\left(\mu_{1}\right)\right] \\
\operatorname{DUTP}_{1} & =\operatorname{DUTP}_{1-1}+\frac{V I N C}{3} \\
& \times\left[F\left(\mu_{1-1}\right)+4 F\left(\frac{\mu_{1-1}+\mu_{1}}{2}\right)+F\left(\mu_{1}\right)\right] .
\end{aligned}
$$

The integrands, as well as the Iimits of integration In Eq. (76), are determined differently depending on whether the reaction represents elastic or discrete inelastic scattering. However, it is assumed that the angular distribution data for these reactions are always given in the center-of-mass system (SYS - 1). The program proceeds as if this were the case, and only a warning message is printed If $S Y S=2$. We consider the elastic and discrete inelastic cases separately.

\section{Elastic Scattering. The first reaction} processed for any material is always the elastic scattering cross section. Thus, for I = 1, ID w11l always be 2, and we can write explicitly the expression for the elastic group-to-group cross section as

$$
\begin{aligned}
\sigma_{1, n, 8,8^{-}} & =\int_{8} d E \Delta(E) \sigma_{Y}(E) \\
& \times \int_{\Delta \mu\left(E, 8^{-}\right)} d \mu T(\mu, E) P_{n}\left(\mu_{1}\right),
\end{aligned}
$$

where $B^{*}+1, \ldots, 8$ and $a=0, \ldots$, mx.

The Integral is carried our over the center-ofanse seatiering cosine $\mu$. The argunant of the Legendre polynonial in Eq. (83)--cosine of the laboratory scattering angle $\mu_{2}-1$ se related to $\mu$ through the expression

$$
\mu_{2}=(1+R 3 \cdot \mu) / \sqrt{R 1+R 2 \cdot \mu} \text {. }
$$

where $\mathrm{R}_{3}=\mathrm{AH}, \mathrm{R2}=2^{\mathrm{NAH}}, \mathrm{R} 1=1+\mathrm{N}^{2}$, $A H=A / 1,00866545$, and $A$ is the atomic wath of the material. The denoninator of the above expresation is tested to avold division by zero. If the quantity Inside the radical 18 less than $0.0001, \mu_{L}$ is set to zero.

The range of $\mu$ allowed for scattering into group $g^{-18}$

$$
\Delta \mu\left(E, 8^{-}\right)=\mu_{\max }\left(E, 8^{\circ}\right)-\mu_{\min }\left(E, 8^{\circ}\right),
$$

where

$$
\left.\mu_{\max }\left(E, 8^{\prime}\right)=\min \mid+1, \frac{1}{E}\left[E_{8^{-}}^{+}+\frac{R 1}{R 2}\left(E_{8^{+}}^{+}-E\right)\right]\right\}
$$

and

$\left.\mu_{\min }\left(E, 8^{\prime}\right)=\max \mid-1, \frac{1}{E}\left[E_{g^{-}-1}^{+}+\frac{R 1}{R 2}\left(E_{8^{-}-1}^{+}-E\right)\right]\right\} \cdot(85)$ 
Thece formulas for the aininis and coximus of the cosine of the scatrering angle can be derived from simple kinmaticy for elaste two-body col11stons as shown in Jackson ${ }^{2}$ and Glesscone, ${ }^{3}$ for example. It is glain that the lower boundery for the higher energy group equals tho upper boundary for the lowar energy grot:p; that $13, L_{m 1 n}\left(E, 8^{\circ}+1\right)$ - Lrax $\left(E, 8^{\circ}\right)$. Furchermore, bin $\left(E, 8^{\circ}\right)=-1$ for $B^{-}-1$. The ecmputation of the lielts is done in SURRCUT INE GETMU.

The values of $T(H, E)$ required as part of the integrand in Eqs. (77) through (82) are detarnined In Function TE. For all energies $E$ such that the probability diatributions are cabulated (pairs of $L_{1}$ and $\left.T\left(L_{1}, E\right)\right)$, IInear interpolation in $:$ is used to deteraine $T(\mu, E)$. Specifically, for $H_{i}<v<w_{i+1}$

$T(\mu, E) \equiv T E-T\left(\mu_{1}, E\right)+\left(\mu-\mu_{1}\right)$

$$
\times\left[\frac{T\left(\mu_{1+1}, E\right)-T\left(\mu_{1} E\right)}{\mu_{1+1}-\mu_{1}}\right] .
$$

The values of $\mu_{1}$ and $T\left(\mu_{1}, E\right)$ are stored in the $T K$ array as described in Sec. II. This function routine can also handle angular distributions expressed In terms of Legendre expansion coefficlents. In this case the TK array contains NF coefficients $F_{n}$ at energy $E$ such that

$T(\mu, E)=\frac{1}{2}\left[1+\sum_{n=1}^{N F}(2 n+1) F_{n} P_{n}(\mu)\right]$.

The Legendre polynomials in Eqs. (77) through (82) with argument $\mu_{L}$ are calculated in FUNCTION PN. It is important to realize that the value of $\mu$ passed to the function through the calling sequence 1s the same $\mu$ over which the numerical integration $1 s$ being carried out. Since $\mu$ and $T(\mu, E)$ are in the center-of-mass aystem, $\mu_{L}$ must be calculated using Eq. (84). If $n=0$, then $P_{0}=1.0$, regardless of the value of $\mu$. Higher order polynomials are calculated using the recurrence relation ${ }^{*}$

\footnotetext{
*Substitution of $l=n \cdot 1$ in Eq. (3-39) an page 106 of Ref. 4 will give Eq. (88) of this report.
}

$P_{n}(\mu)=\frac{(2 n-1) \mu P_{n-1}(\mu)-(n-1) P_{n-2}(\mu)}{n}$.

For $n<2, P_{0}(u)=1.0$, and $P_{1}(\mu)=\mu$.

2. Discrete Inclastic Scacterins. In discrete inclastic scattering reactions, the incident neutron loses a certain anount of energy in the acattering, and the energy lost appears in the target nucleus which is laf in an excited state. The reaction energy $Q_{r}$ is negative, and the cross section for each reaction has a definita threshold energy. There is a will dofined reletionship betwen the scattering angle and the energy of the secondary neutron. These reactions have $S<$ ID $<14$ and $51<$ ID $<80$ and TYPE = 1; provistion has thereby been made for discrete inelastc scattering to as many as 40 excited states of the residual nucleus. The expression for the nth Legendre component of the acatering atrix for the rth reaction appears to be the same as that for elastic scattering:

$$
\begin{aligned}
\sigma_{T, D, 8,8^{-}} & =\int_{B} d E(E) \sigma_{F}(E) \\
& \times \int_{\Delta \mu\left(E, 8^{\prime}\right)} d \mu T(\mu, E) P_{n}\left(\mu_{L}\right) .
\end{aligned}
$$

where $B=1, \ldots, G$ and $n=0, \ldots, \operatorname{MMx}$. The evaluetion of this integral proceeds in the same manner as for elastic scattering, but there are some significant differences.

The expressions for $\mu_{\max }\left(E, 8^{\prime}\right)$ and $\mu_{\min }\left(E, 8^{\prime}\right)$ are generalized as follows:

$\mu_{\max }\left(E, g^{\prime}\right)=\min \left|+1, \frac{1}{E^{\star}}\left[E_{B^{-}}^{+}+f \cdot\left(E_{g^{-}}^{+}-E\right)\right]\right|$

$\mu_{m 1 n}\left(E, g^{\prime}\right)=\max \left|-1, \frac{1}{E^{*}}\left[E_{g^{-}-1}^{+}+f \cdot\left(E_{g^{-}-1}^{+}-E\right)\right]\right| \cdot$

The expressions for $f$ and $\mathrm{E}^{*}$ are

$$
f=\frac{1+A M^{2}-\frac{A M(A M+1)\left|Q_{r}\right|}{E A M}+\frac{A M(\overline{A M}+I)\left|Q_{r}\right|}{E}}{2 A M}
$$




$$
E^{\star}=\frac{E \cdot \sqrt{A^{2}-\frac{A M(A H+1)\left|Q_{I}\right|}{E}}}{A M+\frac{A M(A M+I)\left|Q_{L}\right|}{2 E}},
$$

where ANt $=A / 1.00866544$ as previously and $Q_{r} 18$ the reaction energy. In the 1 imit $Q_{I} \rightarrow 0$, which 18 the case for elastic scittering, we see that

$$
f+\frac{1+A M^{2}}{2 A Y}=\frac{R 1}{R 2} \text { and } E^{\star} \rightarrow E \text {; }
$$

In this $11 \mathrm{mit}$ the expressions in $\mathrm{Eq},(90)$ reduce to those in Eq. (85).

The labozatory scattering cosine $\mu_{L}$ is related to the center-of-mass cosine $\mu$ otill using the formula

$$
\mu_{L}=\frac{1+\mu \cdot R 3}{\sqrt{R I+\mu \cdot R 2}}
$$

In FUNCTION PN, but for discrete inelastic scattering we have

$$
R 3=A M \cdot \sqrt{1-\frac{(A M+1)\left|Q_{Y}\right|}{E \cdot A M}} .
$$

At the present time we assume that $T(\mu, E)=0.5$ In the center-of-mass system for all discrete inelastic reactions. The expression for $N(E)$ becomes

$$
\begin{aligned}
N(E) & =\frac{1}{2} \int_{\Delta \mu} d \mu P_{n}\left(\mu_{L}\right) \\
& =\frac{1}{2} \int_{\Delta \mu} d \mu_{L} \frac{d \mu}{d \mu_{I}} P_{n}\left(\mu_{L}\right)
\end{aligned}
$$

In practice, we proceed to evaluate the Integral as shown in Eq. (94a) using Simpson's integration as discussed in connection with elastic scatiering.

In Eqs. (63) and (64) we defined two quantities $B_{0}$ and $B_{1}$ at energles $E_{a}$ and $E_{b}$ for which angular Jistributions were given. For discrece Inelastic reactions we do not use angular distribution data from the 11brary, but asaume isotropic scattering in the center-of-mass systen at all energies. To wake our Integration procedure work, ve still need NED energiea at which to evaluate Eq. (94a). This special set of energies is calculated in subrourine FINDE.

If $\mathrm{n}=0$, the Integrand in Eq. (94a) is unity, and the Integral is evaluated at only two enersies

$$
E_{1}=\frac{A Y+1}{A H}\left|Q_{x}\right|
$$

the threshold energy, and

$$
E_{2}=50 E_{1}
$$

For $n>0$, a special algorithm is used to yield a set of energies $E_{k}$ with sufficient density to allow the same general Integration scheme to be used as for elastic scattering. It is required that the total number of energles NED be between 4 and 20 . These energies are calculated in SUBROUTIME FINDE as follows:

$$
\begin{aligned}
& E_{1}=\frac{A M+1}{A N}\left|Q_{I}\right| \\
& E_{2}=E_{1} \cdot \operatorname{nin}\left[1+\frac{0.05}{\pi+1}, \frac{A M^{2}}{A M^{2}-1}\right] \\
& E_{3}=\left(1+\frac{0.05}{n+1}\right) E_{2}, \\
& E_{4}=\left(1+\frac{0.05}{n+1}\right) E_{3} \\
& E_{5}=E_{4}^{2} / E_{1} \\
& : \\
& E_{N E D}=E_{N E D-1}^{2} / E_{1}
\end{aligned}
$$

such that $\mathrm{E}_{\mathrm{NED}-1}<15 \mathrm{MeV}<\mathrm{E}_{\mathrm{NED}}$ and $4<\mathrm{NLD}<20$. In computing the integral over the gth group in Eq. (89), recall that the energy range $\mathrm{E}_{\mathrm{g}}^{-}$to $\mathrm{E}_{\mathrm{g}}^{+}$is divided Into smaller Intervals deterwined by the energies at which the fluxes, cross sections, and angular distributions are tabulated. The boundaries of each small energy interval are E1 and E2, as in Eq. (62). In the diacrete Inelastic integrations, it is required that E2 shall be large enough that

$$
\mathrm{AM}^{2}>\frac{A M(\mathrm{AM}+1)\left|Q_{\mathrm{I}}\right|}{\mathrm{E} 2} ;
$$


otherwive, the Integral from E1 to E2 1s set to zero. Th1s 1s really just another way of insuring that the range of integration is above the threshold energy for the reaction and that any integral below the threshold 1a eliminated.

\section{Scattering Computed by Laws}

Monelastc reactions are those for which there 18 no direct relationship between the scattering angle and the energy of the secondary neutron. The energy distribution of secondary neutrons $18 \mathrm{de}-$ scribed instead in terms of the fractional probability that a neutron of incident energy $E$ will produce neutrons of en:argy $E^{\prime}$. The nonelastic reactions in the LAMF have identification numbers $15<$ ID $<31$, of which the fission reactions with $18<$ ID $<21$ are a subset. For f1ssion reactions not only the total cross section is calculated for each group, but in addition the fission fractions and the average number of neutrons per fission are calculated. For all other nonelastic reactions, a scattering matrix is calculated.

1. Nonelantic Scattering Matrices. For a nonelastic reaction $x$ with TYPE $>0$ and $15<$ ID $<17$ or $22<$ ID $<31$, the expression for the nth Legendre component of the scattering matrix is written

$$
\begin{aligned}
\sigma_{r, n, 8,8^{-}} & =\int_{8} d E \sigma(E) \sigma_{r}(E) \\
& \times\left[N_{r, 8^{-}}-(E) \int_{-1}^{+1} d \mu_{L} T_{r}\left(\mu_{L}, E\right) P_{n}\left(\mu_{L}\right)\right],
\end{aligned}
$$

where $8=1, \ldots, G, g^{-}=1, \ldots, 8$, and $n=0, \ldots$, NMX, the same notation as used in Eq. (58) for elastic and discrete inelastic scattering. The quantity $\mathrm{N}_{\mathrm{r}, \mathrm{g}^{-}}$-(E) represents the fractional number of neutrons scattered into group $\mathrm{g}^{\prime}$ from the $\mathrm{rth}$ reaction Induced by an Incoming neutron of energy $E$. It is an integral over the $g^{\text {th }}$ group of the secondary energy probability distribution $P_{r}\left(E \rightarrow E^{0}\right)$, the fractional probability that for this reaction neutrons of energy $E^{\prime}$ will be produced by an incident neutron of energy E. As discussed in Sec. II.D.2 the function $P_{r}\left(E \rightarrow E^{\prime}\right)$ way be a tabulated function or it may be a definite analytic function for which parameters are given.
The angular distributions $T_{r}\left(\mu_{L}, E\right)$ are always given In the laboratory systen (SYS $=2$ ) for these reactions. The angular integral in Eq. (97) 1s over the full range of $\mu_{L}$ from -1 to +1 ; In compariscn with Eq. (58) there is no $\Delta \mu\left(E, B^{\prime}\right)$ because we are 1gnoring energy-angle correlations. If the angular distribution is given in teras of Legendre expansion coefficients, the angular Integral becones especially simple due to the orthogonality of the Legendre polynomials as discussed in Sec. II.D.3. When the angular distribution $T_{r}\left(\mu_{L}, E\right)$ is tabulated as a function of the scattering cosine $\mu_{L}$, we first calculate the $F_{n}(E)$ before proceeding to the integration In energy over group 8 . Specifically, for each of the NED energies at which $T_{r}\left(\mu_{L}, E\right)$ is tabulated, we expand the angular distribution as

$T_{r}\left(\mu_{L}, E\right)=\frac{1}{2}\left[1+\sum_{n=1}^{\max }(2 n+1) F_{n}(E) P_{n}\left(\mu_{L}\right)\right]$.

Then

$$
F_{n}(E)=\int_{-1}^{+1} d \mu_{L} T_{r}\left(\mu_{L}, E\right) P_{n}\left(\mu_{L}\right)
$$

precisely the integral over scattering cosine we find in Eq. (97). The procedure used in SUBROUTINE TININ for evaluating the above Integral is interest1ng. Because we work with one resction at atine and because we evaluate the Integral separately for each reaction $r$ and energy $E$, we can drop the explicit reference to $E$ and $r$ in the following discussion. We also drop the subscript $L$ on $\mu_{L}$ for convenience. It 18 assumed that linear interpolation 18 adequate to describe the angular diatribution $T_{r}(\mu)$ between the angles at which it is tabulated. Thus

$$
\begin{aligned}
T(\mu) & =\frac{\mu_{f} T\left(\mu_{j-1}\right)-\mu_{j-1} T\left(\mu_{f}\right)}{\mu_{j}-\mu_{j-1}}+\frac{T\left(\mu_{f}\right)-T\left(\mu_{j-1}\right)}{\mu_{j}-\mu_{j-1}} \mu \\
& =\alpha+\beta \mu \quad\left(\mu_{j-1}<\mu<\mu_{j}\right) .
\end{aligned}
$$

One sma1l part of the Integral in Eq. (99) 18 approxImated 


$$
\begin{aligned}
& \int_{\mu_{j-1}}^{\mu_{j}} d \mu \tilde{j}(\mu) P_{n}(\mu)=\int_{t_{j-1}}^{\mu_{j}} d \mu(\alpha+\beta \mu) P_{n}(\mu) \quad(101 a) \\
& =\alpha \int_{\mu_{j-1}}^{\mu_{j}} d \mu P_{n}(\mu)+B \int_{\mu_{j-1}}^{\mu_{j}} d \mu \mu P_{n}(\mu) \cdot(101 b)
\end{aligned}
$$

The first integral in Eq. (101b) is rewritten using Integration by parts:

$$
\int d \mu P_{n}(\mu)=\mu P_{n}(\mu)-\int d \mu \mu P_{n}^{*} \mu .
$$

But

$$
\mu P_{n}^{\prime}(\mu)=P_{n-1}^{\prime}(\mu)+n P_{n}(\mu)
$$

therefore,

$\int d \mu P_{n}(\mu)=\mu P_{n}(\mu)-\int d \mu P_{n-1}^{\prime}(\mu)-\int d \mu n P_{n}(\mu)$,

so that

$$
\int d \mu P_{n}(\mu)=\frac{1}{n+1}\left[\mu P_{n}(\mu)-P_{n-1}(\mu)\right] .
$$

The second integral in Fq. (101b) 1s rawritten using another recurrence relation, again taken from Ref. 4,

$\mu P_{n}(\mu)=\frac{1}{2 n+1}\left[(n+1) P_{n+1}(\mu)+n P_{n-1}(\mu)\right]$.

Thus,

$$
\begin{gathered}
\int d \mu P_{n}(\mu)=\frac{n+1}{2 n+1} \int d \mu P_{n+1}(\mu)+\frac{n}{2 n+1} \\
\times \int d \mu P_{n-1}(\mu) .
\end{gathered}
$$

For each angular interval $\mu_{j-1}<\mu<\mu_{j}$ in Eq. (101b), we calculate the Legendre polynomials $P_{n+1}(\mu), P_{n}(\mu)$, and $P_{n-1}(\mu)$ for $\mu=\mu_{f}$ and $\mu_{j-1}$. Then each Legendre polynomial $P_{m}\left(\mu_{j}\right)$ is replaced by $\int_{\mu_{j-1}}^{\mu_{j}} \mathrm{~d} \mu \mathrm{P}_{\mathrm{m}}(\mu) \quad(\mathrm{j}>1$ and $m-n+1, n, n-1)$

calculated using Eq. (102); Eq. (101b) can then be evaluated as

$$
\begin{aligned}
& \int_{j-1}^{\mu_{j}} d \mu T(\mu) P_{n}(\mu)=\alpha \int_{\mu_{j-1}}^{\mu_{j}} d \mu P_{n}(\mu)+\frac{n+1}{2 n+1} \\
& \quad \times \beta \int_{\mu_{j-1}}^{\mu_{j}} d \mu P_{n+1}(\mu)+\frac{n}{2 n+1} \beta \int_{\mu_{j-1}}^{\mu_{j}} \\
& \quad \times d \mu P_{n-1}(\mu)
\end{aligned}
$$

These contributions to the total integral over $\mu$ from -1 to +1 are calculated and sumed to give the Legendre expnnsion coefficlent $F_{n}(E)$ in Eq. (99). If no angular distribution is spectfied, 1.e., if TIDR $_{I}<0$, then the angular distribution 18 assuaed 1sotropic in the laboratory system and the Legendre expansion coefficient $F_{n}(E)$ is

$$
\begin{aligned}
F_{n} & =\int_{-1}^{+1} d \mu_{L} \frac{1}{2} P_{0}\left(\mu_{L}\right) P_{n}\left(\mu_{L}\right)=\frac{2}{2 n+1} \frac{1}{2} \\
& \times \delta_{n, 0} .
\end{aligned}
$$

In Eq. (99) we replaced $T_{r}\left(\mu_{L}, E\right)$ by $1 / 2$; the factor $P_{0}\left(\mu_{L}\right)=1.0$ has been inserted to enphasize tite use of the orthogonality relationship for Legendre polynomials. From Eq. (105) we have $F_{0}=1.0$ and $F_{n}=0.0$ for $n>0$, which is as we expect for an 1sotropic distribution. Of course, for all angular distributions, 1sotropic or not, $F_{0}(E)=1.0$. Equation (97) can be rewritten as

$\sigma_{r, n, g, g^{-}}=\int_{g} \mathrm{dE} \phi(E) \sigma_{r}(E) N_{r, g^{-}}(E) E_{n}(E)$

to emphasize that we use the Legendre expansion coefficients in the integral over energy $E$. As with the absorption integrals, the integration over energy 
E 1s performed numerically be suming the integrals over I smaller Intervals in group $\mathrm{g}$. The lower and upper bounds of the I smaller Intervals are determined by the energies $E_{j}$ and $E_{k}$ at which the cross sections and fluxes, reapectively, are tabulated. In addition the Intervals are subdivided at whatever incident neutron energies $E_{m}$ the secondary angular distribution data are given. Let $\mathrm{El} 1_{1}$ and $E 2$ be the lower and upper energy boundaries of one of the I intervals. The restrictions just discussed on the boundary $11 \mathrm{mits} \mathrm{E} 1_{1}$ and $\mathrm{E} 2$ can be summarized by the promiscuous expression

$$
\begin{aligned}
E_{\mathrm{m}} & <\mathrm{E}_{\mathrm{k}}<\mathrm{E}_{\mathrm{j}}<\mathrm{E1_{1 }}<\mathrm{E}<\mathrm{E2} \mathrm{I}_{1}<\mathrm{E}_{\mathrm{j}+1}<\mathrm{E}_{\mathrm{k}+1} \\
& <\mathrm{E}_{\mathrm{m}+1} .
\end{aligned}
$$

Equation (106) is approximated as

$$
\sigma_{r, n, 8,8^{-}}=\sum_{1=1}^{I} N_{r, 8^{-}}^{1}\left(E_{m}\right) F_{n}\left(E 2_{1}\right) \int_{E 1_{1}}^{E 2}
$$

$$
\times d E \phi(E) \sigma_{r}(E)
$$

The Legendre expangion coefficlent $F_{n}$ is obtalned at energy E2 1 by Iinear interpolation between the NED energies at which the coefficlents are avallab1e. If $\mathrm{E2}{ }_{1}$ 1g less than $\mathrm{E}(1)$, the first energy at which the angular distribution data are given, then $F_{n}\left(E 2_{1}\right)=0.0$. On the other hand, if $E 2_{1}>E(F E D)$, then $F_{n}\left(E 2_{1}\right)=F_{n}(E(N E D))$. The asouption that $F_{n}$ (E) Is approximately constant over the energy interval E1 1 to $\mathrm{E} 2{ }_{1}$ is made because the $F_{n}$ (E) are slowly varying iunctions, interpolated between energles much more widely spaced than the separation between E1 and E2. This situation is Insured by requiring that E2 $1<100 \mathrm{El}_{1}$; on the surface this wight appear to be no restriction at all, but recall that the energies $E(1)$ and $E(N E D)$ are separated by several decades. The simple linear Interpolation is carried out in FUNCTION TINEL.

In Eq. (108) an additional superscrlpt 1 has been added to the quantity $\mathrm{N}_{\mathrm{r}, \mathrm{g}}^{1}-\left(\mathrm{E}_{\mathrm{m}}\right)$. Th1s $1 \mathrm{~s}$ ignificant because 1 t 18 an indication of the special way in which the secondary energy distribution data in the ESJ block are handled. The data and/or parameters for the various laws are given for several incident neutron energles $E_{m}$; these are read in SUBROUTINE FTBLN which sets them up for use in the energy range $E_{\mathrm{m}}<E<E_{m+1}$ as indicated in Eq. (107). There are no contributions to the integral for energies less than $E_{m=1}$, the energy of the first sublist. At all energles above the highest energy $E_{M}$ in the ESJ block, the sublist corresponding to $E_{M}$ is used. Thus, for all intervals such that

$$
\mathrm{E}_{\mathrm{m}}<\mathrm{E} 1_{1}<\mathrm{E} 2_{1},<\mathrm{E}_{\mathrm{m}+1} \text {, }
$$

the same sublist in the ESJ block is applicable. Note that $1^{-}$may be greater than 1 . For each of the several intervals 1 to $1^{\prime}$ in the energy range of this sublist, $\left.\mathrm{N}_{\mathrm{r}, \mathrm{g}}^{1}-\mathrm{E}_{\mathrm{m}}\right)$ is reevaluated using $E=\left(E 1_{1}+E 2_{1}\right) / 2$, the average energy over the Interval. For certain laws, Law 1 for example, $N_{r, 8}^{1}\left(E_{m}\right)=N_{r, g}^{1}-\left(E_{m}\right)$ because the probability ener3y distribution is independent of the incident neutron energy $E$. On the other hand, for Law $5, \mathrm{~N}_{r, g^{-}}^{1}\left(E_{w}\right)$ $+N_{r, g}^{1}-\left(E_{m}\right)$ because $g\left(E, E^{-} / E^{q}\right)$ will vary depending on the value of $E$. New values of $N_{r, g}^{1}-\left(E_{m}\right)$ are calculated in SUBROUTINE NUMBR for each integration Interval in Eq. (108).

As we did in Eq. (48) and those following, let the $f l u x G(E)$ and the rth reaction cross section $\sigma_{r}(E)$ be expressed

$$
Q(E)=e^{P} E^{X} \quad \text { and } \quad \sigma_{r}(E)=e^{S} E^{Y}
$$

Then Eq. (108) 1s written

$$
\begin{aligned}
\sigma_{r, n, 8, B^{-}} & =\sum_{1=1}^{I} N_{r, B^{-}}^{1}\left(E_{m}\right) E_{n}\left(E 2_{1}\right) \\
& \times\left[e^{P_{1}+S_{1}} \int_{E 1_{1}}^{E 2} d E E^{X_{1}+Y_{1}}\right]
\end{aligned}
$$

The term in the square brace in Eq. (110) is written 


$$
\begin{aligned}
& e^{P P_{1}+S_{1}} \int_{E 1_{1}}^{E 21} d E E^{X_{1}+Y_{1}}=\left(E 2_{1}-E 1_{1}\right) \\
& \times\left[\frac{e^{P_{1}+S_{1}}}{E 2_{1}-E 1_{1}} \int_{E 1_{1}}^{E 21} d E E^{X_{1}+Y_{1}}\right],
\end{aligned}
$$

where the term in curly braces is the expression for ASTM In Eq. (68) except that $E_{b}$ and $E_{a}$ have been replaced by $E 2_{1}$ and $E 1_{1}$. The term in the square brace is eveluated in this way for every interval.

2. Fiasion Reactions. Fission renctions are a special subset of the nonelastic reactions; they have Identification numbers $18<$ ID $<21$, although at this time only reactions with ID -18 and 19 are handled by PROGRAM EVXS as mentloned in Sec. II.D.2 under Law 7. These fission ractions have TYPE - 0 as a matter of convention. The total fission cross section is calculated

$\sigma_{r, n, B}=\int_{g} d E \phi(E) \sigma_{r}(E) \int_{-1}^{+1} d \mu_{L} T_{r}\left({ }^{\prime} L_{L}, E\right) P_{n}\left(\mu_{L}\right)$, aad because it 18 assumed that $T_{T}\left(\mu_{L}, E\right)=0.5$,

$$
\sigma_{r, n, 8}=\int_{g} d E(E) \sigma_{r}(E)
$$

for $n=0$ only; $\sigma_{r, n, g}=0.0$ for all $n>0$. The flssion spectrum $X_{g}$ is calculated from the secondary energy dietribution data specifled by the lawe, uqually Law 3 or Law 7;

$$
X_{8}=\int_{g} d E^{\prime} P\left(E+E^{\prime}\right)
$$

where $X_{g}$ represents the fraction of fission neutrons having energy in the gth group. This vector is Independent of the Incident neutron energy $E$. Provision has been made in the code for fission fractions $X_{g, g}$ - dependent on the Inconing energy spectrum as well. Instead of a vector with $G$ elements we have a $G \times G$ matrix (atored in block SS) which can be printed on input option. In addition to the secondary energy diatribution data which are used to calculate the $X_{g}{ }^{\prime} B$, the ESJ block contalns a serles of energy, $V$ pairs used in calculating the integral

$$
\left(U \sigma_{r}\right)_{g}=\int_{g} d E g(E) \sigma_{r}(E) v(E)
$$

From Eqs. (111) and (113) one can calsulate

$$
(\bar{v})_{g}=\frac{\left(v \sigma_{r}\right)^{g}}{\left(\sigma_{r}\right)^{g}}
$$

the average number of neut:ons per fission in the gth group. Equartons (111) and (113) are evaluated following the same procedure described for other reactions. The energy interval $\mathrm{E}_{\mathrm{g}}^{-}$to $\mathrm{E}_{\mathrm{g}}^{+}$is broken Into many small intervals determined by the energles at which the cross sections, fluxes, and $v$ are tabulated. These integrals can be evaluated without approximation, because all of the quantities are tabulated as linear segments on log-log plots.

3. Additional Comments About the Laws. For all nonelastic reactions there must be entries in the ESJ array from which are calculated the energy distributions of secondary neutrons. For fission reactions the cross section record contains not only the ESJ values but also pairs of values of $E$ and $V(E)$ from which group-averaged values of the average number of neutrons per fission are obtalned. It remains to discuss in detall how the $\mathrm{N}_{\mathrm{r}, \mathrm{g}^{-}}\left(\mathrm{E}_{\mathrm{m}}\right)$ and the $X_{g}$ mentioned in the previous section are calculated.

For each of the 1 energy Intervals into which the gth energy group has been subdivided, $g$ values of the factor $N_{r, g}^{i}-\left(E_{m}\right)$ are required to give the fraction of the total number of neutrons scattered Into groups $\mathrm{g}^{\prime}=1, \ldots, \mathrm{g}$; these $\mathrm{g}$ factors are stored in the array BO. The steps taken in SUBROUTINE COEF for evaluating the contributions to $\sigma_{r, n, g, g}$. from the 1th energy interval in Eq. (110) are as follows:

(1) Obtain the value for ASUM from SUBROUTINE SSUM.

(2) Multiply ASUM by $\left(E 2_{1}-E 1_{1}\right)$ and store the result in SUM. 
(3) Multiply StM by $F_{n}\left(E 2_{1}\right)$ which is interpolated from the values of $F_{n}$ in FUNCTION TINEL; store the result again in SUM.

(4) Nultiply SUM by each of the 8 factors stored in the BO array and add the results to contributions from the other small intervals which are stored in the XSTM array.

Thus the question concerning the procedure followed in calculating $N_{r, g}^{1}-\left(E_{m}\right)$ amounts to asking how the $g$ numbers in the $B O$ array are calculated.

The sublist in the ESJ array for energy $E_{m}$ is read once in SUBROUTINE FTBLN and used for all energy intervals in the range $E_{m} \leqslant E \leqslant E_{m+1}$. Provision has been made in SUBROUTINE FTBLN for the elght laws described in Sec. II.D.2, and in the following discussion we use the same notation introduced in that section. The parameters correspondIng to the several allowable laws are read and stored in specific arrays for later access by SUBROUTINE NUMBR which is called for each of the 1 small intervals in the larger energy range. In SUBROUTINE NUMBR the first thing done is to zero out the BO array and to calculate for the 1th small interval the average incldent neutron energy $\overline{\mathrm{E}}_{1}$ $=\left(E 1_{1}+E 2_{1}\right) / 2$. The detalls of how the parameters are handled for the various laws will now be out11ned.

Lav 1. For $8^{\prime}=1, \ldots, 8$ we store into $B 1$ $(g)$ the sum of the product of the weight for Law 1 wth the fractions $f_{\ell}$ of neutrons with secondary energies $E_{l}^{-}$such that $E_{g^{-}}^{-}<E_{\ell}^{-}<E_{g^{-}}^{+}$;

$$
B I\left(g^{\prime}\right)=w_{1} \sum_{\ell} f_{\ell} \quad\left(E_{g^{-}}^{-}<E_{\ell}^{-}<E_{g^{-}}^{+}\right)
$$

It is assumed that $\mathrm{E}_{1}^{-}$, the low energy boundary of the lowest energy group, is 0.0 . Furthermore, the entry in the $B 1$ array for the lowest energy group Is adjusted so that

$$
\sum_{g^{\prime}=1}^{g} B 1\left(g^{\prime}\right)=w_{1}
$$

In any case that $\left|\sum_{\ell} f_{\ell}-1.0\right|>0.005$, an error message is printed. Since for Law 1 there is no explicit dependence on the incident neutron energy $E$, the entries in array $B 1$ are simply transferred to the BO array in SUBROUTINE NUMBR.

Law 2. The parameter $D_{\ell}, A_{\ell}$, and $f_{\ell}$ for this law are read in SUBROUTINE FTBLN and stored into the $F 1$ array in the following arrangement:

$$
\begin{aligned}
F 1(1) & =2 \mathrm{D}_{1} \\
F 1(2) & =0.5 \mathrm{~A}_{1} \\
F 1(3) & =\mathrm{w}_{2} \mathrm{f}_{1} \\
\mathrm{~F} 1(4) & =2 \mathrm{D}_{2} \\
F 1(5) & =0.5 \mathrm{~A}_{2} \\
F 1(6) & =\mathrm{w}_{2} \mathrm{f}_{2} \\
& \\
& \\
F 1(3 \ell & -2)=2 \mathrm{D}_{\ell} \\
F 1(3 \ell & -1)=0.5 \mathrm{~A}_{\ell} \\
F 1(3 \ell) & =w_{2} \mathrm{f}_{\ell} .
\end{aligned}
$$

The weight for Law 2 is $w_{2}$. The difference $w_{2}\left(1.0-\sum_{\ell} f_{\ell}\right)$ is added to $F 1(3 \ell)$; if

$\left|\sum_{\ell} f_{\ell}-1.0\right|>0.005$, an error message is printed. In SUBROUTINE NUMBR the quantity $B O\left(g^{\prime}\right)$ is incremented by the amount $w_{2} \mathrm{~F}_{\ell}$ for $\mathrm{E}_{\mathrm{g}^{-}}^{-}<\mathrm{E}_{\ell}^{*}<\mathrm{E}_{\mathrm{g}^{+}}^{+}$and $E_{\ell}^{\prime}=A_{\ell}\left(\bar{E}_{1}-D_{\ell}\right)$. As with Law 1 , It is assumed that $E_{g^{\prime}=1}^{-}=0.0$. If there exists any $l$ such that these conditions cannot be satisfled for $g^{-} \leqslant g$, then an error message is printed. At the risk of repetition, It should be obvious that these contributions to $\mathrm{BO}\left(\mathrm{g}^{\circ}\right)$ change for each sma11 energy interval 1 because of the change in the average energy $\bar{E}_{1}$.

Lawg 3 and 4. For these laws the forms of the sub-sublists in the ESJ array are Identical because the dependence on energy $E$ in Law 4 is introduced through the use of several sublists. Entries in the B1 array which may already be nonzero because of contributions from Law 1 are incremented by the amount $\Delta \mathrm{Bl}\left(\mathrm{g}^{\prime}\right)$ obtained by integrating over the continuous energy distribution. The tabulated function is read in SUBROUTINE FTBLN; the integral 


$$
\triangle B I\left(g^{\prime}\right)=w \int_{E_{g^{-}}^{-}}^{E_{g^{\prime}}^{+}} d E^{-} f\left(E^{\prime}\right)
$$

is performed numerically in SUBROUTINE LAWFR using the simple trapezoldal rule. The weight for Laws 3 or 4 is denoted by $w$ in the above expression. The incegration mesh is determined only by the energy group boundaries and the points at which the function $f\left(E^{\prime}\right)$ is tabulated. Obviously, there are no contributions to the $\Delta \mathrm{BI}\left(\mathrm{g}_{\max }^{\prime}\right)$ at energles above the highest energy for which $f\left(E^{\prime}\right)$ is tabulated. The quantity

$$
\left|\sum_{g^{-}-1}^{g^{\prime} \max } \Delta \mathrm{B} 1\left(g^{\prime}\right)-w\right|
$$

is forced to vanish by adjusting $\Delta \mathrm{B} 1\left(\mathrm{~g}_{\max }^{\prime}\right)$. However, if the quantity inside the absolute value sign is greater than $0.005 \mathrm{w}$, an error message is printed. The index $g_{\max }^{-}$should not be greater than $g$ because $E^{\prime}$ should never be greater than $E$ in the IAMDF. Because we have calculated additions to the $B l$ array, these results are automatically transferred to the $B O$ array when the Bl array is shifted in SUBROUTINE NUMBR.

If Law 3 or 4 is used to describe the energy distribution of fission neutrons, then $g_{\max }^{-}=G$ and the $\triangle B I\left(g^{\prime}\right)$ are transferred to the $S 1$ array in which the fission fractions $X_{\mathrm{g}}$ are stored.

Laws 5 and 6. These two laws are identical in form except that $q=1 / 2$ and 1 , respectively, for Laws 5 and 6 in the expression $g\left(E, E^{-} / E^{q}\right)$; this function is tabulated as a function of $\mathrm{x}$, where $x=E^{-} / E^{q}$. In SUBROUTINE FTBLN we store the tabulated function in array FO as follows:

$$
\begin{aligned}
& F O(1)=0.0 \\
& F O(2)=w \\
& F O(3)=x_{1} \\
& F O(4)=1 / 2 * g\left(E, x_{1}\right) \\
& \vdots \\
& F O(K-1)=x_{I} \\
& F O(R)=1 / 2 w g\left(E, x_{I}\right) \\
& F O(K+1)=-4.0 .
\end{aligned}
$$

Here, $w$ is the welght for elther Law 5 or 6 . If both laws are used, the data for Law 6 follow those for Law 5 in the same format. In SUBROUTINE NUMBR the integral is evaluated numerically in $x$ space between limits $x_{g}^{-}$, and $x_{g}^{+}$, where $x_{g^{-}}^{-}=E_{g}^{-}-/ \bar{E}_{I}^{q}$ and $x_{g^{-}}^{+}=E_{g}^{+}-/ \bar{E}_{1}^{q}$. The integration is carried out from $x_{1}(=F O(3))$ to $x_{\max }$, which is calculated taking into account the $Q$ value for the reaction; since $E_{\max }^{\prime}=\bar{E}_{1}+Q=\bar{E}_{1}-|Q|$, then $x_{\max }=\left(\bar{E}_{1}+Q\right) / \bar{E}_{i} q$. The integrals over each of the $g$ ' groups are stored in the $B 3$ array;

$$
B 3\left(g^{\prime}\right)=w \int_{x_{g^{-}}^{-}}^{x_{g^{-}}^{+}} d x g(E, x)
$$

The values of $\mathrm{B} 3\left(\mathrm{~g}^{\prime}\right)$ are then added to the numbers In the BO array, but only after they have been renormalized so that

$$
\sum_{g^{\prime}=1}^{8} B 3\left(g^{\prime}\right)=w
$$

Law 7. The parameters $\alpha, b, c$, and $E_{f}$ of the generalized fission spectrum as written in Eq. (33) are read in SUPROUTINE FTBLN. Control is Immediate1y transferred to SUBROUTINE NAY where it is required that $\alpha=b=0$. The integral

$$
\begin{gathered}
S 1\left(g^{\prime}\right)=\frac{2}{\sqrt{\pi}} \frac{1}{B^{3 / 2}} \int_{E_{g^{-}}^{-}}^{E_{g^{-}}^{+}} d E^{-} \sqrt{E^{-}} e^{-E^{-} / B} \\
\left(g^{-}=1, \ldots, G\right)
\end{gathered}
$$

is required. As indicated in Eq. (114), the results for $G$ groups are stored directly into the $S 1$ array where the fission fractions $\chi_{g}$ are found. Equation (114) can be rewritten after dropping the primes on $\mathbf{E}$ as

$$
\begin{aligned}
x_{g} \equiv & S I(g)=\frac{2}{\sqrt{\pi}} \frac{1}{B^{3 / 2}} \int_{0}^{E_{g}^{+}} d E \sqrt{E} e^{-\frac{E}{B}}-\frac{2}{\sqrt{\pi}} \frac{1}{B^{3 / 2}} \\
& \times \int_{6}^{E^{-}} d E \sqrt{E} e^{-\frac{E}{B}} .
\end{aligned}
$$


But

$\frac{2}{\sqrt{\pi}} \frac{1}{B^{3 / 2}} \int_{0}^{E} d E^{\prime} \sqrt{E^{\prime}} e^{-\frac{E^{\prime}}{B}}=\operatorname{erf} \sqrt{\frac{E}{b}}-\frac{2}{\sqrt{\pi}} \sqrt{\frac{E}{B}} e^{-\frac{E}{B}}$

so that

$$
\begin{aligned}
x_{8}=\operatorname{erf} & \sqrt{\frac{E_{8}^{+}}{B}}-\operatorname{erf} \sqrt{\frac{E_{8}^{-}}{B}}-\frac{2}{\sqrt{\pi}} \\
& \times\left[\sqrt{\frac{E_{8}^{+}}{B}} e^{-\frac{E_{8}^{+}}{B}}-\sqrt{\frac{E_{g}^{-}}{B}} e^{-\frac{E_{8}^{-}}{B}}\right] .
\end{aligned}
$$

We force the normalization to unity,

$$
\sum_{8} x_{g}=1.0
$$

by calculating the fission fraction for the Gth group as

$$
x_{G}=1.0-\sum_{g=1}^{G-1} x_{B}
$$

The lower energy boundary of the first group $\mathrm{E}_{\mathrm{g}=1}^{-}$is assuned to be 0.0 . Law 7 is used only for fission reactions, and ance SUBROUTINE NUMBR is never called for such reactions, there is no need to provide for that Iaw in the aforementioned subroutine.

Lev 10. There is but one parameter read from the sub-sublist for this law, the quantity a in the expreaston $T=\sqrt{E} / \mathrm{a}$ for use in Eq. $(40)$ and

Eq. (115). In SUBROUTINE FTBLN the weight $w_{10}$ for Law 10 is stored in F2(1) and a 18 stored in F2(2). In SUBROUTIRE MNABR contributions are calculated and added directly to the BO array for each of the $g^{\prime}$ groups: viz.,

$$
\begin{gathered}
\Delta B O\left(8^{\prime}\right) \propto \frac{1}{T^{2}} \int_{E_{8^{-}}^{-}}^{E_{8^{+}}^{+}} d E^{-} E^{-} e^{-\frac{E^{\prime}}{T}} \\
\left(E^{-}-1, \ldots, B\right)
\end{gathered}
$$

Here, as In Laws 5 and 6 , the $Q$ vaiue for the reaction is taken into account when calculating the maxionum allowed value of $E^{\prime}$. Thus $E_{\max }^{\prime}=\bar{E}_{1}+Q$. As Indicated in Eq. (115) the $\triangle B O\left(g^{\circ}\right)$ are proportional to the integral of the evaporation spectrum over the $g^{\prime}$ th group. However, the normalization condition requires that

$$
\sum_{g=1}^{g} \Delta B O\left(g^{\prime}\right)=w_{10}
$$

which leids to the introduction of a normalization factor. It is easy to show uaing Integration by parts that

$$
\frac{1}{T^{2}} \int_{0}^{E} d E^{\prime} E^{-} e^{-\frac{E^{\prime}}{T}}=1-\frac{1}{T}(E+r) e^{-\frac{E}{T}} \text {, }
$$

so that

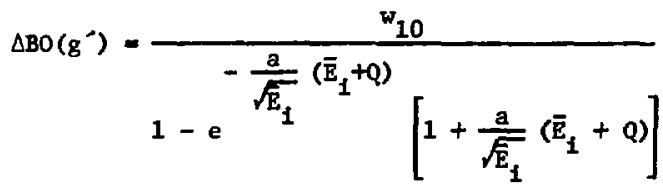

$$
\begin{aligned}
& \times\left\{\left(\frac{a E_{g^{-}-1}^{+}}{\sqrt{E_{1}}}+1\right) e^{-\frac{a E_{g^{-}-1}^{+}}{\sqrt{E_{1}}}}-\left(\frac{a E_{g^{+}+1}^{+}}{\sqrt{E_{1}}}+1\right)^{-\frac{a E_{g}^{+}}{\sqrt{E_{1}}}}\right\}
\end{aligned}
$$

In contemplating $\mathrm{Eq}$. (116) it is well to remember that $\overline{\mathrm{E}}_{1}$ is the average incident neutron energy corresponding to one of the 1 small intervals in the integration over energy $\mathrm{B}$ in Eq. (110). It is the analytic properties of the evaporation spectrum in secondary energy $E^{-}$that allowed us to arrive at the expression for $\triangle B O\left(g^{\prime}\right)$ in closed form as shown here. Again, it is understood that $E_{g_{-1}^{-}}^{-}=0.0$. Finally, we have a provision in the code to care for such cases where there might not be a law specified at all! Parameters for Law 2 are set up in SUBROUTINE FTBLN as follows:

$$
\begin{aligned}
& F 1(1)=-2 * Q \\
& F 1(2)=0.5 / T Y P E \\
& F 1(3)=\text { TYPE }
\end{aligned}
$$


This is equivalent to saying that the total aval1able secondary neutron energy $E+Q$ is distributed evenly among the TYPE secondary neutrons.

\section{E. Transport Approximations and the Cross-Section}

Tables

In Parts A through $D$ of Sec. III we have discussed how, for a single material, the Legendre components of the cross sections for the varlous types of reactions are calculated. The calculations for a single material are not complete, however, unt1l we combine the inultigroup reaction cross sections and scattering matrices into various formats sultable for Input to neutron transport calculations; for example, the DTF-IV format. Although Ref. (5) refers to the DTF-IV transport code, it should be understood that the cross-section format described thereln is widely used and 18 approprlate for many transport codes. This becomes more obvious when it is realized that cross sections with a variety of special corrections can be put into DTF format. To understend the various ways of comblnIng the reaction cross sections, It may be helpful to discuss generally how the multigroup-averaged cross sections are handled once they have been calculated In SUBROUTINE COEF.

The cross sectlons calculated for each reaction in SUBROUTINE COEF and stored In the XSUM array are transferred to the SS array in SUBROUTINE PRTGG. One significant change is made--a change which across the years has been the source of untold confusion for those involved with multigroup processing coles--the cross sections are stored so that group 1 corresponds to the highest energy group and group $G$ to the lowest energy group. All the printed and punched output conforms to this convention, whereas all Input quantities follow the convention that group 1 is the lowest energy group. The number of entries in the SS array varies depending on the type of reaction.

(a) For absorption reactions, only $G$ values of the total cross section $\sigma_{r, g}$ are calculated, and these $G$ values are stored in $S S(K, 1), K=1, \ldots, G$. Any cross section less than $1.0 \times 10^{-6}$ barn 18 set to zero. After these values are printed on the output file MTAP - 2, they are stored Into extended core storage (ECS) for future reference. (b) For elastic, discrete Inelastic, and nonelastic reactions, except fission, a scattering matrix is calculated for each Legendre component $P_{0}$ to $P_{\text {NMAX-1 }}$. The storage array for each scattering matrix is dimensioned $G \times(G+1)$, the first colum beling reserved for the total cross section $\sigma_{r, n, g}$; the second column for the self-scatter cross section $\sigma_{\mathrm{r}, \mathrm{n}, \mathrm{g}, \mathrm{g}}$, and the remaining $\mathrm{G}-1$ colume for the downscatter terms $\sigma_{I, n, g, 8^{-}}$Specifically,

$$
\begin{aligned}
S S(1,1)= & \sigma_{r, n, G}, \text { the total cross section for } \\
& \text { the highest energy group; } \\
S S(1,2)= & \sigma_{r, n, G, G} \text {, the self-scatter term for } \\
& \text { the highest energy group; } \\
S S(1, G+1)= & \sigma_{r, n, G, 1} \text {, the cross aection for } \\
& \text { downscattering from the highest to } \\
& \text { the lowest energy group; } \\
S S(G, 1)= & \sigma_{r, n, 1}, \text { the total cross section for } \\
& \text { the lowest energy group; } \\
S S(G, 2)= & \sigma_{r, n, 1,1}, \text { the self-scatter tern for } \\
& \text { the lowest energy group; } \\
S S(G, j)= & 0.0 \text { for } f=3, \ldots, G+1 \text { because } \\
& \text { these would correapond to upscatter } \\
& \text { terms which are not calculated in } \\
& \text { this code. }
\end{aligned}
$$

It is required that every nonzero entry in the matrix be greater than $1.0 \times 10^{-6}$. The matrix 1s scanned by SUBROUTINE SCAN to determine $1_{\text {max' }}$ the grallest value of $j$, such that for any $1, \operatorname{sS}(1, j)$ - 0 for $j>j_{\max }$. The matrix $\operatorname{sS}(i, j)$ is then printed in the output for $i=1$ to $G$ and $j=1$ to $j_{\max }$. The full SS matrix is transferred to ECS for each Legendre component. In computing traneport-corrected cross sections only the total scattering crose section $\sigma_{\mathrm{r}, \mathrm{MMAX}, \mathrm{g}}$ is calculated for the $\mathrm{P}_{\mathrm{MMAX}}$ Legendre component; this is stored and printed just as though It were an absorption cross section and occupies only $G$ words in the SS array. The total number of ECS storage words required by any reaction for which scattering matrices are calculated 18 , therefore, $G(G+1)$ NMAX $+G$.

(c) For fission reactions three arraye are passed to SUBROUTINE PRTGG from SUBROUTIRE COEF: the $S 1$ array contains the fiseion fractions $x_{8}$ calculated in SUBKOUTINES LAWFR or MAY, the S2 array contains values of $\left(v \sigma_{f}\right)_{g}$, and the $X S U_{M}$ array contains values of $\left(\sigma_{f}\right)_{g}$. Ang values lese than 1.0 $\times 10^{-6}$ in absolute value are set to zero. The 
numbers are stored in three columns of the SS array so that

$\operatorname{ss}(1,1)=\left(\sigma_{f}\right)_{G}, \operatorname{ss}(1,2)=\left(v_{f}\right)_{G}, \operatorname{ss}(1,3)=x_{G}$,
$\vdots$
$\operatorname{ss}(G, 1)=\left(c_{f}\right)_{1}, \operatorname{ss}(G, 2)=\left(w_{f}\right)_{1}, \operatorname{ss}(G, 3)=x_{1}$

Before these three columns of the SS array are stored in ECS, the average value of $v, \bar{v}$, for each group is calculated and $\sigma_{f}, v_{f}, \bar{v}$, and $x$ are printed for each group.

Special attention must be given to the sequence of events tf the fission fractions $X$ are to be dependent on the incident neutron energy $E$. As mentioned in Sec. III.D.2, we would write $X$ as a $G \times G$ matrix representing for any incident neutron group $g$ the fraction of fiseion neutrons with secondary energy $E^{\prime}$ in group $\mathrm{g}^{\prime}$. In the original MaNIAC code the fission fractions $\chi_{g}$ were calculated using the parameters in the ESJ aublist for energy $E_{m}$, where $E_{m}<E_{G^{*}}^{+}$The dependence of $X_{g}$ on incident neutron energy was thereby Ignored--of ten the case In present-generation multigroup processors. This option is still avallable 1n EVXS by setting the input parameter KF = 1. Provision has also been made for a two-dimensional $X$ calculation which is carried out in SUBROUTINE FTBLN after the fission fractions for a particular $E_{m}$ have been calculated in SUBROUTINES LAWFR or NAY. The fission fractions $x_{8,8^{-}}=0.0$ for all $g$ such that $E_{g}^{+}<E_{m=1}$, the first energy for which secondary energy distribution data are given. In the case $\mathrm{E}_{\mathrm{m}}<\mathrm{E}_{\mathrm{g}}^{-}<\mathrm{E}_{\mathrm{g}}^{+}<\mathrm{E}_{\mathrm{m}+1}, X_{\mathrm{g}, \mathrm{g}}$. $=X\left(E_{m}, 8^{\prime}\right)$, where $X\left(E_{m}, 8^{\prime}\right)$ represents the values of the fission fractions calculated using the sublist for $E_{m}$. In cases where $E_{g}^{-}<E_{m}<F_{g}^{+}$, the contributions to $X_{g, g}$-are welghted according to the energy Interval over which the ESJ sublist is applicable. Specifically,

$$
\begin{array}{r}
\chi_{g, 8^{-}}=\chi\left(E_{m-1}, 8^{-}\right) \frac{E_{m}-E_{g}^{-}}{E_{g}^{+}-E_{g}^{-}}+\chi\left(E_{m}, 8^{-}\right) \frac{E_{g}^{+}-E_{m}}{E_{g}^{+}-E_{g}^{-}} \\
\left(E_{g}^{-}<E_{m}<E_{g}^{+}\right) \text {and }\left(g, 8^{-}-1, \ldots, G\right) .
\end{array}
$$

As discussed under Laws 3,4, and 7 in Sec. III.D.3, the $X\left(E_{m}, g^{\prime}\right)$ are normelized so that

$$
\sum_{g^{\prime}=1}^{G} x\left(E_{m}, 8^{\prime}\right)=1.0 .
$$

Therefore,

$$
\sum_{g=1}^{G} x_{g, g^{-}}=1.0
$$

and

$$
\sum_{g=1}^{G} \sum_{8^{-=1}}^{G} x_{8,8^{-}}=G
$$

In SUBROUTINE FTBLN the $x_{g, g}$ - matrix is stored in the ss array. The average value of $\bar{x}_{g}$ - is obtained by averaging $X_{g, g}$ - over the Incoming energy groups represented by the first subscript $g$; viz.,

$$
\bar{x}_{8},-\sum_{8=1}^{G} x_{8,8^{-1 G}}
$$

These values of $\bar{X}_{\mathrm{g}}$ - are stored in the S1 array. In SUBROUTINE PRTGG if KF $=2$, the SS array in which the $x_{g, g}$ - matrix is stored is printed immediately. Then, and only then, are the values of $\left(\sigma_{f}\right)_{g}$, $\left(v \sigma_{f}\right)_{g}$, and $\bar{x}_{g}$ stored into the first three columb of the SS array.

It remains to describe SUBROUTINE FINIS in which the cross sections for all the reactions are read from ECS and combined according to one of three recipes chosen on input option. Then cards are produced in DTF format according to one of several conventions. The procedure for combining the reaction cross sections depends on input parameters IPN and IW4.

(1) If IPN $=1$, consistent $P_{n}$ cross sections are produced.

(2) If IPN -0 and IW4 -0 , transport-corrected cross sections are produced in accordance with the prescription by Bel1, Hansen, and Sandmeler. ${ }^{6}$ 
(3) If IPN $=0$ and IW4 $=1$, the cross bections are transport-corrected in accordance with the practice of Group TD-4 at LASL.

The number of Legendre components, or "tables," calculated depends on the Input parameters ISO and IK. The degree of anisotropy is Indicated by ISO. If $I K=0$, only ISO tables are prepared; if $I K=1$, there w111 be $1+2+\ldots \ldots+$ ISO tables prepared corresponding to all possible degrees of anisotropy from 1 to ISO. The $P_{\mathfrak{n}}$ tables for different values of ISO differ only for transport-corrected cross sections (IPN $=0$ ).

The first table, the $P_{0}$ table, contains values of $\sigma_{a b s}, v \sigma_{f 18 s i o n}$, and $\sigma_{\text {transport }}$, as well as the $P_{0}$ scattering matrix for $\sigma_{\mathrm{g}+\mathrm{g}^{-0}}$ All higher order tables contaln only the scattering matrix for the particular table. The absorption cross section for group 8 is defined as

$$
\begin{aligned}
\sigma_{g}^{a b s} & =\sum_{r=1}^{R} \sigma_{r, 8}^{T Y P E_{I}=n}+\sum_{r=1}^{R}\left(1-\mathrm{TYPE}_{r}\right) \\
& \times \sigma_{r, 0,8}^{\mathrm{TYPE}_{r}>0}
\end{aligned}
$$

Included in the summation are total cross sections for absorption reactions (TYPE - 0) from Eq. (47), total nonelastic scattering cross sections from Eqs. (97) and (59) for $n=0$, and total fission cross sections from $\mathrm{Eq}$. (1II). The downscatter terms of the scattering matr $1 x$ for the $P_{n}$ table are obtained by suming the appropriate terms for each reaction;

$\sigma_{g \rightarrow g^{\prime}}^{n}=\sum_{r=1}^{R} \sigma_{r, n, 8, g^{-}} \quad\left(g^{-}<g\right)$

Equations (119) and (120) hold, regardless of the aaximum degree of anisotropy or the tranaport approximation.

For consistent $P_{n}$ crose sections

$$
\begin{aligned}
& \sigma_{8}^{\text {trensport }} \equiv \sigma_{8}^{\text {total }}-\sum_{r=1}^{R} \sigma_{r, 8}^{\text {TYPE }}=0 \\
& \times \sigma_{r, 0,8}^{\sigma_{r P E}>0},
\end{aligned}
$$

and

$$
\sigma_{8+8}^{n}=\sum_{I=1}^{R} \sigma_{r, n, 8,8}
$$

Thus, the $P_{n}$ table for consistent $P_{n}$ cross sections is the same, regardless of the degree of anisotropy. Note that MMAX > ISO.

For transport-corrected cross aections $\sigma_{g}^{\text {transport }}$ and $\sigma_{g+g}^{n}$ differ depending on the degree of anisotropy $\mathrm{X}$ ( $<$ ISO) and depending, of course, on the method of effecting the transport correction. If IPN $=0$ and IW4 $=0$, the Bell, Hansen, Sendineter 6 approximation for transport correction is used; there

$$
\begin{aligned}
\sigma_{g}^{\text {transport }} & =\sum_{r=1}^{R} \sigma_{r, 8}^{\operatorname{TYPE}_{r}=0}+\sum_{r=1}^{R} \sigma_{r, 0,8}^{\operatorname{TYPE}_{r}>0} \\
& -\sum_{r=1}^{R} \operatorname{TYPE}_{r} \sigma_{r, K, 8}
\end{aligned}
$$

and

$\sigma_{g \rightarrow g}^{n}=\sum_{r=1}^{R} \sigma_{r, n, g, g}-\sum_{r=1}^{R} T Y P E_{r} \sigma_{r, K, B}$

The $P_{n}$ table depends on $K$ because of the $K$ dependeuce in the last summation. For this option Max $>$ ISO. If IPN $=0$ and IW4 $=1$, the tranaportsorrected cross sections are celculated as

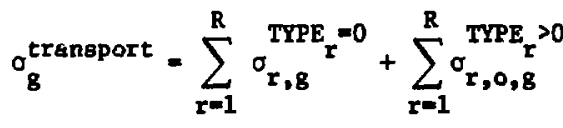

$$
-\sum_{r=1}^{R} \operatorname{TYPE}_{r} \sigma_{r, K, B, 8}
$$

and

$\sigma_{8 \rightarrow 8}^{n}=\sum_{r=1}^{R} \sigma_{r, n, 8,8}-\sum_{r=1}^{R} T_{T P E} \sigma_{r, K, 8,8}$. 
Before they are punched, the cross sections calculated under this option are multiplied by the factor $N / A$, where $N$ is Avogadro's number and $A$ is the atomic mass number. Careful atcention must be paid to the last summation In Eqs. (123a and b). The correction is effected using the self-scacter term for the Kth table and noT the total scattering cross section $\sigma_{r, K, g^{*}}$ Now, EVXS is set up to calculate only $\sigma_{r, n, g}$ for $n$ - NMAX; therefore, to calculate using the $\mathrm{TD}-4$ transport correction it is essential that MMAX $>$ ISO +1 .

The quantities $\sigma_{g}^{a b s},\left(v \sigma_{f}\right)_{g}, \sigma_{g}^{\text {transport }}$, and $\sigma_{g^{-1}-\mathrm{g}}^{\mathrm{n}}$ are calculated one table at a time and stored in arrays SF, STO, and ST1 which then are printed on the output file. Finally, numerical values in these arrays must be arranged in DTF format in preparstion for output in 80-column BCD format. A few detalls concerning the format are in order. Each "table" corresponding to one Legendre component is a matrix consisting of $G$ columns, ITL in length. The table length ITL is specified in the Input; its default value is $G+3$. Within any column corresponding to one of the $G$ groups, we specify IHT, the position of the transport or total cross section, and IHS, the position of the self-scatter cross section. All other entries are positioned relative to these, as shown In Table VIII. Usually, one has IHT $=3$ and IHS $=4$, In which case the upscatter terins, none of which is calculated in EVXS anyway, are eliminated and there are no empty positions at the head of the column. The default value for ITL is $G+3$; if ITL $=G+3$ and IKS $=4$, then $j$ in Table VIII is G - 1, just the length required to include all possible downscatter terms. If ITL and IHS are chosen so that $j<G$ - 1 , the downscattering beyond the 11mits imposed by this table length is handled In one of two ways, depending on Input variable ITBL. If ITBL $=0$, the cross-section matrix is "floored"; no scattering is perwitted below the lowest energy group allowed by the table length and all entrles along the diagonal referring to a single initial group are added to the last-allowed initial group. Thus,

$$
\sigma_{8-j+g}^{n} 18 \text { replaced by } \sigma_{g-j+g}^{n}+\sum_{1>g} \sigma_{g-j+1}^{n} \text {. }
$$

\section{TABLE VIIT}

ONE COLUMN OF A CROSS-SECTION TABLE

$$
\begin{aligned}
& \text { Position Entry * } \\
& 1 \\
& \text { B Blanks } \\
& \text { IHT - } 2 \quad \sigma_{\mathrm{g}}^{\mathrm{abs}} \\
& \text { IKT }-1 \quad\left(v \sigma_{f}\right)_{8} \\
& \text { IHT } \quad \sigma_{8}^{t r} \\
& \begin{array}{cc}
\vdots & \\
\text { IHS - } 1 & \sigma_{\mathbf{g}+1+\mathrm{g}}^{\mathrm{n}}
\end{array} \text { Upscatter terms } \\
& \text { IHS } \quad \sigma_{g+g}^{n} \text { self-scatter term } \\
& \text { IHS }+1 \quad \sigma_{8-1+g}^{n} \\
& \text { IHS }+2 \quad \sigma_{g-2+g}^{n}
\end{aligned}
$$

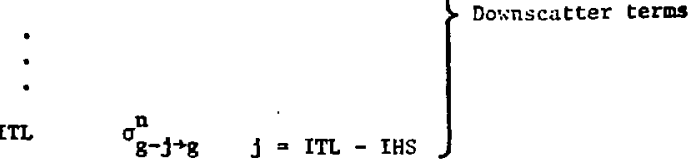

Equation (124) shows the procedure followed for the MANIAC code. If ITBL $=1$, the cross-sections matrix is "truncated" and all scattering below the lowest allowed energy group is treated as absorption so that

$$
\sigma_{g}^{a b s} 1 s \text { replaced by } \sigma_{g}^{a b s}+\sum_{1>g} \sigma_{g-j-1}^{n} \text {. }
$$

In either case neutron balance is maintained. If the sum of the remaining terms below the cutoff, the summations in Egs. (124) or (125), amounts to less than $0.001 \%$ of the transport cross section for that particular group, the cutoff terms are simply 1gnored.

The elements of each scattering table are stored in a column vector ITL $\times G$ in length, ITL numbers for each group as shown in Table vIII. ThIs vector is then written in $B C D$ format (six floating point numbers per card plus sequencing informstion) onto the output tape and onto a scratch file TAPE4. This disk file can then be punched using the PUNCHIT 
control card avallable at LASL or by setting up the PUNCH file in the PROGRAM card and adding the equivalence TAPE4 $=$ PUNCH. For a single table there will be $\left(\operatorname{ITL}^{\star} \mathrm{G} / 6\right)+I$ cards punched. Sometimes, the repetition of many zeroes in the tables results in a rather bulky card output. This problem can be circurvented by use of the ANISN ${ }^{7}$ format; spectal control. flags are punched preceding the repeated numbers to indicate how many times the numbers would be found successively in a vector array. Other special format options are avallable through the IW4 Input flag. These optlons make use of SUBROUTINES PUNREP and PUNCL prepared for use at LASL by Forrest Brinkley of Group T-1.

\section{F. Nonf1ssion Neutron and Gamma Energy Deposition}

In weapons vulnerability and radiation shielding problems at LASL there is interest in material heating caused by nonfission lieutrons and neutronInduced gama rays. To calculate the energy deposition due to Incident neutrons, one must know the Individual reaction cross sections and the $Q$ values for each riaction. This information is included in the heating numbers $\mathrm{H}_{g}$ which are defined such that the product $1, \mathrm{~g}_{\mathrm{g}}^{\mathrm{K}}$ gives the amount of energy deposited by the Incoming neutron beam; $\emptyset_{1,8}$ 1a the neutron flux (neut $/ \mathrm{cm}^{2}$ ) at space point 1 for neutron energy group $8 ; \mathrm{H}_{\mathrm{g}}$ is the heating number for neutron energy group $8 \mathrm{in}\left(\mathrm{cal} / \mathrm{kg}\right.$ per neut $\left./ \mathrm{cm}^{2}\right) \times 10^{-13}$. A complete discussion of the energy deposition problem is available in Refs. (8) and (9), where it Is shown that $\mathrm{H}_{\mathrm{g}}$ for one reaction is calculated

$$
H_{g}=\frac{230.5}{A} \sigma_{r, g} \vec{E}_{g}\left(\frac{\mathrm{cal} / \mathrm{kg}}{\text { neut } / \mathrm{cm}^{2}} \times 10^{-13}\right) \text {; }
$$

$\sigma_{r, g}$ 1s the total reaction cross section, $\bar{E}_{g}$ is the medlan energy for group $g$, and $A$ is the atomic mass. The EvXs code has been modifled to calculate appropriate heatirig terms. The calculations, which are performed in SUBROUTINE SSS, are carried out if IW4 $=$ ?, and IPN = I for any material.

For each reaction the following quantitles are computed and printed for each group:

$$
\begin{aligned}
& f_{r, g}=\sigma_{r, g}^{\operatorname{tot}} * \bar{E}_{g}, \\
& f_{r, q}=\sigma_{r, g}^{\operatorname{tot}} * Q_{r},
\end{aligned}
$$

$$
\begin{aligned}
& \hat{f}_{r, g}=\bar{E}_{g} \sum_{g^{\prime}=1}^{g} \sigma_{r, o, g, g^{\prime}}, \\
& \hat{f}_{r, g}^{\prime}=\sum_{g^{\prime}=1}^{g} \bar{E}_{g}-\sigma_{r, o, g, g^{\prime}}, \\
& f_{r, g}^{\operatorname{tot}}=\frac{230.5}{A}\left[f_{r, g}+f_{r, q}-\hat{f}_{r, g}^{\prime}\right]
\end{aligned}
$$

where $\tilde{E}_{g}$ is the median energy for group $g$ and 16 given in the library as part of the group structure information. The first quantity $\mathrm{f}_{\mathrm{r}, \mathrm{g}}$ is the $\mathrm{B}_{\mathrm{g}}$ number for the reaction multiplied by the factor $A / 230.5 ; f_{F, q}$ represents the energy loss due to the Inelastic nature of the reaction; $\hat{\mathrm{F}}_{\mathrm{r}, \mathrm{g}}^{-}$includes the kInetic energy of the secondary neutrong produced in the reaction. Thus, the quantity $f_{r, g}^{\text {tot }}$ is related to the kinetic energy of the charged particles and gamma rays produced by the reaction. This would be the total energy deposition if all gana rays were aboorbed in the material. After the quantities $f_{r, g}^{\text {tot }}$ have been calculated for all reactlons, they are sumed to give the total energy deposition for all gammas aboorbed; $\mathrm{GA}_{\mathbf{g}}$.

To get an estimate of the amount of energy deposited due to the kinetic energy of the charged particles, we subtract from $\mathrm{GA}_{g}$ a quantity proportIonal to the groupmaveraged gamma energy production cross section, $\mathrm{GI}_{g}$. The array GI is read In to EVXS and multiplied by the factor $230.5 / \mathrm{A}$ to give $\mathrm{GP}_{\mathrm{g}}$. Finally, to obtaln the total energy deposition when all gammas leak out, $\mathrm{GD}_{8}$ is calculated; viz,; $G D_{g}=G_{g}-G P_{g}$. All of these heating quantities are printed in the summary output.

\section{$\because$. DESCRIPTION OF THE CODE}

\section{A. Overa11 Operation}

A diagram Indicating the relationship of the princlpal subroutines in this progran is given in F1g. 3. The subroutines have been arranged on four "levels," depending on the frequency with which they are called; the more frequently called subroutines are placed on a lower level in the figure.

1. EVXS--0verall Control. The overall control of the flow in this code is governed by PROGRA EvXs. The main program serves to define the longth 


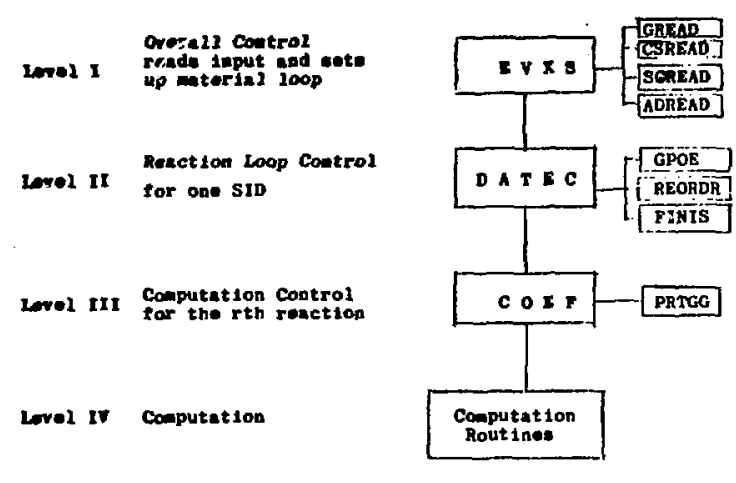

F1g. 3. Arrangement of principal subroutines.

of unlabelled common, of courge, and to set up the necessary disk files. The input data are read to determine for which materlala multigroup cross sectlons are to be calculated and which group structures are desired. The first file of the library is then read by SUBROUTINE GREAD to find the desired group structure sets and to store them into ECS for future use. At this point any group structures that are to be taken from carde are also read by GREAD and stored Into ECS. Materials for which no gromp atructurea are found are eliminated frou the problem after a compent has been printed.

The rest of the main program consists of a large loop over the remining requested materials. The Identification, or SID, number of each of the remining files in the LAMF is read and compared with the SID numbers requested. If there is a mutch, the firat racord of the cross-section file is read by SUBROUTINE CSREAD and the energles at which the cross sections are tabulated are stored into ECS. The cross-aection records for the $\mathrm{R}$ reactione are rend by SUBROUTINE SGREAD and stored Into ECS; finally, the ND angular distribution zecords for meterial SID are read by SUBROUTINE ADREAD and the energies, probability distribution data, and range Indicatora are stored Into ECS. Contrc! is then transferred to SUBROUTINE DATEC which æupervises the group-everaging of the crose sections for all reactions. If there is no match when the Identification nuber SID 1s read from the firet rocurd in the cross-section file, the reasinder of tine file 1 . akipped and the Identification number of the next file is read sgin, watching agaivet the raterials requested. Thus the code procaede through the LARF until multigroup cross sections for all requested materials have been calculated or until the end of the I1brary tape has been reached.

\section{DATEC--Reaction Loop Control for One Mater-}

1al. The control of the multigroup averaging of the reaction cross sections for one material lies In SUBROUTINE DATEC. It reads the appropriate group structure fInm ECS and Calls SUBROUTINE GPOE where the $x_{1}$ and $P_{1}$ of Eqs. (50) and (51) are calculated and stored $1 \mathrm{n}$ arrays $X$ and POE. Next, $a$ loop over all reactions is executed in which the cross bections, the secondary energy distribution data, and the appropriate set of angular distributions for a single reaction are read from ECS into arrays in unlabelled common. Before the crose sections are stored Into the SIG arxay, they are shifted by SUBROUTINE REORDR so that the values are In poattions corresponding to those of the energy array ES. The values for the highest and lowest energies for which the cross sections are defined are excended to the highest and the lowest energies for which the energy wesh is given. These values should normally be zeru but, to handle the log-10g Interpolation, $10^{-20}$ is used. The culculation of the mitigroup-averaged cross sections for each reaction is carried out in SUBROUTINE COEF which is called from DATEC.

After the cross sections for all reactions have been calculated, printed, and stored Into ECS, SUbROUTINE FIMIS is culled; this routine retrievea the group-averaged reaction croas sectione from BCS and bullds up the Legendre components of the scattering tables in DTP ${ }^{5}$ forwat. Five subroutines are celled by FINIS:

(a) SUBROUTINE SCAN checks every scettering table to deterulne which values of the scetterine netrix can be regarded as within the level of aignificance of the wathods used in the code, 1.e., greater in abaolute value than $10^{-6}$ baxa.

(b) SUBROUTINE PRTB printe scatterins tables In the output.

(c) SUBROUTIRE CARDS vrited the acatteriug tables In BCD card 1age fornat on untt LTAP $=4$.

(d) SUBROUTIKES PURREP and PONCL crente special BCD card Inagea approprinte for Input to the AMISN ${ }^{7}$ and DTF 5 loaders. Theae routinea were written by Forreat Brinkley of LASL. 
(e) SUBROUTINE NEKPG restores the page on the output file and prints a page header including the date and the description of the materlal being processed as found in the array SDES (B).

After all the scattering takles have been prepared, control is returned from FINIS to DATEC, where a check 1 s made to see whether calculations with the same SID are to be made with different parameters. If so, the calculation is carried out; if not, control is returned to EVxS.

3. COEF--COmutation Control for one Reaction. The computation of multigroup-averaged cross sections, as discussed in detail in Sec. III, is carried out in SUBROUTINE COEF and 16 other computational routines. In addition to the initial section in which required parameters are set, COEF can be divided into three principal sections whose purposes are to compute absorption reactions, to compute elastic and discrete inelastic reactions, and to compute nonelastic and fission reactions. The particular section to be entered depends on the TYPE and ID for the reaction, as shown in Table $V$ and sumarized in Table $I X$. In the first section we evaluate integrals like those in Eqs. (47) and (48); in the second section we deal with the eva1vation of expressions like Eq. (58); the third section is designed to handle expressions such as that found in Eq. (97). There is one thing common to these different expressions: they all involve integration in incident neutron energy between the group boundaries $E_{g}^{-}$and $E_{g}^{+}$; this is the work accomplished in COEF with the aid of SUBROUTINES SPACE and GSOE. The relationship of SPACE and GSOE to COEF is best understood by referring momentarily to Eqs. (48), (49), (52), and (57); the quantity INT in Eq. (57) is evaluated in COEF, but SPACE deter-

\begin{tabular}{|c|c|c|c|c|}
\hline \multicolumn{5}{|c|}{ 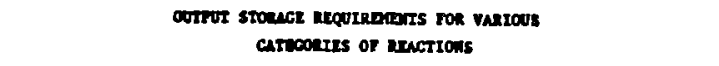 } \\
\hline Centerer & ID & syes & $\begin{array}{l}\text { Ans: Dtet. } \\
\text { Cintet }\end{array}$ & Leragth the \\
\hline Deste & 2 & 1 & Tea & Gopaninx +0 \\
\hline Dfectete Imolente & $\left\{\begin{array}{l}5 \text { thru } 14 \\
51 \text { thru } 80\end{array}\right.$ & 1 & $\omega$ & goposient +6 \\
\hline Jieston & $20,19,20,21$ & $0,1,2$ & mo & 306 \\
\hline Aneoption & 101 thru 108 & 0 & 10 & c \\
\hline nom-aleotic & $\begin{array}{l}15 \text { thru } 17 \\
22 \text { thru } 31\end{array}$ & $1,2,3$ & $\left\{_{100}^{700}\right.$ & $\operatorname{cog}$ Gegp \\
\hline
\end{tabular}

Wetet $G-$ wher of stoups tron group ent GD,

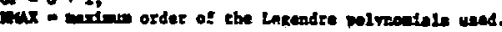

mines the values of $k$ and $f$ such that $E_{k}<E_{1}<E_{k+1}$ and $E_{j}<E_{i}<E_{j+1}$. The quantities $Y_{1}$ and $S_{1}$ defined in Eqs. (53) and (54) are calculated in GSOE once $f$ has been determined in SPACE. The quantities $X_{1}$ and $P_{1}$ of Eqs. (50) and (5I) were previously calculated and stored by DATEC. SUBROUTINES SPACE and COEF are Included among the 16 "compistational routines" mentioned In Fig. 3; only these two routines are called from the first principal section of COEF.

We have seen in Sec. III that Bq. (58) for elastic and discrete inelastic scattering can be reduced to the sum of a series of Integrals over small energy intervals as written In Eqs. (62) and (69). The exprefision for INT is evaluated in COEF., but the components of the expression are evaluated In the computational routines. Referring to the expressions in Eq. (68), we know that $S$ and $Y$ are eva?uated in GSOE; it remalns to review how $\bar{J}_{0}\left(\equiv B\left(E_{a}\right)\right)$ and $B_{1}\left(\equiv B\left(E_{b}\right)\right)$ in Eqa. (63) and (64) are calculated. The range of $\mu$ allowed for scattering Into group $g^{\circ}$ is determined in SUBROUTINE GETM. The Legendre polynomials $P_{n}\left(\mu_{L}\right)$ are calculated in FUNCTION $P N$; the angular distribution function $T(\mu, E)$ is calculated in FUNCTION TE; the NINC integrale for $f_{1}(E)$ as written $1 n \mathrm{Eq}$. (77) are calculated in SUBROUTINE INTG. The Interpolation of the values of $E_{1}$ (E) to $\mu_{\text {min }}$ and $\mu_{\max }$ is carried out in FUNCTION FF. Having obtained the integrals over the range of $\mu, B_{0}$ and $B_{1}$ are calculated in COEF. Quantities ASUM and BSUM are obtalned in sUBRourtive SSUM and the results are conbined in COEF. For discrete Inelastic acattering SUBROUTINE FINDE is used to determine energtes to use as $E_{a}$ and $E_{b}$ according to the formulas in Eq. (95).

The expreasion in Eq. (97) for nonelastic scattering matrices can be rewritten as ahow in Eq. (106) and further approximated as shown in Eq. (110). The expreseion in square braces in Eq. (110) Is evaluated with the ald of ssuk; the Legendre expansion coefficient: $F_{n}$ are obtained at the energiea given in the library from suarouting TININ and Interpolated to energies E2 in Function TINEL. The secondary energy diatribution data are read in SUBROUTINE FTBLN; the fractions $\mathrm{N}_{r, 8}^{1}-(\mathrm{E})$ are calculated In SUBROUTINE NUNBR.

For fiasion reactions the parameters $z$ and $20 \mathrm{E}$ for use in the expreanion 


$$
v(E)=e^{2 O E} E^{Z}
$$

are calculated in SUBROUTINE FISSN. The fission fractions $X_{g}$ may be calculated in SUBROUTINES LAWFR or NAY depending on the parameters read by FTBLN.

The results of the calculations in COEF for each reaction are printed by SUBROUTINE PRTGG for each value of $n$ from 0 to $M M A X$ as they are finished; the results then are stored into ECS for retrieval later by FINIS.

4. Other Routines. SUBROUTINE ERROR is called from subroutines at all levels in the code. There are certain non-ASA standard system routines and functions used in the code. These are SUBRoutinEs DATE1, CPAREA, ECRD, ECKR, EXIT, ERF, ENCODE, and DECODE.

\section{B. Storege Allocation--ECS and COMMON}

Although PROGRAM EVXS is not "varlably dimensloned" according to the 11teral usage of that expresston, large blocks of core in ECS and unlabelled common are used for storing those large arrays whose dimenstons are not known until the arrays are read. It 18 not necessary to provide storage for the "worst" possible needs, but Instead one can plan on a trade-off in the comblnation of grcup structure, cross sections, and output storage demands. The arrays are stored one after another in the large storage block; of course, one must keep track of which location in the large block corresponds to the first word of each array. These location markers are often called "pointers"; they point to the firet word of each array. We consider first the arrangement of data in ECS and then turn to the storage of arrays in block $A(21000)$ in unlabelled common.

The arrangement of data in ECS 1s shown in F1g. 4. The first block contains the Information which is stored Into the IA array when the Irput cards are read by the main program. S1nce NT, the number of cross-gection request cards, may be as large as 20, the IA array requires a block of ECS storage no larger than 200, as indicated under "Coments" in F1g. 4. The group structure Information for every GID requested in the input cards is stored next to ECS. If some GID is requested which does not exist on the 11braxy tape or in the input

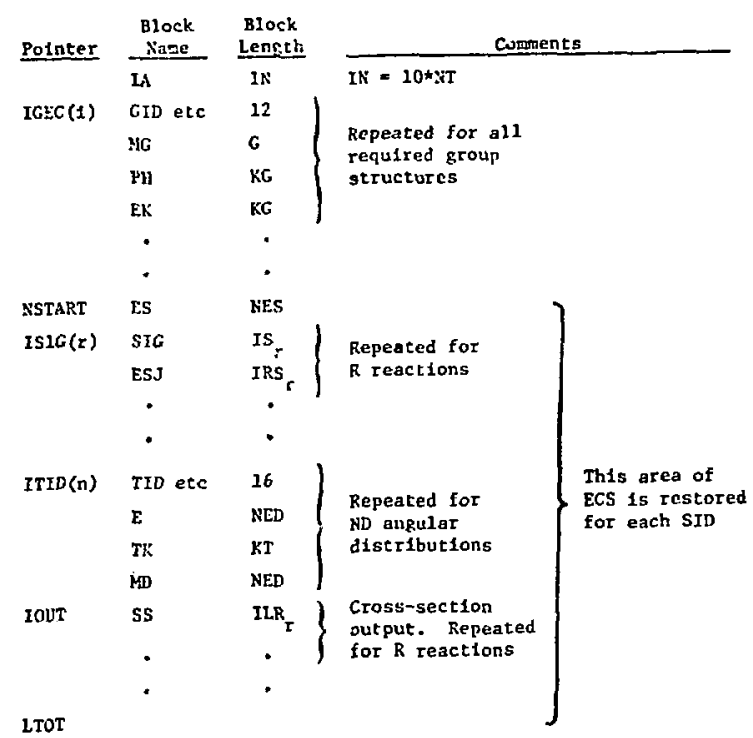

F18. 4. Arrangement of data in extended core storage.

data, the request is Ignored and the program proceeds as though there were NT - 1 materlals to be processed. Each GID requires $2 * K G+G+12$ words of storage, $G$ belag the number of groups and $K G$ the number of flux, energy pairs. The 12 words represented by "GID etc" In Fig. 4 are GID, GDES(8), G, $K G$, and LGID, where LGID $=2 \star K G+G$. The location of the first word GID in the 1th group structure block is saved in IGEC(I). These blocks are stored into ECS in SUBROUTINE GREAD. The order in which the group structure data are stored is not the order In which they are requested but instead the order in which they appear on the 1ibrary tape.

The pointer NSTART marks the first location of storage used for each SID. The library tape is searched until one of the requested materlals is found. In SUBROUTINE CSREAD the first record of the material file 18 read and the NES energies at which the cross sectlons are tabulated are stored into ECS, starting at NSTART. In SUBROUTINE SGREAD the cross-section records for the $\mathrm{R}$ reactions are read and stored Into ECS; the locations of the first words of storage for each record are saved in the ISIG array. Similarly, the angular distribution records are read from the library tape in SUBROUTINE ADREAD and stored Into RCS; the pointer words are saved in the ITID array. The 16 words represented 
by "TID etc" In F1g. 4 are TID, TDES(8), NED, SY, LEG, KT, NINC, LTID, and A. F1nally, ECS locations must be allocated for the output of the calculations. The SS array is the array into which results obcained in SUBROUTINE COEF are stored in SUBROUTINE PRTGG. After the calculations for a given reaction are completed, PRTGG prints the results and stores the contents of SS into ECS. The firat word of storage for the first reaction 18 marked by pointer IOUT. The lengths ILR ${ }_{r}$ of the output blocks for each reaction $r$ ciepend on the type of reaction as sumarized In Table IX. The last word of ECS storage required Is at location LTOT; before the calculations are started, LTOT 18 calculated to be sure that the ECS requested on the JOB card is sufficient. If it is not, LTOT is printed but the calculations are skipped and we proceed to the next SID.

The large AA(21000) array in unlabelled common is used for core atorage of arrays of varlable lengths. The arrangement of the arrays, their lengths, and their pointer words are summarized in Fig. 5. With the exception of the SS array, all of these arrays are stored in SUBROUTINE DATEC. The exception, SS, into which data are written in SUBROUTINE PRTGG, is also an exception in that it is the only doubly dimensioned array. If we recall that LGID $=2 * K G+E$, It can be seen at once that the pointer word IAES $=2$ *LGID +1 . The first IGID words contain the group structure information read back from ECS Into the AA array. Quantities POE and $X$ and $P_{1}$ and $X_{1}$, respectively, of Eqs. (51) and (50); the ESP array contains the values for $E_{g}^{+}$. The ES array contalns the energles at which the reaction

\begin{tabular}{|c|c|c|c|c|c|}
\hline Polnter & $\begin{array}{l}\text { Actay } \\
\text { Name } \\
\end{array}$ & $\begin{array}{c}\text { Array } \\
\text { Lenteb }\end{array}$ & \multicolumn{3}{|c|}{ Cokmente } \\
\hline DrF & HE & G & & \multirow{6}{*}{\multicolumn{2}{|c|}{$\begin{array}{l}\text { For a } \\
\text { particular } \\
\text { GID }\end{array}$}} \\
\hline IPa & FH & $x$ & Thend into core & & \\
\hline $\operatorname{IEx}$ & Ex & xc & & & \\
\hline IPOE & POE & IC & & & \\
\hline $\mathbf{I X}$ & $x$ & $x \in$ & $\begin{array}{l}\text { Conputed in } \\
\text { Datec }\end{array}$ & & \\
\hline IESP & ESP & C & & & \\
\hline Les & ES & ELS & \multirow{2}{*}{\multicolumn{2}{|c|}{$\begin{array}{l}\text { Cront-section enorgic: } \\
\text { Output etorage }\end{array}$}} & \multirow{7}{*}{$\begin{array}{l}\text { Tor a } \\
\text { perticular } \\
\text { SID }\end{array}$} \\
\hline Iss & sS & $c(c+1)$ & & & \\
\hline IEx & $\boldsymbol{E}$ & IED & Antular & \multirow{5}{*}{$\begin{array}{l}\text { Rentored } \\
\text { for ench } \\
\text { reaction }\end{array}$} & \\
\hline ITR. & TR & $\mathbf{m}$ & dietribution & & \\
\hline סמד & 80 & NED & & & \\
\hline I56 & 316 & IESS & values for $\sigma_{r}$ & & \\
\hline IESJ & IsJ & Ins $_{x}$ & Date for leve & & \\
\hline
\end{tabular}

Fig. 5. Arrangement of data in large common storage array $A$. cross sections are tabulated; array SS continis the group-averaged cross sections which are calculated : In SUBROUTINE COEF. The next three arrays contain the data for the angular distribution set appro- . . priate for reaction $r$, and the crose sections and secondary energy distribution data for reect:on $r$ are given in the last two arrays. The naximin otorage required for any materlal is calculated in EVXS and DATEC; the total is compared with 21000 to Insure the avallability of sufficlent storage in MA.

\section{Definition of Varlables}

A catalog of most variable names introduced in this program and the subroutines in which they are usad is found in this section. Four classes of varlables have been considered: Integers which serve as temporary Indices, counters, or polnters; arraya In which Hollerth data are stored; varlables used for temporary storage; and varlables used more untversally throughout the code.

Integers used locally in various subroutines as temporary Indices, counters, and polnters are. $I, I C$, IER, IG, II, IL, IT, J, K, KR, L, LG, LI, L2, N, MI, N2, and N3.

Arrays In which Hollerith data are stored are listed In Table $X$; the names of the subroutines in which the arrays are used are included in parentheses following the array name.

\section{TABLE $\mathrm{X}$}

ARRAYS CONTAINING HOLLERITH DATA

ASTR (EVXS)
ATMP ( IBLN, LAWE)
FS (ERROR)
FTB (FTBLN)
F1 (ERROR)
F2 (ERROR)
F3 (ERROR)
IALLBK (PUNCL)
IBLNK (PUNCL,CARDS)
IHOLAR (PUNREP)
IHOLB (PUNREP)
IHOLDR (PUNREP)
IHOLL (PUNREP, PUNCL)
IHOLT (PUNREP
IDC (PUNREP)
IPIEGN (PUNCL)
IPISNN (PUNCL)


Certain temporary atorage varlables have been assigned names for conventence. They are 11sted in Table XI; the names of the subroutines in which the variables are used are given in parentheses. For variables in th1s category there is no relationship between quantitles with the same name in different subroutines. The word MANY in parentheses refers not to the name of a subroutine but to the fact that the var1able appears in many subroutines.

TABLE XI

TEPIPORARY STORAGE VARIABLES IN SUBROUTINES

\begin{tabular}{|c|c|}
\hline AR (NUMBR) & $\operatorname{IRP}(\mathrm{SSS})$ \\
\hline BT (COEF, FINIS) & ITEMP (PUNREP) \\
\hline EGG(SSS) & ITERM(PUNCL) \\
\hline EM(FTBLN) & ITLX(EVXS) \\
\hline EP (FTBLN) & IVECR (PUNREP) \\
\hline ESX (LAWFR) & IWI (SSS) \\
\hline ETMP (COEF) & IO (FTbLN) \\
\hline EX (GPOE, GETMU) & JT (INTG, TE) \\
\hline GIN (EVXS, DATEC) & LD (ADREAD) \\
\hline GM(FTBLN) & $M(T E, P N)$ \\
\hline GP (FTBLN) & $\operatorname{MAX}(C O E F, F I N I S)$ \\
\hline ICARDC (PUNCL) & MEC (EVXS, DATEC) \\
\hline ICILD (PUNCL) & $M U(P N)$ \\
\hline IDEL.(SSS) & $\mathrm{N} 1, \mathrm{~N} 2, \mathrm{~N} 33, \mathrm{~N} 4$ (ERROR) \\
\hline IDENC (PUNCL) & $\mathrm{PM}, \mathrm{PP}(\mathrm{TE}, \mathrm{PN})$ \\
\hline IDX(PUNREP) & $\mathrm{PZ}(\mathrm{TE}, \mathrm{PN})$ \\
\hline IDXBLD (PUNCL) & $\mathrm{RQT}(\mathrm{COEF})$ \\
\hline IDXILD (PUNCL) & TERP (EVXS, PRTGG) \\
\hline IDXRLD (PJNCL) & TEST (COEF, SSUM, INTG, PRTGG) \\
\hline IDY (PUNCL) & TL (INTG) \\
\hline ICE (EVXS, DATEC, SSS) & THPI (CETHU) \\
\hline ICX (PRIGG, SCAN, FINIS, SSS) & $\operatorname{TRP} 2$ (GETMU) \\
\hline IGN (PRTGG, SCAY, F IIIIS, PRTB) & TN (NOMBR) \\
\hline IGT(FINIS) & TII (NUNiBR) \\
\hline IG4, IG5 (FINIS) & $\mathrm{II}, \mathrm{T} 2, \mathrm{~T} 3$ (MANY) \\
\hline IH (FF) & T4 (NAY) \\
\hline IHSX (EVXS) & I9 (NUMBR) \\
\hline IHTX (EVXS) & T99 (NUNBR) \\
\hline ILIM(FINIS) & VINC (INTG) \\
\hline ILL (NUMBR, FINIS) & VK(INTG) \\
\hline ILN (FINIS) & $v 1, v 2, v_{3}, v_{4}, v 5, v 6(s S s)$ \\
\hline IPOSCH (PUNCL) & $\mathrm{XN}, \mathrm{XT}$ (MUMBR) \\
\hline IPT (ERROR) & $\mathrm{XX}(F F)$ \\
\hline IREI(SSS) & $\mathrm{X} 1, \mathrm{X} 2, \mathrm{X} 3, \mathrm{X} 4$ (MANY) \\
\hline IKET (INTG) & $\mathrm{YY}(\mathrm{PN})$ \\
\hline
\end{tabular}

By far the largest 11st of names is that for varlables which are common to many subroutines. These vartables may appear in labelled or unlabelled common statements, or they may be transferred through the calling sequences when control is transferred between subroutines. In Table XII the varlables are given, aiong with their storage locations and definitions. The storage is located most frequently in blank or labelled common; local storage is Indicated along with the subroutines in which the variables appear.

TABLE XII

VARLABLES DEFINED UNIQUELY IN PROGRAM EVXS

\begin{tabular}{|c|c|c|}
\hline Name & Scorage Locarion & Definition \\
\hline$A$ & Blank Common & Mass of target gaterial \\
\hline$M$ & Blenk Common & $\begin{array}{l}\text { Block used to store data from } \\
\text { ECS for current material }\end{array}$ \\
\hline $\mathbf{A F}$ & Local FTBLN, NAY & $\begin{array}{l}\text { Input parameter for Law } 7 \\
\text { (currently } 0 \text { ) }\end{array}$ \\
\hline ALP & Local ivXs & Block to contalo Input title card \\
\hline $\mathbf{A M}$ & INT Common & $-A / 1.00866545$ \\
\hline ArP & INT Cousmon & $\approx A S *(A Y+1.0) \star R Q$ \\
\hline AY2 & IHT Cosmon & $-A M^{2}$ \\
\hline ASUH & Local COEF, SSUM & $\begin{array}{l}\text { First part of the Integral for } \\
\text { interval fron El to E2 }\end{array}$ \\
\hline BB & Local COEE & $\begin{array}{l}=E_{j} \star E_{j-1} \star\left(f\left(E_{j-1}\right)-f\left(E_{j}\right)\right) \\
\text { or }{ }^{2} * D_{g}-E 1 * B_{g}\end{array}$ \\
\hline $\mathbf{B F}$ & LOCal FTBLN, NAY & $\begin{array}{l}\text { Input parameter for Law } 7 \text { (cur- } \\
\text { rently 0) }\end{array}$ \\
\hline BSUM & Local COEF, SSUN & $\begin{array}{l}\text { Second part of the Integral for } \\
\text { interval frow El to E2 }\end{array}$ \\
\hline BO & CAPUTE Common & $\begin{array}{l}\text { For elastic and discrete } \\
\text { inelastic: } B(E) \text { for El }\end{array}$ \\
\hline B1 & CYPUTE Common & $\begin{array}{l}\text { For elastic and discrete } \\
\text { inelastic: } B(E) \text { for E2 }\end{array}$ \\
\hline 83 & $\begin{array}{l}\text { CMPUTE COEF, FTBLN } \\
\text { AUMBR }\end{array}$ & $\begin{array}{l}\text { Integral storage block for } \\
\text { Laws } 5 / 6\end{array}$ \\
\hline $\mathrm{CF}$ & LOCAl FTBLN, NAY & $\begin{array}{l}\text { Input parameter for Law } 7 \\
\text { (currently 0) }\end{array}$ \\
\hline DAT & Blunk Common & $\begin{array}{l}\text { Date on which processing is } \\
\text { done }\end{array}$ \\
\hline nF1 & LOCaI COEF & $-F I X-F I N$ \\
\hline DF2 & Local COEF & $-F 2 X-F 2 N$ \\
\hline DUTL & CNPUTE Common & $\begin{array}{l}\text { Integrals over dy for angular } \\
\text { distribution energy } E_{\mathrm{J}-1} \\
\text { (preifous) }\end{array}$ \\
\hline DUTP & GIPUTE Comon & $\begin{array}{l}\text { Integrals over du for angular dis- } \\
\text { tribution energy } E_{j} \text { (current) }\end{array}$ \\
\hline $\mathbf{E}$ & $\begin{array}{l}\text { LOCAI ADREAD, COFF } \\
\text { FINDE, TINEL }\end{array}$ & $\begin{array}{l}\text { Black of engular distribution } \\
\text { energies }(<400)\end{array}$ \\
\hline sc & Local COEF & $\begin{array}{l}\text { Current value of cross-bection } \\
\text { energy }\end{array}$ \\
\hline ED & 1NT Common & $\begin{array}{l}\text { Current yalue of angular dietri- } \\
\text { bution energy }\end{array}$ \\
\hline$\Sigma \mathrm{DL}$ & Lacal COLF & $\begin{array}{l}\text { Previous angular diatribution } \\
\text { energy }\end{array}$ \\
\hline EE & $\begin{array}{l}\text { Local COEF, SSUS } \\
\text { GETMU, MLMRR }\end{array}$ & $\begin{array}{l}\text { Difference between } \ell \text { h of two } \\
\text { energies ( }-E 2 L-E 1 L \text { ) or between } \\
\text { two energiea (-ED - EDL) }\end{array}$ \\
\hline EF & LOCAl COEF, EISSION & $\begin{array}{l}\text { Current energy naximua for fiesion } \\
\text { reaction in computing } v\end{array}$ \\
\hline EG & LOCal GREAD, COEF & $\begin{array}{l}\text { Current energy value for flux } \\
\text { function }\end{array}$ \\
\hline
\end{tabular}




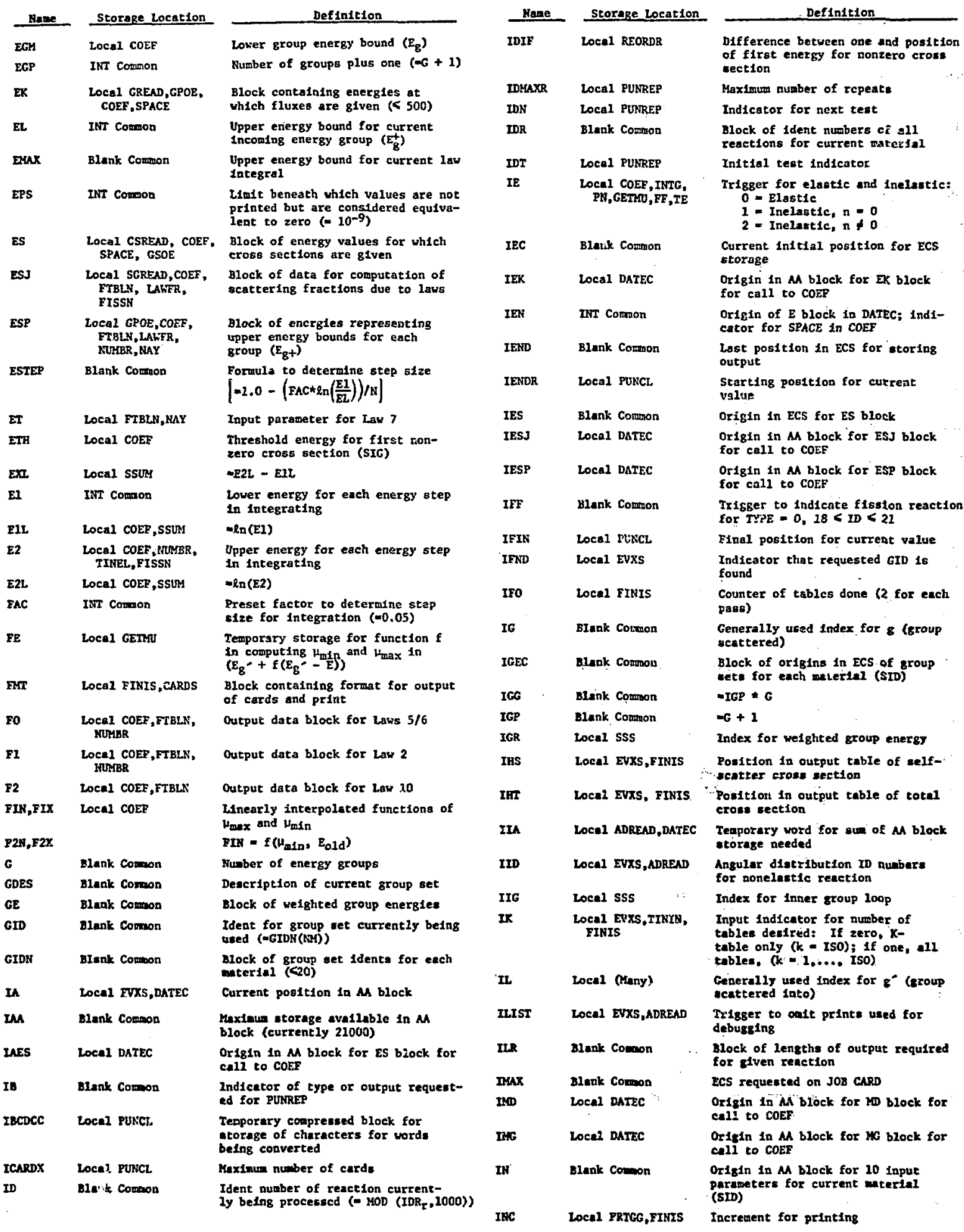




\begin{tabular}{|c|c|c|c|c|}
\hline nese & Stordire Location & Defincion & Mane. & Storage Locat lon \\
\hline antc & Local PUACL & $\begin{array}{l}\text { Indicator of type of output re- } \\
\text { quited }\end{array}$ & ITL & $\begin{array}{l}\text { LOCal EHXS, FINIS, } \\
\text { CANDSS }\end{array}$ \\
\hline INDTR & LOGAl PUNREP & $\begin{array}{l}\text { Indicator of number of eigits to } \\
\text { uee in numbering card output: } 0 \text { - } \\
\text { three; } 1 \text { = two }\end{array}$ & ITYPE & Local PURREP \\
\hline INIT & Local SSS & $\begin{array}{l}\text { Pointer to M block for output } \\
\text { prints }\end{array}$ & IกI & $\begin{array}{l}\text { LOCA1 COER, FTBL, } \\
\text { FISSA }\end{array}$ \\
\hline INP & Loeal EVXS & $\begin{array}{l}\text { Total number of sets of lnput data } \\
\text { ellosed in ore run }(<20)\end{array}$ & IT2 & Jocal FTaLX \\
\hline IOUT & Blank Comaod & $\begin{array}{l}\text { Initiel pueftion in ECS for storing } \\
\text { ourput }\end{array}$ & & \\
\hline IP & Blenk Cunson & $\begin{array}{l}\text { Number of Input parancters utored } \\
\text { on ECS for each material (currently } \\
\text { 10) }\end{array}$ & 124 & $\begin{array}{l}\text { LOCAL FTBL, LAKFR, } \\
\text { RUMER }\end{array}$ \\
\hline IPA: & Mlank Cosmon & $\begin{array}{l}\text { Terporary block for twitching para- } \\
\text { eeter sete }\end{array}$ & ITS & Local FT BLA, NUMTBR \\
\hline IrA & Local DATEC & $\begin{array}{l}\text { Origin in } M \text { block for PH block for } \\
\text { call to coEF }\end{array}$ & IVECP & LOCAl PUAREP \\
\hline 1Pa & Local EVXS,FIKIS & $\begin{array}{l}\text { Input parageter: } 0 \text { = Transport } \\
\text { correct Ion for output; } 1 \text { - Conatst- } \\
\text { ent PN }\end{array}$ & IWRT & Local SSS \\
\hline IPOE & tocal DATEC & $\begin{array}{l}\text { Orfein In MA block for POE block } \\
\text { for coll to COEF }\end{array}$ & IK4 & Local EVXS, FIFIS \\
\hline IP & Locel ERROR & $\begin{array}{l}\text { Indjcotor of type of error and } \\
\text { act lon to be taken }\end{array}$ & $I x$ & Local EIXS,DATEC \\
\hline In & Blank Conen & $\begin{array}{l}\text { Index for reaction currently beins } \\
\text { procesued (IR }-1, \ldots, R)\end{array}$ & & $\begin{array}{l}\text { Local DATEC } \\
\text { Locel FTBLX, ATHE }\end{array}$ \\
\hline IRDCT & DOCAI PUKREP & $\begin{array}{l}\text { Scoran blocke (6 for each card) } \\
\text { for o. } y \text { of repeste for each }\end{array}$ & IXS & PRTC6, FINIS \\
\hline IRDSUת & Local PUSTEP & $\begin{array}{l}\text { Ileld } \\
\text { Storaze block for value froe each }\end{array}$ & w & 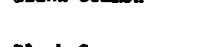 \\
\hline & & field & I2 & Miank Colmon \\
\hline IDWo: & Local PUNREP & $\begin{array}{l}\text { Storabe block for operation to be } \\
\text { appised to value in field }\end{array}$ & & \\
\hline INPS & Local SSS & Kumber left to prdat & & \\
\hline Ins & Blask Comon & $\begin{array}{l}\text { Length of blocks of date (ESJ) for } \\
\text { "leus" for each renetion (S 3000) }\end{array}$ & & \\
\hline Is & Elank Conand & $\begin{array}{l}\text { Lengths of cross-section blocks } \\
\text { (SIC) for each reaction ( } 40 \text { jo) }\end{array}$ & $\mathbf{I}$ & $\begin{array}{l}\text { LOCA1 EYXS, GREAD, } \\
\text { GPOE, COEF, FINIS }\end{array}$ \\
\hline $\begin{array}{l}\text { ISAT } \\
\text { ISC }\end{array}$ & $\begin{array}{l}\text { Local SSS } \\
\text { Local DATEC }\end{array}$ & $\begin{array}{l}\text { Polntar to } M \text { blosk for printins } \\
\text { oriein in } M \text { block fer SC blcek }\end{array}$ & 12 & $\begin{array}{l}\text { LOCA1 EVXS, GREAD, } \\
\text { GROE, COCF, FIXIS }\end{array}$ \\
\hline & & for call to FIMIS & 124 & Blank Curmon \\
\hline ISF & Local DATEC & $\begin{array}{l}\text { Origin In } M \text { block for SF block } \\
\text { for call to FIRIS }\end{array}$ & 13 & Blenk Comon \\
\hline 156 & LOCAL DATEC & $\begin{array}{l}\text { orieln in } M \text { block: for sIC block } \\
\text { for cell coEF }\end{array}$ & $14,15,16$ & Blank Corman \\
\hline IS1G & Mank Cormon & $\begin{array}{l}\text { Block of origins in ECS for SIC } \\
\text { and ESJ blocks for each reaction }\end{array}$ & 18 & LOCA1 COEF, TIMEL. \\
\hline 150 & Local EYIS,FLIS & $\begin{array}{l}\text { Input paraseter for degree of en- } \\
\text { Ieotropy ( } 4 \text { kux) }\end{array}$ & & \\
\hline ISR & LOCal EYXS,DATEC & $\begin{array}{l}\text { Sum of leogths (for ECS) of SIC } \\
\text { and ESJ blocks for all reactions } \\
-\sum_{\mathbf{r}}\left(\mathrm{IS}_{6}+\mathrm{IRS}_{\mathbf{r}}\right)\end{array}$ & $\begin{array}{l}\text { JD } \\
\text { JEC } \\
\text { JF }\end{array}$ & $\begin{array}{l}\text { INT Comon } \\
\text { Local EVXS, DATEC } \\
\text { Local COEP, FISSH }\end{array}$ \\
\hline ISS & Local DATEC,EIHIS & $\begin{array}{l}\text { Origin of output blosk in M block } \\
\text { (SS) }\end{array}$ & JG & INT Comron \\
\hline I5T0 & Locel DATEC & $\begin{array}{l}\text { Origin in } M \text { block for STo block } \\
\text { for cell to Finis }\end{array}$ & $\mathbf{J X}$ & 2 m Cormon \\
\hline IST: & Local DATEC & $\begin{array}{l}\text { Origin In } M A \text { block for STI for } \\
\text { call co fISIS }\end{array}$ & J1 & InT Comion \\
\hline ITAP & Blank Comen & Scraceh tapc $(-3)$ & $\mathbf{J 2}$ & INI Comonn \\
\hline ITI & Local KEKPG,FIMIS & Number of the table being printed & J3 & locel COEP \\
\hline IIET & Local HAIN, FIMIS & $\begin{array}{l}\text { Input parascter for ITL }<(c+3): \\
0 \text { - Floor output cross sectlons; } \\
1 \text { - Iruncate }\end{array}$ & $\boldsymbol{x r}$ & Dlank Common \\
\hline IIID & Elenk lonen & $\begin{array}{l}\text { Block of origins in ECS for angular } \\
\text { dietribut lons }\end{array}$ & & \\
\hline IIX & Locel DATEC & $\begin{array}{l}\text { Origin in } A \text { block for TK block for } \\
\text { COEF }\end{array}$ & & \\
\hline
\end{tabular}

Input paraneter for output table
length deslred (if $<0$, print only)

Type of output format to ute: -1

- ANISN, 0 on UIE (ead witi 3), t1

- DIT (end with g)

Integer value to test for ESJ polnter, -1.0, sc Indicate end of subIIacs and/or end of block:

Integer velne to test for ESJ polocer, -2.0 , to ladicate end of oublist.

Inteter value to test for ESJ pointer, -4.0 to indicate cnd of cublists

Integer ralue to test for $85 J$ potnear, -5.0, to Indicate end of cublist:

Vector conteining data to be processed

Pointer to first number to be vitten

Input paraneter for type of output dealred

Total ECS atorage requited for output

Origin of $x$ block in M block for cell to $\operatorname{COEF}$

Ievporary index

Type of atoraze requ1red for output for a given revetion

Indicacor for gave deposirion calculation if $>0$ :

2 - Save storage

3 - Calculation for ore

reaction

4 - Final celculation for one naterial

Index for $E_{s}-$ from block EX

Index for $E_{s}+$ from block Ex

Data for unpacking Indices from blockt HE, HE, HD (- octel 108) Count of number of times ETBLK has been encerad, Initially zero

Counters for Laus 2,5 , and 6 , respect Ively

If nonzero, ladicates angular distribution for nonelestic reaction

Index for current value of antular distribution energy (E(JD))

Current ordgla in ECS to read data Polnter for the $v$ block for fission reaction

Index for current value of cronsuecilon energy; (ES(JC))

Index for current slue of crosecection enersy (Es(JX))

Index for Intelal value in $T R$ and ESJ blocks

Index for final values in Th block

Initial value of JX, poeftion of firat nopzero SIG in table

Input peraweter for type of chi handlins: 0 - nornal; 1 - like munc code; 2 - print entrix before suning 


\begin{tabular}{|c|c|c|c|c|c|}
\hline Nave & Storese Location & Definition & Mave & Storute Location & Definteloa \\
\hline $\mathbf{R c}$ & Blank Comeon & $\begin{array}{l}\text { Nubber of flux (PH) and energy (EK) } \\
\text { values for group set GID (C 500) }\end{array}$ & MES & Mank Comon & $\begin{array}{l}\text { Muber of energies in Es block } \\
\text { (5 3000) }\end{array}$ \\
\hline $\mathbf{K B}$ & Locel NEWPG & $\begin{array}{l}\text { Tewporary Indicator of type of out- } \\
\text { put dealred }\end{array}$ & $\mathbf{X F}$ & Local TE, FINIS & $\begin{array}{l}\text { Nunber of functions in } \pi \text { block for } \\
F_{n}\left(\mu_{L}\right)\end{array}$ \\
\hline $\mathbf{E J}$ & Dlank Cosson & $\begin{array}{l}\text { Current value of IRS } \text {, length of } \\
\text { ES.J block for reaction being con- } \\
\text { puted }\end{array}$ & NG & Blark Comenn & $\begin{array}{l}\text { Wuber of nete of eroup dete to be } \\
\text { weed }(\leqslant 10)\end{array}$ \\
\hline D: & Local MEXPC & Number of tables being computed & NIKC & Blank Coman & $\begin{array}{l}\text { Muber of subdivisione to une in } d u \\
\text { intecrel (uavally 40) }\end{array}$ \\
\hline $\mathbf{x T}$ & Blank Common & $\begin{array}{l}\text { Number of vords in angular distri- } \\
\text { bution block IK }\end{array}$ & MINP & Locel COEF, FTBLA & $-\operatorname{MInc}+1$ \\
\hline $\mathbf{L}$ & Blank Comon & $\begin{array}{l}\text { Number of date to describe energy } \\
\text { distribution of outcoming neutrons } \\
\text { (not used in EVxs) } \\
\text { Length of storage in } M \text { block }\end{array}$ & Rat & $\begin{array}{l}\text { Blank Common } \\
\text { Blank Comaon }\end{array}$ & $\begin{array}{l}\text { Index of weterial proceasing loop } \\
\text { slock of velues of anximun } P_{\mathrm{n}} \text { to } \\
\text { use for wateriel being evelueted } \\
\text { (5 10) }\end{array}$ \\
\hline & & needed for given material & & Blenk Comon & Index a for $P_{n}$ \\
\hline LAST & Locel SSS & Pointer for final number to urite & HOERC & Locel PUNCL & Cuczent nubber of entries \\
\hline LAT & LOCAl DATEC. FISIS & $\begin{array}{l}\text { Temporary word for leneth of } \mathrm{AA} \\
\text { block }\end{array}$ & $\begin{array}{l}\text { moEkR } \\
\text { moENT }\end{array}$ & $\begin{array}{l}\text { Local PUNCL } \\
\text { Local PUXCL }\end{array}$ & $\begin{array}{l}\text { Huber of entrdes reveining } \\
\text { Nuber of entries per eard }\end{array}$ \\
\hline LDIF & Loces REORDA & $\begin{array}{l}\text { Difference between las: nonzero } \\
\text { crons eection and largest enersy }\end{array}$ & MOINP & Local PUNCL & $\begin{array}{l}\text { Mmber of single charectera for } \\
\text { Input }\end{array}$ \\
\hline LEFT & LOCal CARDS & $\begin{array}{l}\text { Nubber of rewining volues less } \\
\text { than enough to fill a card }\end{array}$ & MOHEC & Local PUHCL & Sount of chnracters being nomed \\
\hline $\begin{array}{l}\text { LEG } \\
\text { LEGN }\end{array}$ & $\begin{array}{l}\text { Blonk Comen } \\
\text { INT Conmon }\end{array}$ & $\begin{array}{l}\text { Nuber of Legendre coefficients } \\
\text { used: } 0 \text { - Lone, n - NED }\end{array}$ & KOSSCCH & Local PUNCL & $\begin{array}{l}\text { Mober of single characters to } \\
\text { change }\end{array}$ \\
\hline LEN & LOCal FINIS, CARDS & $\begin{array}{l}\text { Tetaporury word for gatma energy } \\
\text { deposition calculation }(-G * \text { ITL) }\end{array}$ & $\begin{array}{l}\text { BothP } \\
\text { novr }\end{array}$ & $\begin{array}{l}\text { LOCal PUNCL } \\
\text { LOCAI PUSREP, PUNCL }\end{array}$ & $\begin{array}{l}\text { Scratch file } \\
\text { Vertable nate of output file }\end{array}$ \\
\hline LCID & Blank Common & $\begin{array}{l}\text { Length of block stored for each } \\
\text { group oet (CID) }(-\mathrm{G}+2 * \text { KC) }\end{array}$ & WP & Local EVXs, TIAIN & $\begin{array}{l}\text { Index for proceasing loop for all } \\
\text { meterials }\end{array}$ \\
\hline LIS & Blank Comnon & $\begin{array}{l}\text { Storage required in AA block for } \\
\text { longest ESJ }\left(- \text { IRS }_{r}\right)\end{array}$ & NTE & Dlank Common & $\begin{array}{l}\text { Iemporary etorage for Im for } \\
\text { eurrent waterial }\end{array}$ \\
\hline LEC & $\begin{array}{l}\text { Local EVKS, DATEC, } \\
\text { PRTGG }\end{array}$ & $\begin{array}{l}\text { Value to une in cosputins torage } \\
\text { needed for output (* IGP * } \mathrm{G} \text { * NAX) }\end{array}$ & $\mathbf{m R}$ & $\begin{array}{l}\text { Loeal PRTCG,FIMIS, } \\
\text { ERTE }\end{array}$ & $\begin{array}{l}\text { Mubar of ralue remintas to be } \\
\text { printed }\end{array}$ \\
\hline $\begin{array}{l}\text { LTAP } \\
\text { LTID }\end{array}$ & $\begin{array}{l}\text { BLonk Coswon } \\
\text { Elank Common }\end{array}$ & $\begin{array}{l}\text { Scratch tope (- 4) } \\
\text { Storage required in ECS for given }\end{array}$ & MRENod & Local PUNCL & $\begin{array}{l}\text { Muber of eingle characters for } \\
\text { output }\end{array}$ \\
\hline LTOT & Locel EVXS,ADREAD & $\begin{array}{l}\text { angular diatrlbution (- KT + } 2 \text { * NED) } \\
\text { Total Ecs atorage required for } \\
\text { siven material }\end{array}$ & is & Blank Comon & $\begin{array}{l}\text { Muber of enterial seta in library } \\
\text { Orfigit of output parmeter bleck }\end{array}$ \\
\hline LKRT & Locel sss & $\begin{array}{l}\text { Pointer to last word to be uritten } \\
\text { frow } \mathrm{M} \text { block }\end{array}$ & ATTART & Ilank Cormon & 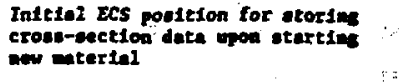 \\
\hline Len & $\begin{array}{l}\text { Local SSS } \\
\text { Blank Comenon }\end{array}$ & $\begin{array}{l}\text { Index fur LKRT } \\
\text { Counter for LuW } 10\end{array}$ & $\boldsymbol{m}$ & Dlenk Common & 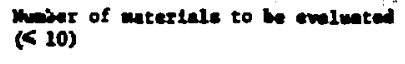 \\
\hline $\mathbf{M}$ & $\begin{array}{l}\text { LOCAI ADREAD, COET } \\
\text { TIMIX }\end{array}$ & $\begin{array}{l}\text { Packed Indlces to the TK block cor- } \\
\text { reaponding to energies in the E } \\
\text { block }\end{array}$ & $\begin{array}{l}\text { MTAP } \\
\text { ITAPE }\end{array}$ & $\begin{array}{l}\text { Dlank Comen } \\
\text { Locel Fucl, FUNREP }\end{array}$ & 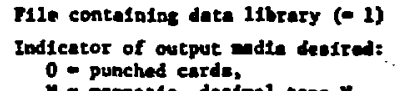 \\
\hline & Blank Common & $\begin{array}{l}\text { Packed Indices to ES block for } \\
\text { wich nonzero crose sections (SIG) } \\
\text { are tiven for each reaction }\end{array}$ & MTARET & Local FokneP & $\begin{array}{l}\text { M entetic, decienl tape } x \\
\text { serateh file }\end{array}$ \\
\hline ; & $\begin{array}{l}\text { LOCAl GREAD,GPOE } \\
\text { COEF }\end{array}$ & $\begin{array}{l}\text { Packed Indices for kG block Ia- } \\
\text { diceting energy bounda }\end{array}$ & RE & $\begin{array}{l}\text { Blank Conson } \\
\text { Lacel COEF }\end{array}$ & $\begin{array}{l}\text { 2-muber for metertal } \\
\text { - EDL * ED }\end{array}$ \\
\hline mix & Mlank cosmon & $\begin{array}{l}\text { Indicator of type of asterial: } \\
0 \text { - Isotope, } 1 \text { - Mixture (not uned } \\
\text { In EVXS) }\end{array}$ & PH & $\begin{array}{l}\text { IOCal GREAD,GPDE, } \\
\text { COEF }\end{array}$ & $\begin{array}{l}\text { Ilock of values for flux-ueighting } \\
\text { correspending to enorg values in } \\
\text { IX block }\end{array}$ \\
\hline ISR & MSG Comen & $\begin{array}{l}\text { slock containing dneeription of } \\
\text { reaction for each ID for output }\end{array}$ & $\mathbf{R L}$ & Local COEF, TININ & $\begin{array}{l}\text { wlock of tenporary functions for } \\
\text { wallestic anguinr dietributions }\end{array}$ \\
\hline$P$ & & Variable nume for output f1le $(-2)$ & POE & LOCAl GPOE, COEF & $\begin{array}{l}\text { Pot }(E) d F, \text { POE }=P_{1}=\ln \left(r_{k_{k}}\right) \\
-x_{1} \ln \left(E x_{k}\right)\end{array}$ \\
\hline $\mathbf{a x}$ & Blank Coman & 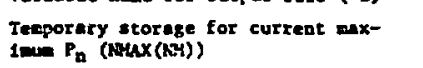 & PS & Local COET, SSUM & $\begin{array}{l}- \text { FOE (JG) + SOE (+ 2OE If fisalion } \\
\text { reaction) }\end{array}$ \\
\hline ARD & $\begin{array}{l}\text { LOCal PUAREP } \\
\text { LOCal PLAREP }\end{array}$ & $\begin{array}{l}\text { Nuaber of entrie: per card } \\
\text { Nubber of characters co couvert }\end{array}$ & QR & $\begin{array}{l}\text { Mlank Comson } \\
\text { Blank Comen }\end{array}$ & $\begin{array}{l}\text { Value of QRr for current reaction } \\
\text { Block of enerties releesed for } \\
\text { such reaction }(550)\end{array}$ \\
\hline D & Blank Cosmon & $\begin{array}{l}\text { Mumber of angular discributione } \\
\text { for current miteriol }\end{array}$ & $\mathbb{R}$ & Blank Comon & $\begin{array}{l}\text { Muber of ryetions for tiven } \\
\text { anterial }(6 j 0)\end{array}$ \\
\hline $\mathbf{E C}$ & Blank Comson & $\begin{array}{l}\text { Current Inteinl position in ECS } \\
\text { into which input date is to be } \\
\text { stored }\end{array}$ & $\mathbf{R Q}$ & INT Cosm & $\begin{array}{l}\text { Absolute value of Q for curreat } \\
\text { reaction } \\
=1.0+\mathrm{AH}^{2}\end{array}$ \\
\hline (200) & Blank Common & $\begin{array}{l}\text { Muber of energics for whtch } \\
\text { angular dietributions are tiven } \\
(6400)\end{array}$ & $\begin{array}{l}\mathbf{2} 2 \\
\mathbf{m 3}\end{array}$ & $\begin{array}{l}\text { IfT Comon } \\
\text { IfT Comon }\end{array}$ & $\begin{array}{l}-2 * A H \\
=\Delta H\end{array}$ \\
\hline
\end{tabular}




$\frac{\text { Nane }}{\mathrm{s}} \frac{\text { Storage Location }}{\text { Local IE }}$

sc

Local FTKIS

SDES

SE

SF

sID

SIDN

sIC:

SIN

so:

ss

50

st1

TH

$\boldsymbol{x}$

si

$\mathbf{5 2}$

510

TAD

TDES

IID

III)

IIDs

IX

IIt

$\mathbf{m p}$

TOL

TOT

IT

TYPE

TYPER

Blenk Corzon

Blask Comenn

Local EVXS, DATEC

IrT Coman

Local (Many

Local frkis

Local PIMIs

Local COEF, IHTE

Dlank Coman

In com

Locel COEF, FTBLX.

MY,PATCC

Lucal COEF, RRTCC

Locel nUthe

Locel MAIH

slank Comon

Blank Comon

Blek Com

blenk Comon

LOCAl ARREAD, COEF, IHTG,TE, ININ

LOCAl COEF, INTC, Geñd

Local ITBLN, LALFA, FIfIS

Dink Cotion

Local COEF, PRTCG

LOCE COEF, GETHU

Blenk Comen

MSG Comon
Defintition

Temorary storage while somalig
to IF for: $2 \star T\left(\mu, E_{1}\right)-1$

$+\sum_{n=1}^{m}(2 n+1) * F_{n} * P_{n}(\mu)$

Block in which final DTF fornat crons sections are stored

Deacription of aterial requested

Difference between two consecut Ive angular distribution energies (ED - EDL)

Storage block for au-sigma fiarlong $\left(\mathrm{Nog}_{\mathrm{g}} \mathrm{f}\right)$

Ident number of enterial requested (- $\operatorname{sinN}(\operatorname{tat})$ )

Block of material Identa (SID) to be processed ( 5 10)

Loeal SGREAD, REORDR, Bloek of cross-section data valuea COEF, SPACE, GSOE corresponding to energies in the

Es block (c 3000)
Temporary atorage for current SID

For $\sigma_{r}\left(E_{1}\right), \operatorname{sOE}-s_{1}-\ln \left(\sigma_{j}\right)$

$-Y \neq \ln \left(E_{j}\right)$

Black Into which output fc: each reaction 1 atored as computed befora vriting on ECS

Crosa-acetion block storage for oven k-table odd k-table

Tomporazy storage for ouralin an Integral

Syaten used in calculation: 1 - centar-of-asas; 2 - 1ab system

slock of Ch1' by group for fiention reactions $\left(x_{2}\right)$

Block of vof for fiasion reactions

Temporary storage for $\frac{\mathrm{E}+\mathrm{E} 1}{2}$

Block Into which title and description of current version of library erte read

Description block for current encular distribution

Identification number for current anguiar diatribution (- TIDR $_{\mathrm{r}}$ )

Ident numbere of angular diatribution to be used with $r$ th reaction (aone if $<0$ )

Ident number of ancular dietributions in order found in library for eIvan waterial (6 25)

slock of angula: distribution data (4 4000)

Main in elestic and discrete inelastic calculation

Absolute value of difference between weight and integral

Value to deternine step size in integrating nonelastic

Temporary storage for total scattering crose section for given raection

Hax In elsstic and discrete inelastic calculatien

Type of reaction being procesaed (- TYPER(ID))

Block of type nubers corresonding to ID number for each reaction
Crose-section block otorage for

\begin{tabular}{|c|c|}
\hline Yises & Storese Location \\
\hline $\boldsymbol{U}$ & Local INTC, TE, PH, II \\
\hline U. & $\begin{array}{l}\text { Local CCr, , TIKIM, } \\
\text { IINEL }\end{array}$ \\
\hline $\begin{array}{l}\mathrm{UL}, \mathrm{UH}, \\
\mathrm{U} 1, \mathrm{U2}\end{array}$ & Local IMTC \\
\hline
\end{tabular}

Definteton

Tesporary value of cosine in comput ing angular diseribution Anguler distribution functions for nonelaste computation

Temporary storage for u valuea wen picking up interwediate polnte where data are ilven (pornel step size is 1/40 of discance fron -1.0 to +1.0 )

VECP Loenl PUXCI slock of data to be processed

$\boldsymbol{w}$

LOCA1 FIBLS, LAWER, NUMiD:

L Local FIAIS

WT4 Local FINIS

$x$ LOCA1 GPOE, COEF

XSUM CPUTE Common

XY LOCAl COEF, SSUY

$Y$ IKT Comon

2 Locel COEF,FISSA

ZOE LOCal COEF, EISSN

Weight factor from ESJ block

Welght currently belog used

Special weight function $(-0.6023 / A)$ for TD4

Block of values for $x_{1}$ $\left(-\ln \left(\theta_{k+1} / 0_{k}\right) / \ln \left(E_{k+1} / E_{k}\right)\right)$

Iotegral for $g$ or $:^{\circ}$

- $X(J C)+Y(+Z$ if fission renction)

Current value of:

$-\ln \left(\sigma_{j+1} / \sigma_{j}\right) / \ln \left(E_{j+1} / E_{j}\right)$

Current value of:

- $\ln \left(v_{1+1} / v_{1}\right) / \ln \left(E_{1+1} / E_{1}\right)$

For fisetion reaction $=\ln \left(v_{1}\right)$

$-2 * \ln \left(E_{1}\right)$

\section{v. CODE OPERATION}

At this time the program and the LAMF are stored together on a magnetic tape in binary format, the code as an UPDATE ${ }^{10}$ OLDPL in the first file and the data on the following is files as described In Sec. II.A. Ulcimately, we hope to have both the program and the 11brary permanently stored on disk.

The FORTRAN code 18 prepared for execution by making an UPDATE run in whtch a BCD card Image file 18 written to the COMPILE file which, In turn, is Input to the compiler. The UPDATE program allows conventent modification of the current version of the code, but if sufficient use is made of the code and modifications are not general1y required, a compiled binary version could be stored elther on disk, on the tape in place of the OLDPL, or on the tape as an additional file preceding the OLDPL. In this section we summarize the input and output options avallable in EVXS.

A. Invut

The data deck required to obtain crose sectlons for one or more materials iti the LADF constats of the following cards:

\section{(1) Title card - Contains descriptive data} supplied by the uaer to identify the particular run (8A10 format). 
(2) Parameter Cards - Contain control parameters, one card for each meterial for which cross sections are desired. The details are given in Table XIII. The first three parameters are required for each material, whlle the rest are optional, with defaults as shown in the table (12I6 format).

(3) Blank Card - Signifies the end of the paramezer cards.

TABLE XIII

INPUT PARAMETERS FOR EVXS

\begin{tabular}{|c|c|c|c|c|}
\hline $\begin{array}{l}\begin{array}{l}\text { Parameter } \\
\text { Name }\end{array} \\
\end{array}$ & $\begin{array}{l}\text { End in } \\
\text { Column }\end{array}$ & & Description & Default \\
\hline GIDN & 6 & $\mathbf{N}$ & $\begin{array}{l}\text { Group set to be used (if GIDN }<0 \text {, group } \\
\text { structure Information must follow the blank } \\
\text { card as described in text) }\end{array}$ & None \\
\hline SILN & 12 & $\mathbf{N}$ & $\begin{array}{l}=\text { Identification of cross section to be } \\
\text { processed }\end{array}$ & None \\
\hline NMAX & 18 & N & $\begin{aligned}= & \text { Number of } P_{n} \text { components to be calculated. } \\
& \text { See restrictions discussed in Sec. III.E } \\
& \text { below Eqs. (121b), (122b), and (123b) }\end{aligned}$ & None \\
\hline ITL & 24 & $\mathbf{N}$ & $\begin{array}{l}=\text { Output table length desired (1f list only } \\
\text { 1s desired, set negative) }\end{array}$ & $\mathbf{G}+3$ \\
\hline IHT & 30 & $\mathbf{N}$ & $=$ Position in table of total cross section & 3 \\
\hline IHS & 36 & $\mathbf{N}$ & $\begin{aligned}= & \text { Position in table of self-scatter cross } \\
& \text { section }^{\mathrm{a}}\end{aligned}$ & 4 \\
\hline Iso & 42 & $\mathbf{N}$ & $=$ Degree of anisotropy & 1 \\
\hline IPN & 48 & $0 / 1$ & $\begin{array}{l}=\text { Transport correction/consistent } P_{n} \text { (see } \\
\text { Sec. III.E) }\end{array}$ & 0 \\
\hline ITBL & 54 & $0 / 1$ & $=$ Floor/truncate output ${ }^{b}$ & 0 \\
\hline IW4 & 60 & $\mathbf{N}$ & - Special output option ${ }^{c}$ & $\mathbf{0}$ \\
\hline IK & 66 & $0 / 1$ & $\begin{array}{l}=\mathrm{K}-\text { Table only }(\mathrm{K}=\mathrm{ISO}) / \mathrm{all} \text { tables, } \\
\mathrm{K}=1, \ldots, \mathrm{ISO}\end{array}$ & 0 \\
\hline $\mathbf{K F}$ & 72 & $0 / 1 / 2$ & $\begin{array}{l}\text { Fission matrix handling: normal/11ke } \\
\text { MANIAC code/matrix printed (Bee Sec. III.E, } \\
\text { Eqs. (117) and (118) }\end{array}$ & 0 \\
\hline \multicolumn{5}{|c|}{$\begin{array}{l}\text { aspace can be allowed for upscatter terms between IHT and IHS and for other special } \\
\text { terms at the beginning of the table as shown in Table VIII. } \\
\text { b } \\
\text { ITBL indicates how scattering beyond limits imposed by table length will be } \\
\text { handled: Floored - Scattering is not permitted below the lowest energy group } \\
\text { allowed by table length and is added to next higher group "up the diagonal" } \\
\text { (method used by the MANIAC code). Truncated - Scattering below the lowest } \\
\text { energy group ls added into the absorption cross section to maintain the neutron } \\
\text { balance (see sec. III.E, especially Eqs. (124) and (125)). }\end{array}$} \\
\hline \multicolumn{5}{|c|}{$\begin{array}{l}\text { CDepending on values of IW4, the following output options are available: } \\
0=\text { Old DTF output } \\
1 \text { - TD4 version of output } \\
2 \text { = Gamm energy deposition calculation } \\
3 \text { = Output for the ANISN loader } \\
4 \text { = Output for the DTF loader, blocks terminate (end wth } 3 \text { ) } \\
5 \text { - Output for the DTF loader, blocks continue (end with 9) }\end{array}$} \\
\hline
\end{tabular}


In general, group setis and materials can be paired in any fashion desired, with the same group set used for some of the materlals or the same materlal being used with different group sets or different input parameters. No particular order is required of the input material requests since they are sorted and $w 111$ be calculated in the order in which they are found in the 11brary. A spectal exception is the Gamma Disposition Calculation input which will be described. More than one group of requeste can be included in one run by separatIng the grougs by blank cards and omftting the t1tle card after the first aet. The library will. be rewound and the second set processed. A Gamma Deposition falculation could be run here.

When group set data are to be added from the Input stream rather than taken from among those existing in the LAMDF, the parameter GIDN is set to GID and the set of cards is added directly behtidd the blank card which ends the set of cross-section requests. The required format for the group sets Is given In Table XIV.

The special option for nonfisgion neutron and gatna energy deposition calculations is described In Sec. III.F. To make such calculations, IW4 must be set to 2 and IPN to 1 . The trigger IW4 = 2 need be set on onily one of the parameter cards. The same group set (GID) must be used for all materfals In one run for this special option. The materials must be requested in the same order in which they are avallable in the LAMDF; this is an exception to the general rule. Other Input data requirad are the gemus energy production crose sections for each group for each materlal requested in the parameter cards. These additional cards follow the blank

TAUE IIT

Geop set cued ronket

\begin{tabular}{|c|c|c|c|}
\hline $\begin{array}{l}\text { Card } \\
\text { pleek }\end{array}$ & Lenech & Torant & Contente \\
\hline 2 & 2 card & $(316,(N) D)$ & CID, C, XC, Coment (60 ECD characters) \\
\hline 2 & o values & (1.216) & $\begin{array}{l}\text { Wh block, Indices for the FH and EK } \\
\text { blocke }\end{array}$ \\
\hline 3 & C velues & $(6 E 12.4)$ & GE block, serup energles" in MeV \\
\hline 4 & Es values & $(6 \overline{12.4)}$ & TH Block, vefghctat fluxea in $\mathrm{HeV}^{-1}$ \\
\hline $\mathbf{s}$ & te values & (6E.12.4) & $\begin{array}{l}\text { ER block, energies In MeP at which } \\
\text { fluxee are siven }\end{array}$ \\
\hline
\end{tabular}

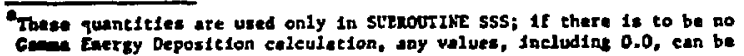
wed hare. card; however, if the GID group set is read In on cards, then the speclal cards follow the group set cards. For each material we put in a title card (8A10 format) and as many cards as are needea for the gamma energy production cross sections $\mathrm{GI}_{g}$ " $g=1, \ldots, G$ in $6 \mathrm{E} 12.5$ format. The Index $g$ here runs from the lowest to the highest energy group. It may be helpful to review the overall input card structure for the gamm energy deposition option:

(1) Title card for the run.

(2) Data cards for all materfals destred with the same GID on each card; NMAX $=1, I P N=1$, and IW4 $=2$.

(3) Blank card.

(4) Gamma energy production cross sections in MeV-barns for all materials, in the same order as the materials are requested above, each set of cross sections preceded by a tilie card.

\section{B. Output}

The options for card or tape output from EVXS are:

If ITL $<0$ the cross sections are listed only on the output file.

If ITL $>0$, the cross sections are ligted on the output file and written in BCD card tmage format on untt LTAP $=4$. The specific format depends on the value of IW4.

If IW $=0$, the BCD card imges are in standard DTF format.

If IW/ $=3$, the BCD card Images are In DTF format acceptable to the ANISN loader.

If IW4 $=4$, the BCD card images are in DTF format appropriate for the DTF loader with data blocks ending with termination character 3.

If IW4 - 5, the BCD card Images are in DTF format appropriate for the DTF losder with data blocks ending with continuation character 9 .

The BCD card tmages on untt LTAP may be punched $u$, Ing the PUNCHIT control card or else by assigniag TAPE 4 to PUNCH in the PROGRAM card. 


\section{REFERENCES}

1. K. Parker, "The Format and Conventions of the U.K.A.E.A. Nuclear Data Library as of May 1963," Atomic Weapons Research Establishment report AWRE 0-70/63, Aldermaston, England (1963). A proposed revision of this report was in circulation in 1965, but apparently has never been published.

2. J. D. Jackson, Classical Electrodynamics (John Wiley and Sons, Inc., New York, 1962) pp. 391404.

3. 5. Glasstone, Principles of Nuclesr Reactor Engineering (D. Van Nostrand Company, Inc., New York, 195.5), Chap. 3, Pp. 147-151.

4. H. Margenau and G. M. Murphy, The Mathematics of Physics and Chemistry (D. Van Nostrand Company, Inc., lew York, 1956), Pp. 104-106.

5. K. D. Lathrop, "DTF-IV, A FORTRAN-IV Program for Solving the Multigroup Transport Equation with Anisotropic Scattering," Los Alamos Scientiflc Laboratory report $[A-3373$ (1965).
6. G. I. Bell, G. E. Hansen, and H. A. Sandmeler, "Multitable Treatments of Anisotropic Scattering In $S_{N}$ Multigroup Transport Calculations." Nucl. Sc1. Eng. 28, 376-383 (1967).

7. พ. W. Engle, Jr., "A User's Manual for AKISN, A One-Dimensional Discrete Ordinates Transport Code with Anfsotropic Scattering," Union Carbide Corporation, Nuclear DIvision report K-1693 (1967).

8. H. A. Sandmeter, G. E. Hansen, and M. E. Asprey, "Non-F1ssion Neutron and Neutron-Induced Gama Heating Numbers $\mathrm{H}_{\mathrm{g}}$," Los Alamos ScIentific Laboratory Internal report (September 10, 1971).

9. H. A. Sandmeier, G. E. Hansen, and M. E. Asprey, "An Automated Method to Calculate Non-Fisaion Neutron and Neutron-Induced Gamma Heating in A1r and Other Materials from Basic Multigroup Cross Section Data," Los Alamos Scientific Laboratory Internal report (October 25, 1971).

10. UPDATE Reference Manual, Control Data Corporac10a publicat1on 60342500B (1971). 